Aus der Klinik für Unfallchirurgie, Orthopädie und Plastische Chirurgie

(Prof. Dr. med. W. Lehmann)

der Medizinischen Fakultät der Universität Göttingen

\title{
Einfluss der selektiven Inhibition proinflammatorischer Lipoxygenase auf den osteoporotischen Knochen im Ovariektomiemodell der Ratte
}

\author{
INAUGURAL-DISSERTATION \\ zur Erlangung des Doktorgrades \\ für Zahnheilkunde \\ der Medizinischen Fakultät der \\ Georg-August-Universität zu Göttingen \\ vorgelegt von \\ Marc Hendrik Zimmermann
}

aus

Münster

Göttingen 2017 
Dekan:

Referent/in

Ko-Referent/in:

Drittreferent/in:
Prof. Dr. rer. nat. H. K. Kroemer

Prof. Dr. med. S. Sehmisch

Prof. Dr. rer. nat. H. Jarry

Prof. Dr. med. dent. R. Mausberg

Datum der mündlichen Prüfung: 26. 03. 2018 
Hiermit erkläre ich, die Dissertation mit dem Titel "Einfluss der selektiven Inhibition proinflammatorischer Lipoxygenase auf den osteoporotischen Knochen im Ovariektomodell der Ratte" eigenständig angefertigt und keine anderen als die von mir angegebenen Quellen und Hilfsmittel verwendet zu haben.

Göttingen, den

(Unterschrift) 


\section{Inhaltsverzeichnis}

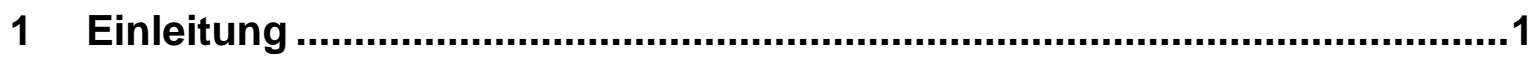

$1.1 \quad$ Einführung in das Thema und Zielsetzung .............................................. 1

1.2 Theoretische Grundlagen ....................................................................... 2

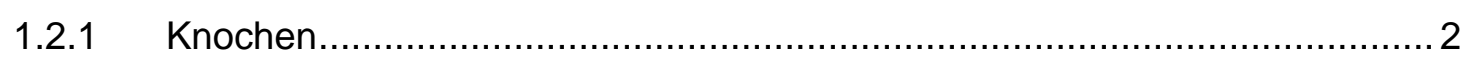

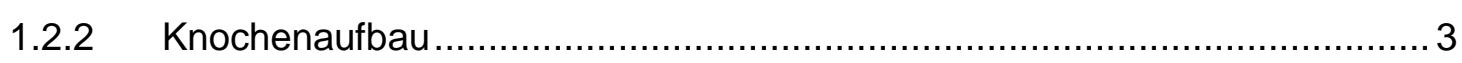

1.2.3 Knochenzellen .............................................................................. 4

1.2.3.1 Osteoprogenitorzellen................................................................. 4

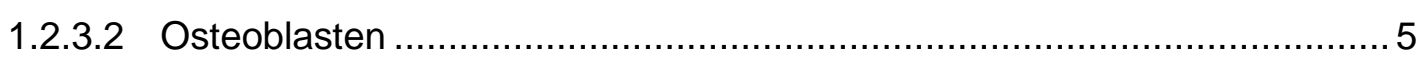

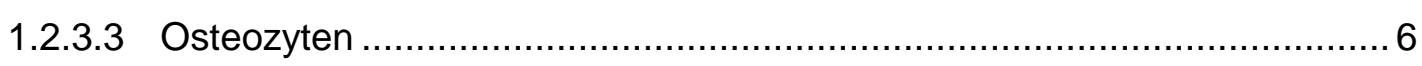

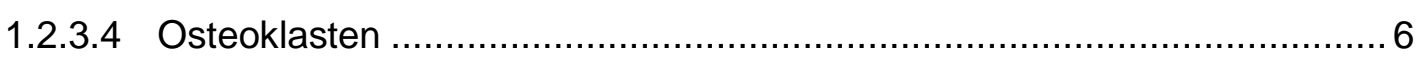

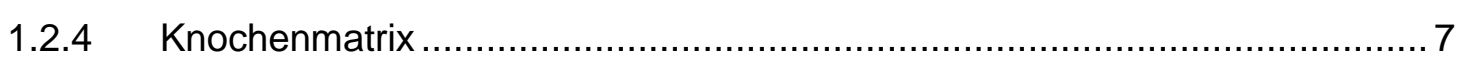

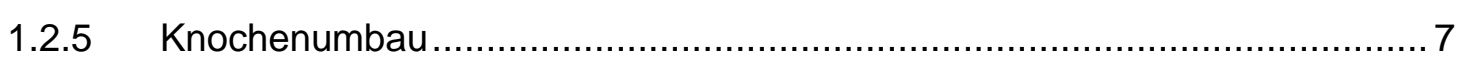

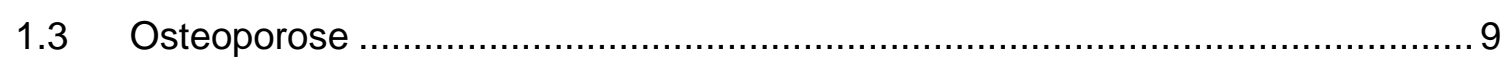

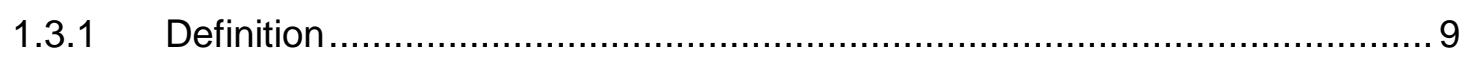

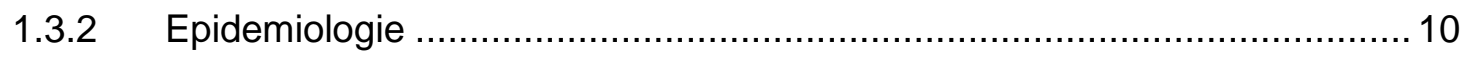

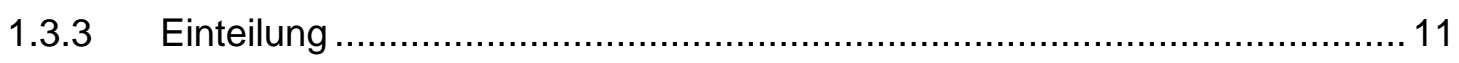

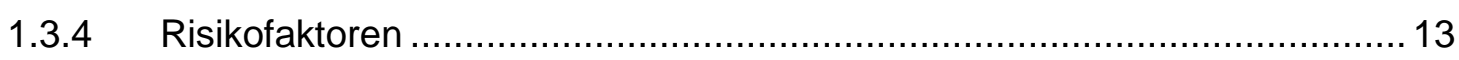

1.4 Diagnostik osteoporotischer Veränderungen ............................................... 15

1.4.1 Anamnese und klinischer Befund ................................................... 15

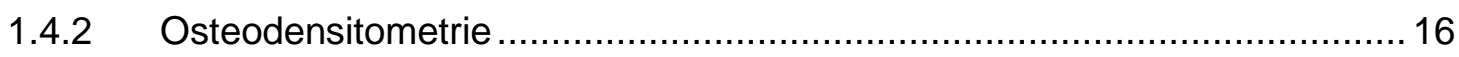

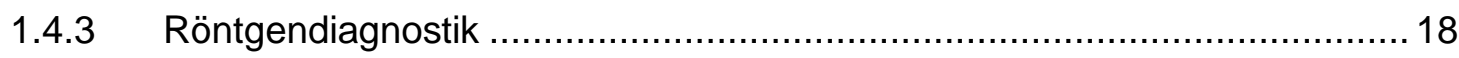

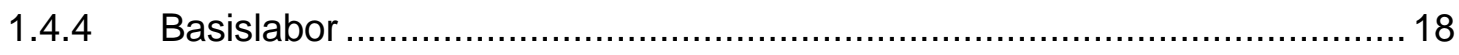

1.5 Prävention und Therapie der Osteoporose ................................................ 19

1.5.1 Allgemeine Basis- und Präventionsmaßnahmen ...................................... 19

1.5.2 Indikationen für eine medikamentöse Behandlung …............................. 20

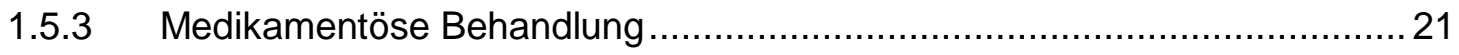

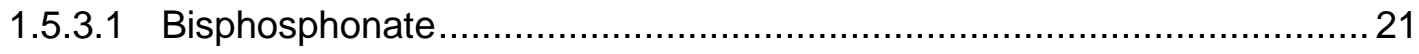

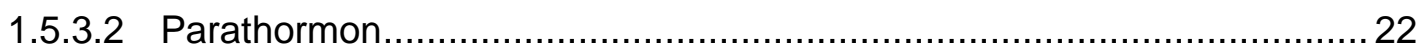

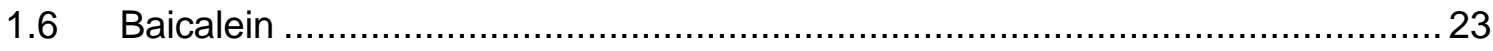

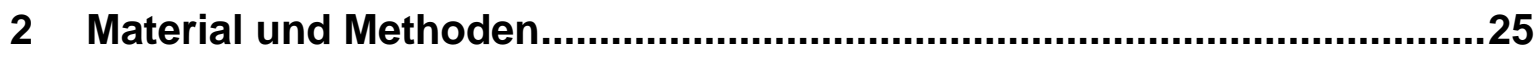

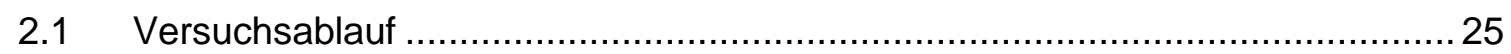

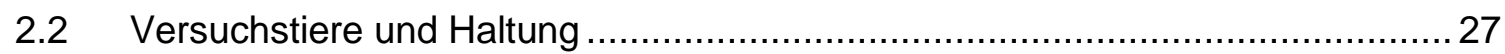

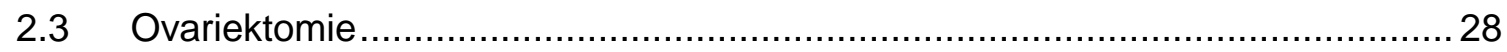


2.4 Osteotomie, Osteosynthese und medikamentöse Behandlung.........................29

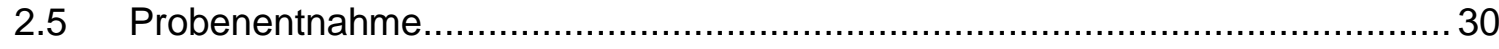

2.6 Präparation und Lagerung der Femora ....................................................... 30

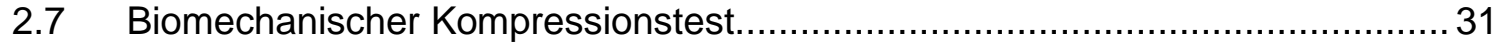

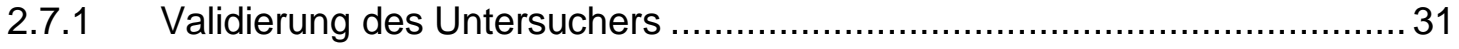

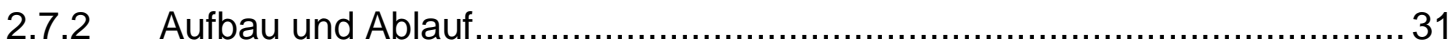

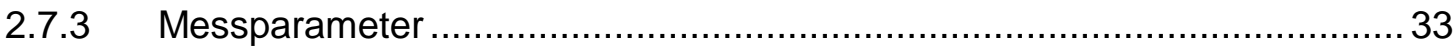

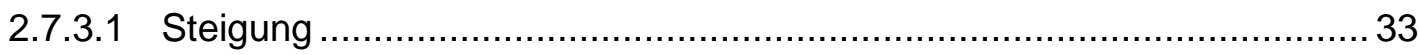

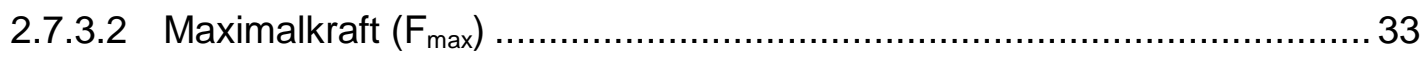

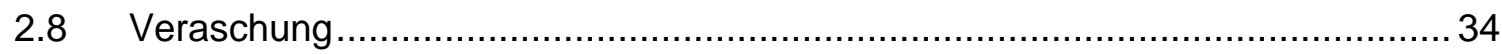

2.8.1 Bestimmung der organischen und anorganischen Knochensubstanz......... 34

2.8.2 Bestimmung des Calcium- und Phosphatgehaltes ................................. 35

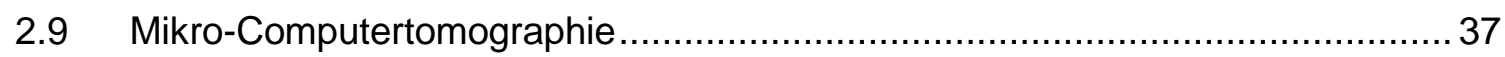

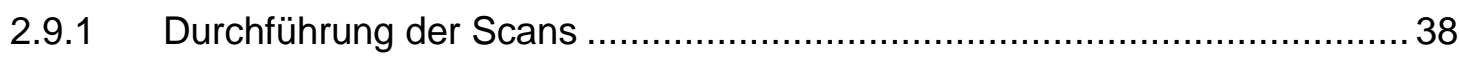

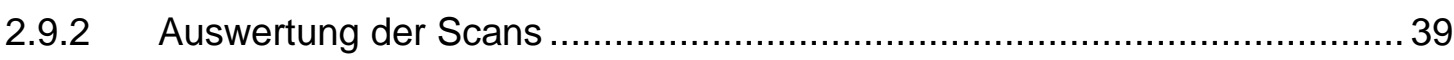

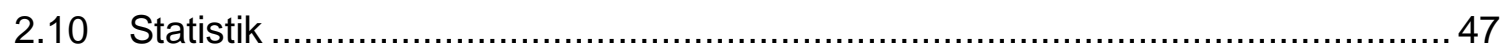

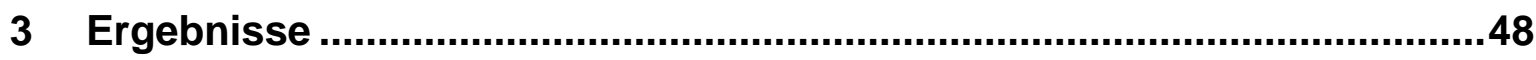

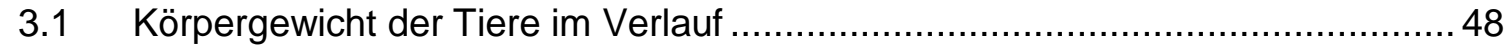

3.2 Futteraufnahme der Tiere im Verlauf ........................................................ 49

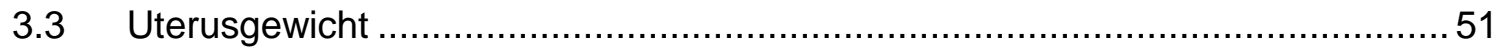

3.4 Ergebnisse des biomechanischen Kompressionstests ................................. 52

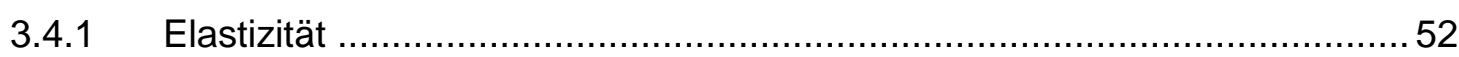

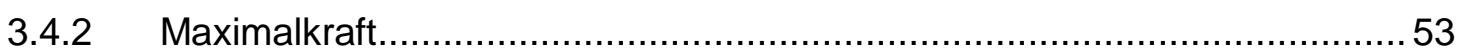

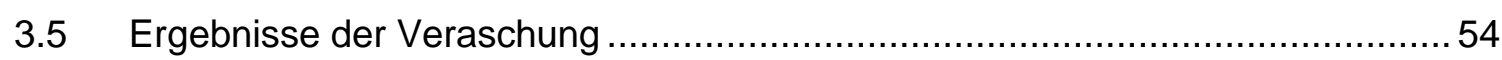

3.5.1 Organische und anorganische Masse ................................................ 54

3.5.2 Calcium- und Phosphatgehalt ........................................................ 55

3.6 Ergebnisse der Mikro-Computertomographie ............................................... 57

3.6.1 Dichte und Volumen des Gesamtknochens........................................ 57

3.6.2 Dichte und Volumen des kortikalen Knochens ......................................... 58

3.6.3 Dichte und Volumen des trabekulären Knochens .................................... 59

3.6.4 Dichte und Volumen von kortikalem und trabekulärem Knochen.................61 61

3.6.5 Dichte und Volumen des Weichteilgewebes ............................................. 62

3.6.6 Fläche des kortikalen Knochens............................................................ 64

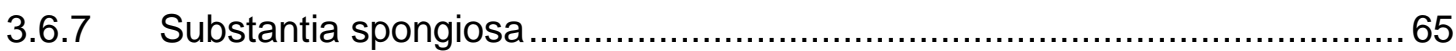




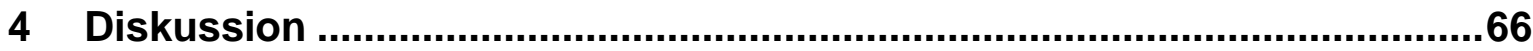

4.1 Die ovariektomierte Ratte als Tiermodell für die postmenopausale

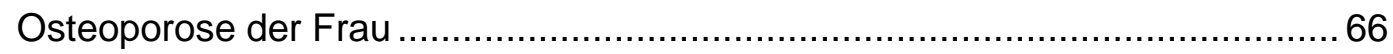

4.2 Körpergewicht und tägliche Futteraufnahme ............................................... 68

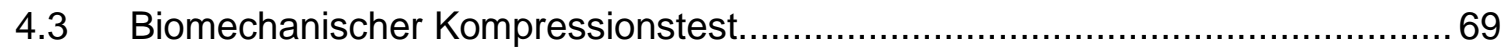

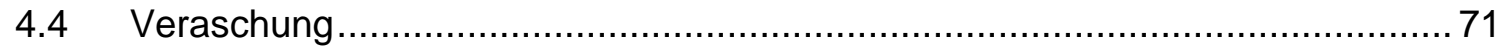

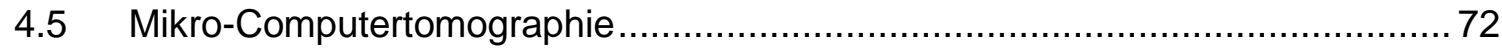

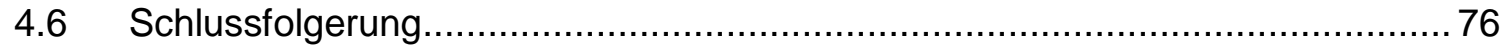

5 Zusammenfassung ..............................................................................

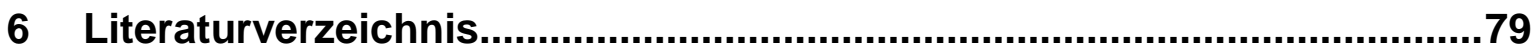




\section{Abbildungsverzeichnis}

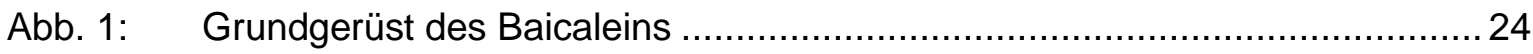

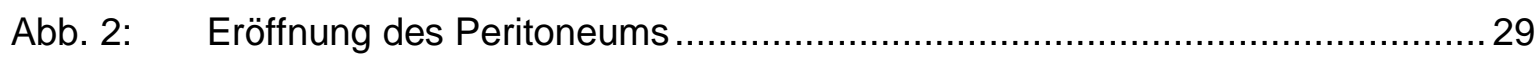

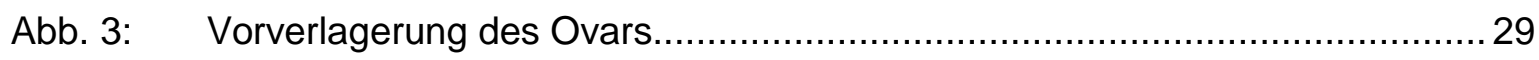

Abb. 4: $\quad$ Abtrennung des linken Ovars nach Ligatur der Tuba uterina ........................29

Abb. 5: $\quad$ Wundverschluss mit Klammern und Wunddesinfektion ................................2 29

Abb. 6: Korrekte Lage des Femurs auf der Trägerplatte mit heruntergefahrenem

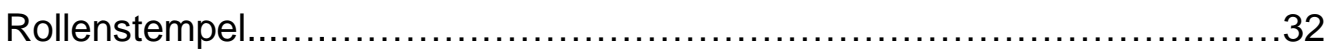

Abb. 7: Korrekte Position der Trägerplatte (inkl. darauf gelagertem Femur) in

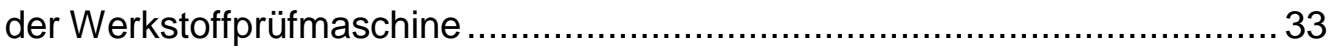

Abb. 8: Veraschung der Knochenproben in einem Muffelofen ................................ 34

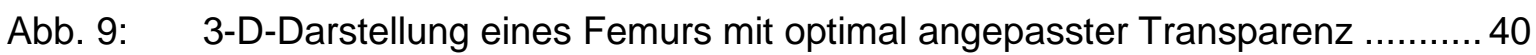

Abb. 10: Grauwerthistogramm der 3-D-Darstellung (Abb. 9) für die optimale

Anpassung der Transparenz . .40

Abb. 11: 2-D-Darstellung eines Femurs mit optimal angepasstem Kontrast 40

Abb. 12: Grauwerthistogramm der 2-D-Darstellung (Abb. 11) für die optimale

Anpassung des Kontrasts. 40

Abb. 13: 3-D-Darstellung des Kalibrierungsphantoms ............................................. 41

Abb. 14: Histogramm des Kalibrierungsphantoms ................................................. 41

Abb. 15: 3-D-Darstellung von Kalibrierungsphantom und Femur ................................ 43

Abb. 16: Caput femoris in der 3-D-Darstellung vor der Bestimmung der

Knochendichte

Abb. 17: 3-D-Darstellung von unten auf den Querschnitt des Collum femoris und Markierung der Knochenoberfläche 45

Abb. 18: 3-D-Darstellung von unten auf den Querschnitt des Collum femoris und Markierung der Substantia spongiosa

Abb. 19: 3-D-Ansicht von unten auf den Querschnitt des Collum femoris und zentrale Anpassung des Messrahmens 
Abb. 20: 3-D-Ansicht von lateral zur Überprüfung und Anpassung des Messrahmens

Abb. 21: 3-D-Ansicht von lateral auf den Untersuchungsabschnitt, welcher zuvor durch den Messrahmen ausgewählt wurde

Abb. 22: 3-D-Ansicht von lateral auf die in Abb. 21 markierte trabekuläre Struktur der Substantia spongiosa

Abb. 23: Verlauf der wöchentlich ermittelten Körpergewichte als Mittelwert jeder einzelnen Versuchsgruppe

Abb. 24: Gruppenspezifische Darstellung des mittleren Uterusgewichtes \pm Standardabweichungen nach der Tötung

Abb. 25: Darstellung der gruppenspezifischen Mittelwerte \pm Standardabweichungen der Messgröße Elastizität

Abb. 26: Darstellung der gruppenspezifischen Mittelwerte \pm Standardabweichungen der Messgröße Maximalkraft

Abb. 27: Darstellung der gruppenspezifischen Mittelwerte \pm Standardabweichungen der organischen Masse

Abb. 28: Darstellung der gruppenspezifischen Mittelwerte \pm Standardabweichungen der anorganischen Masse

Abb. 29: Darstellung der gruppenspezifischen Mittelwerte \pm Standardabweichungen des Calcium-Gehaltes nach der Veraschung

Abb. 30: Darstellung der gruppenspezifischen Mittelwerte \pm Standardabweichungen des Phosphat-Gehaltes nach der Veraschung.....

Abb. 31: Darstellung der gruppenspezifischen Mittelwerte \pm Standardabweichungen des Verhältnis von Calcium und Phosphat nach der Veraschung

Abb. 32: Darstellung der gruppenspezifischen Mittelwerte \pm Standardabweichungen der Dichtebestimmung des Gesamtknochens

Abb. 33: Darstellung der gruppenspezifischen Mittelwerte \pm Standardabweichungen der Volumenbestimmung des Gesamtknochens 
Abb. 34: Darstellung der gruppenspezifischen Mittelwerte \pm Standardabweichungen der Dichtebestimmung des kortikalen Knochens

Abb. 35: Darstellung der gruppenspezifischen Mittelwerte \pm Standardabweichungen der Volumenbestimmung des kortikalen Knochens

Abb. 36: Darstellung der gruppenspezifischen Mittelwerte \pm Standardabweichungen der Dichtebestimmung des trabekulären Knochens.

Abb. 37: Darstellung der gruppenspezifischen Mittelwerte \pm Standardabweichungen der Volumenbestimmung des trabekulären Knochens.

Abb. 38: Darstellung der gruppenspezifischen Mittelwerte \pm Standardabweichungen der Dichtebestimmung von Kortikalis und trabekulärem Knochen.

Abb. 39: Darstellung der gruppenspezifischen Mittelwerte \pm Standardabweichungen der Volumenbestimmung von Kortikalis und trabekulärem Knochen.

Abb. 40: Darstellung der gruppenspezifischen Mittelwerte \pm Standardabweichungen der Dichtebestimmung des Weichteilgewebes.

Abb. 41: Darstellung der gruppenspezifischen Mittelwerte \pm Standardabweichungen der Volumenbestimmung des Weichteilgewebes

Abb. 42: Darstellung der gruppenspezifischen Mittelwerte \pm Standardabweichungen der Flächenbestimmung des kortikalen Knochens

\section{Tabellenverzeichnis}

Tab. 1: $\quad$ Osteoporose - Stadieneinteilung ...................................................... 10

Tab. 2: $\quad$ Einteilung der Versuchstiere in Gruppen zu Beginn des Versuchs ...............25

Tab. 3: $\quad$ Einteilung und Behandlungsart der Versuchstiere nach

Ovariektomie und Osteotomie 26

Tab. 4: $\quad$ Einheiten und Messparameter der Calcium- und Phosphatbestimmung ........ 36

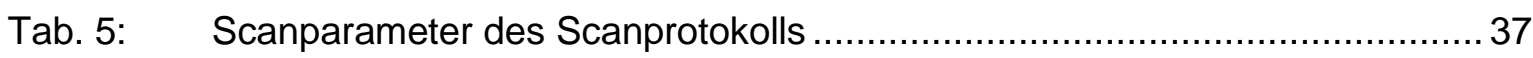

Tab. 6: Darstellung der ermittelten definierten unteren Schwellenwerte ..................44

Tab. 7: $\quad$ Messparameter der Dichte- und Volumenbestimmung ................................ 44 
Tab. 8: $\quad$ Messparameter für die Analyse der Substantia spongiosa

Tab. 9: $\quad$ Verlauf der täglichen Futteraufnahme als Mittelwert \pm Standardabweichung pro Tier jeder einzelnen Versuchsgruppe .50

Tab. 10: Ergebnisse der Analyse der Substantia spongiosa .65

\section{Abkürzungsverzeichnis}

2-D zweidimensional

3-D dreidimensional

$\mu \mathrm{m} \quad$ Mikrometer

Abb. Abbildung

ANOVA Analysis of Variance

BMC Bone Mineral Content

BMD Bone Mineral Density

BMI Body Mass Index

BMU Basic Multicellular Unit

BUA Broadband Ultrasound and Attenuation

$\mathrm{CO}_{2} \quad$ Kohlenstoffdioxid

CT Computertomographie

dB Dezibel

DEXA Dual Energy X-Ray Absorptiometry

DVO Dachverband Osteologie

DXA Dual X-Ray Absorptiometry

$\mathrm{H}^{+} \quad$ Wasserstoffion

IE Internationale Einheit

KG Körpergewicht

kV Kilovolt

$\mu S v \quad$ Mikrosievert

$\mu$ - CT Mikro-Computertomographie

$\mathrm{MHz} \quad$ Megahertz

$\min \quad$ Minute

ms Millisekunde 


\begin{tabular}{ll} 
N & Newton \\
$\mathrm{NaCl}$ & Natriumchlorid \\
$\mathrm{NIH}$ & National Institute of Health \\
$\mathrm{nm}$ & Nanometer \\
$\mathrm{OVX}$ & Ovariektomie \\
$\mathrm{pH}$ & Potentia hydrogenii \\
PTH & Parathormon \\
QCT & Quantitative Computertomographie \\
QUS & Quantitative Ultraschallmessung \\
RKI & Robert Koch-Institut \\
S. & Seite \\
S & Sekunde \\
SD & Standardabweichung \\
SOS & Speed of Sound \\
Tab. & Tabelle \\
vgl. & vergleiche \\
WHO & Weltgesundheitsorganisation \\
z.B. & zum Beispiel \\
ZTE & Zentrale Tierexperimentelle Einrichtung der Universitätsmedizin \\
& Göttingen \\
\hline
\end{tabular}




\section{Einleitung}

\subsection{Einführung in das Thema und Zielsetzung}

Die Osteoporose ist Schätzungen zur Folge eine Erkrankung, von der weltweit mehr als 200 Mio. Menschen betroffen sind (Lane 2006). Daher zählt sie laut der WHO zu den 10 bedeutendsten Krankheiten der Welt.

Experten gehen davon aus, dass allein in der Bundesrepublik Deutschland ca. 8 Mio. Menschen zu den Osteoporose-Erkrankten gehören. Somit handelt es sich um ein ernstzunehmendes Volksleiden. Schon jetzt erweisen sich die jährlichen Folgekosten von mehr als $5 \mathrm{Mrd}$. $€$ in Bezug auf das Gesundheitssystem als von hoher Relevanz (Bartl und Bartl 2011, Häussler et al. 2007).

Im Hinblick auf eine steigende Lebenserwartung mit veränderten Lebensgewohnheiten und einer sich altersstrukturell verändernden Gesellschaft ist in der Zukunft von einer deutlichen Zunahme der Osteoporose-Patienten auszugehen. Die Erkrankung wird aufgrund der medizinischen und sozioökonomischen Bedeutung stetig mehr in das Bewusstsein des öffentlichen Interesses rücken und die Gesellschaft vor große Herausforderungen stellen.

Bei der Osteoporose handelt es sich um eine systemische Skeletterkrankung. Der Krankheitsverlauf ist dadurch gekennzeichnet, dass es sowohl zu einer Abnahme der Knochenmasse als auch zu einem Strukturverlust des Knochengewebes kommt. Bedingt durch diesen quantitativen und qualitativen Knochenverlust resultiert eine erhöhte Knochenbrüchigkeit (Deuss 2005).

$\mathrm{Zu}$ einer der bedeutendsten Prädilektionsstellen für osteoporoseassoziierten Frakturen gehört das Femur, da Femurfrakturen für die Patienten mit erheblichen Einschränkungen im Alltag verbunden sind. Statistiken belegen, dass $25-30 \%$ der Betroffenen in der Folge auf Fremdhilfe angewiesen und 15-20\% ständig pflegebedürttig sind. Die 1-Jahres-Mortalität liegt zwischen 12-20\% (Kunczik und Ringe 1994).

Derzeit werden in der Osteoporose-Therapie vor allem osteoanabole Medikamente wie z. B. Parathormon oder antiresorptive Medikamente, etwa Bisphosphonate eingesetzt. Da mit dem Einsatz von diesen Medikamenten jedoch einige Nebenwirkungen wie kardiovaskuläre und gastrointestinale Komplikationen sowie bisphosphonatassoziierte Knochennekrosen im Kieferbereich hervorgerufen 
werden können, ist die Wissenschaft weiterhin auf der Suche nach besser geeigneten Wirkstoffen, welche vor allem eine geringere Toxizität aufweisen ( $\mathrm{Li}$ et al. 2015, Otto et al. 2011).

Bei Baicalein handelt es sich um ein Flavon des Baikal-Helmkrautes (Scrutellaria baicalensis), welches seit Jahrhunderten in der traditionellen chinesischen Medizin verwendet wird. Da unter anderem selektiv inhibitorische Eigenschaften in Bezug auf einige Lipoxygenasen nachgewiesen werden konnten (Deschamps et al. 2006, Mascayano et al. 2013), wird ein positiver Effekt auf den osteoporotischen Knochen angenommen.

Ziel der vorliegenden Dissertationsarbeit war es, die Auswirkungen des Baicaleins, welches in unterschiedlichen Konzentrationen appliziert wurde, auf den osteoporotischen Knochen am Beispiel des Femurs am Tiermodell der Ratte zu untersuchen. Neben der morphologischen und mechanischen Beschaffenheit wurde auch der Calcium- und Phosphatgehalt analysiert.

\subsection{Theoretische Grundlagen}

\subsubsection{Knochen}

Beim Knochen handelt es sich um eine spezielle Form des Binde- und Stützgewebes. Im Vergleich zu anderen Geweben zeichnet er sich besonders durch seine enorme Festigkeit aus. Die chemische Zusammensetzung besteht zu $50 \%$ aus anorganischen Materialien, zu 25\% aus organischer Grundsubstanz und zu 25\% aus Wasser (Brückle 2014, Junqueira et al. 2005).

Das Skelett des menschlichen Körpers besteht insgesamt aus 220 einzelnen Knochen, die mit ungefähr $10 \mathrm{~kg}$ etwa 15\% des Körpergewichts ausmachen. Man kann es in das Skelett des Stamms, genauer gesagt in das Rumpf- oder Axialskelett, und in das Skelett der Extremitäten, das sogenannte Extremitätenskelett oder periphere Skelett, unterteilen (Bartl und Bartl 2011). Im menschlichen Körper erfüllt der Knochen ganz unterschiedliche Funktionen. Neben Stütz- und Fortbewegungsfunktion werden lebenswichtige Organe vor Verletzungen geschützt. Der Knochen bildet zudem eine Einheit mit dem Hohlräume auskleidenden Knochenmark. Hier findet die Bildung fast aller Blutzellarten statt. Darüber hinaus handelt es sich beim Knochen um ein großes 
Mineraldepot. In inm werden 99\% des gesamten Calciums, 85\% des Phosphats und 50\% des Magnesiums gespeichert (Bartl und Bartl 2011, Ulfig 2005).

\subsubsection{Knochenaufbau}

Grundsätzlich unterscheidet man zwei unterschiedliche Typen von Knochen. Zum einen den aus der Osteogenese primär hervorgehenden Geflechtknochen (Faserknochen), zum anderen den sich durch spezielle Umbauvorgänge schrittweise aus Geflechtknochen bildenden Lamellenknochen (Ulfig 2005).

Bei der Bildung von Geflechtknochen entsteht zunächst eine unverkalkte organische Extrazellulärmatrix, welche als Osteoid bezeichnet wird. Diese besteht aus 95\% Kollagen und 5\% Proteoglykanen. Durch Mineralisationsprozesse wird Calciumphosphat als Hydroxylapatit eingelagert. Unter stetigem Wachstum wird die primäre Spongiosa mit ihren charakteristischen Leisten und Bälkchen ausgebildet. Der Geflechtknochen besitzt im Vergleich zum Lamellenknochen eine deutlich geringere mechanische Festigkeit. Dies liegt unter anderem an dem noch ungeordneten Kollagenfaserverlauf, der reduzierten Anzahl von Osteozyten und an dem geringeren Mineralisierungsgrad der Interzellularsubstanz (Schünke 2014).

Die funktionelle Umwandlung von Geflechtknochen zu Lamellenknochen ist anfangs davon geprägt, dass über die Blutgefäße Osteoklasten in das Knochengewebe eindringen. Diese bilden einen Resorptionskanal, durch den Osteoblasten, welche sich aus Osteoprogenitorzellen differenzieren, einwandern und sich der Kanalwand anlagern können. Durch Matrixsekretion wird die erste konzentrische Knochenlamelle gebildet. Zu Beginn entsteht jedoch erst Osteoid, welches durch anschließende Mineralisierungsprozesse umgewandelt wird. Wenn die Osteoblasten vollständig von Osteoid umgeben sind, wandeln sie sich zu Osteozyten um. Durch die Angliederung von weiteren konzentrischen Knochenlamellen wird das Lumen des Resorptionskanals immer kleiner. Am Ende kommt es zur Ausbildung eines Osteons mit zentralem Haverskanal, welcher von perivaskulärem Bindegewebe ausgekleidet wird. Im Haverskanal verlaufen ein zentrales Gefäß und mehrere Nervenfasern (Schünke 2014).

Die einzelnen längs orientierten Haverskanäle sind untereinander durch querverlaufende Volkmann-Kanäle verbunden (Ulfig 2005). Ein Osteon kann aus 4 
bis 20 Knochenlamellen aufgebaut sein und einen Durchmesser von $100-400 \mu \mathrm{m}$ aufweisen. Zwischen den Osteonen befinden sich Schaltlamellen, welche Reste von abgebauten Osteonen darstellen (Deller 2014).

Bei der makroskopischen Betrachtung fallen zwei unterschiedliche Formen von Lamellenknochen auf. Im äußeren Bereich ist die stabile Substantia compacta lokalisiert, welche etwa $80 \%$ der gesamten knöchernen Skelettmasse ausmacht. Im Inneren werden rund 20\% von der Substantia spongiosa eingenommen. Diese bildet ein trabekuläres Netzwerk aus, welches sich dreidimensional aus Bälkchen, Stäben und Platten zusammenstellt. Durch diese Bauweise wird gewährleistet, dass der Knochen auch bei geringem Eigengewicht große mechanische Belastungen aushalten kann. Außer den überknorpelten Gelenkflächen wird die gesamte äußere Knochenoberfläche vom Periost überzogen (Schünke 2014). Im Inneren wird die Oberfläche der Hohlräume vom Endost ausgekleidet. Da beide Strukturen aus Bindegewebe und knochenbildenden Zellen bestehen, halten sie vor allem die Ernährung, das Wachstum und die Reparatur des Knochengewebes aufrecht (Junqueira et al. 2005).

In der vorliegenden Arbeit steht der osteoporotische Oberschenkelknochen im Mittelpunkt der verschiedenen Untersuchungen. Bei diesem Knochen handelt es sich um einen Röhrenknochen. Dieser besteht aus einem langen Schaft (Diaphyse) und aus zwei von Gelenkknorpel überzogenen Enden, welche als proximale und distale Epiphyse bezeichnet werden. Auffällig ist der unterschiedliche Aufbau dieser Kompartimente. Wohingegen bei der Diaphyse außen eine kräftige Kompakta mit nur dünner Spongiosa im Inneren vorzufinden ist, besteht die Epiphyse vorwiegend aus spongiösem Knochen, der nur von einer dünnen Kompakta bedeckt wird (Schünke 2014).

\subsubsection{Knochenzellen}

\subsubsection{Osteoprogenitorzellen}

Bei den Osteoprogenitorzellen handelt es sich um Vorläuferzellen der Osteoblasten. Sie entwickeln sich aus mesenchymalen Stammzellen und sind im Endost und Periost lokalisiert. Erst nach Umwandlung zu Präosteoblasten differenzieren sie zu Osteoblasten. Bei der histologischen Betrachtung fällt besonders ihr helles, schmales Zytoplasma und ihr länglicher bis ovaler Zellkern 
auf. Bei Knochenfrakturen sorgen sie durch Proliferation und Differenzierung für die im Anschluss stattfindende Osteogenese (Deller 2014).

\subsubsection{Osteoblasten}

Osteoblasten sind für die Bildung der organischen Bestandteile der Knochenmatrix im wachsenden und ausgereiften Knochen verantwortlich. Im aktiven Zustand besitzen sie kubische bis prismatische Form und sind auf der Matrixoberfläche in epithelähnlicher Anordnung angesiedelt. Sie zeichnen sich durch einen großen, hellen Zellkern, viele freie Ribosomen, einen großen Golgi-Apparat und basophiles Zytoplasma aus (Deller 2014). Zudem verfügen sie über ein besonders gut entwickeltes endoplasmatisches Retikulum, in welchem die Matrixproteine hergestellt werden. Die Modifikation und Verpackung erfolgt im Golgi-Apparat, ehe sie konstitutiv sezerniert werden. An der mit der Knochenmatrix in Verbindung stehenden Zelloberfläche werden sie schließlich freigesetzt (Junqueira et al. 2005). Es werden unter anderem Kollagen, Proteoglykane, Osteokalzin, Osteopontin, Osteonektin, aber auch Wachstumsfaktoren sekretiert. Die Regulation erfolgt durch verschiedene Zytokine, Vitamine und Hormone, wie bspw. Androgene, Östrogene, PTH oder Cacitriol an Rezeptoren. Zu Beginn ist die von den Osteoblasten freigesetzte Matrix nicht verkalkt und wird Osteoid genannt (Deller 2014, Jerosch et al. 2002).

In der Folge kommt es durch Einlagerung von Calciumphosphat, welches wiederum zu Hydroxylapatitkristallen umgeformt wird, zu einer Mineralisierung. Zusammen mit der alkalischen Phosphatase, welche sich auf der äußeren Oberfläche der Osteoblasten befindet, wirken sich die Proteine Osteocalcin und Osteopontin auf diesen Umwandlungsprozess unterstützend aus. Der Gesamtvorgang wird als Apposition bezeichnet. Bei anhaltender Apposition werden Osteoblasten in der Knochenmatrix eingeschlossen. Infolgedessen erfolgt ihre Differenzierung zu Osteozyten (Junqueira et al. 2005).

Ruhende Osteoblasten sind mit $80-95 \%$ vor allem auf der Oberfläche des Knochens anzufinden. Sie werden als endosteal lining cells bezeichnet. Diese charakteristisch sehr flachen Zellen übernehmen Schutz- und Überwachungsfunktion. Zudem beeinflussen sie die Aktivierungsphase der Osteoklasten (Bartl und Bartl 2011). 


\subsubsection{Osteozyten}

Im verkalkten Knochen sind Osteozyten komplett von mineralisierter Knochenmatrix umgeben. Sie befinden sich in linsenförmigen Lakunen und bilden Fortsätze in die Canaliculi aus, welche den mineralisierten Knochen wie ein Netzwerk durchziehen (Junqueira et al. 2005, Lüllmann-Rauch 2009).

Untereinander stehen die Osteozyten durch gap junctions in Verbindung, wodurch ein Stoffaustausch von Signalstoffen und Metaboliten gewährleistet wird (Noble 2008). Osteozyten sind mechanosensorische Zellen, welche maßgeblich an der funktionellen Adaption des Knochens beteiligt sind und wachen über den Zustand und die Reparaturbedürftigkeit der Knochenmatrix. Ferner nehmen sie das Alter des Knochens wahr und sind aktiv am Knochenumbau und der Aufrechterhaltung der extrazellulären Matrix beteiligt. Ein Absterben von Osteozyten führt zu einer von Osteoklasten durchgeführten Resorption der Knochenmatrix. In der Folge kommt es sowohl zu einer Abnahme der Osteozytenzahl als auch zu einer Verschlechterung der Knochenmasse. Somit besteht eine direkte Korrelation zwischen der Dichte der vorhandenen Osteozyten und der Knochendichte (Bartl und Bartl 2011).

\subsubsection{Osteoklasten}

Osteoklasten zählen zu dem mononukleären Phagozytensystem und entwickeln sich aus Vorläuferzellen, den Monozyten, im Knochenmark (Deller 2014, Roodman 1996).

Die großen, mehr- bis vielkernigen Zellen (bis zu 100 Kerne) sind für die Resorption der verkalkten Knochenmatrix verantwortlich. Sie liegen an der Knochenoberfläche in flachen Höhlungen, welche als Howship-Lakunen bezeichnet werden. Im Gegensatz zu ruhenden Osteoklasten lagern sich resorbierende Osteoklasten auf der Knochenmatrix an und bilden einen dicht aneinander liegenden Faltensaum (ruffled border), der von der clear zone, einer Zone mit vielen Aktinfilamenten, umgeben wird. Dadurch kommt es zur Ausbildung einer Resorptionslakune, die eine abgedichtete Verbindung zwischen Osteoklasten und Knochen sicherstellt. In diese Resorptionslakune werden vermehrt Wasserstoffionen und lysosomale Enzyme freigesetzt. Dadurch werden die Hydroxyapatitkristalle aufgelöst und es kommt zur Knochendemineralisation. 
Im Anschluss wird die organische Matrix, vor allem freiliegende Kollagenfibrillen, von Proteasen hydrolysiert (Deller 2014, Junqueira et al. 2005, Manolagas 2000). Die übrig bleibenden Abbauprodukte werden von den Osteoklasten phagozytiert. Die Aktivitätsphasen der langlebigen Osteoklasten werden von diversen Hormonen wie Leptin, Calcitonin, Östrogen oder Parathormon, aber auch von Wachstumsfaktoren kontrolliert (Bartl und Bartl 2011, Deller 2014).

\subsubsection{Knochenmatrix}

Die Knochenmatrix setzt sich aus organischen und anorganischen Bestandteilen sowie Wasser zusammen. Anorganische Komponenten wie Calcium und Phosphat sind in Form von Hydroxylapatitkristallen an Kollagenfibrillen angelagert und bilden mit mehr als 50\% den Hauptanteil der Matrix. Ebenfalls vertreten sind amorphes Calciumphosphat, Zitrat, Bikarbonat zudem Kalium-, Magnesium- und Natriumsalze. Dadurch erhält der Knochen vor allem eine große Festigkeit (Junqueira et al. 2005).

Der organische Bestandteil macht etwa ein Viertel der Knochenmatrix aus und besteht zu etwa 85-90\% aus Kollagen Typ I (Batge et al. 1992). Dies verleiht dem Knochen wiederum eine hohe Elastizität, so dass Zugkräfte optimal aufgefangen werden können. Der restliche Teil besteht aus Proteoglykanen und Glykoproteinen. Es wird vermutet, dass besonders die Glykoproteine eine wichtige Rolle in Bezug auf die Bindung von Calcium spielen und sich daher förderlich auf die Verkalkung der Knochenmatrix auswirken. Aufgrund dieser speziellen Zusammensetzung erhält der Knochen seine spezifische Härte und Widerstandsfähigkeit (Junqueira et al. 2005). Die restlichen 25\% der Knochenmatrix bestehen aus Wasser (Bartl und Bartl 2011).

\subsubsection{Knochenumbau}

Aufgrund seiner hohen Durchblutung und Stoffwechselaktivität befindet sich der Knochen in einem permanenten Umbauprozess. Das Größenwachstum und die damit zusammenhängende Anpassung von Knochenquerschnitt und Knochenlänge in den ersten beiden Lebensjahrzehnten ist Ausdruck eines vorwiegenden Knochenanbaus, welcher als modeling bezeichnet wird. Diese 
Phase ist mit dem Erreichen des 25. - 30. Lebensjahres abgeschlossen. Es ist bekannt, dass zu dieser Zeit auch die Spitzenknochenmasse (peak bone mass) erreicht wird (Bartl und Bartl 2011).

Nach Abschluss des Knochenwachstums findet eine Verlagerung von Knochenanbau hin zu Knochenumbau (remodeling) statt (Siegrist et al. 2008). Durch Adaptation an neue Belastungsanforderungen, sowie dem Austausch von alten und beschädigten Knochen durch neuen, wird eine Anpassung der Knochenverhältnisse zur Aufrechterhaltung der Funktion gewährleistet. Ebenfalls stellt dies die Verfügbarkeit von Calcium sicher (Bartl und Bartl 2011, Minne et al. 2002). Laut Lüllmann-Rauch werden jährlich insgesamt $28 \%$ der Spongiosa und $4 \%$ der Kompakta umgebaut, wodurch sich ein jährlicher Umbau des Skeletts von insgesamt 10\% ergibt (Lüllmann-Rauch 2009).

Ausgangspunkt des Knochenumbaus in der Kompakta ist die Knochenoberfläche. Hier sorgt ein Zusammenspiel von Osteoklasten, Osteozyten und Osteoblasten für einen zeitlich und räumlich koordinierten Ab- und Aufbau des Knochens. Dieser Zellverbund wird als Basic Multicellular Unit (BMU) bezeichnet. Zu Beginn eines Umbauprozesses werden die Osteoklasten aktiviert, welche oberflächliche Knochenzellen (bone lining cells) und darunter liegende Knochenmatrix resorbieren, so dass ein Bohrkanal entsteht. In diesen wachsen Bindegewebe, marklose Nervenfasern und Gefäße ein. Den Osteoklasten zuvor gefolgte Osteoblasten füllen die entstandenen Hohlräume durch Osteoid-Lamellen rasch wieder auf und bleiben bei vollständiger Einmauerung als Osteozyten, wie unter Punkt 1.2.3.2 beschrieben, zurück. Eine vollständige Mineralisierung der Knochenmatrix findet erst nach einigen Monaten statt (Lüllmann-Rauch 2009).

In der Spongiosa läuft der Knochenumbauprozess ähnlich ab, jedoch entstehen hier vor allem flächige Lakunen, welche in der Folge mit neuen Lamellen von Osteoblasten ersetzt werden.

Für die Regulierung des Knochenumbaus ist die mechanische Beanspruchung des Knochens von enormer Wichtigkeit. Es wird vermutet, dass Osteozyten die Rolle von "Mechanosensoren" einnehmen und Signale an Osteoblasten weiterleiten, die wiederum Osteoklasten aktivieren (Lüllmann-Rauch 2009).

Trotz vorhandener Regulationsmechanismen ist der Prozess des Knochenumbaus spätestens ab dem 30. Lebensjahr gestört. Durch einen erhöhten Knochenabbau 
kommt es zu einer negativen Bilanz, wodurch ein geschlechtsunabhängiger Knochenverlust von durchschnittlich 1\% pro Jahr resultiert (Bartl und Bartl 2011). Beim Vergleich der Geschlechter fällt auf, dass bei postmenopausalen Frauen sogar ein Knochenverlust von bis zu 4\% pro Jahr festzustellen ist. Laut Bartl bedeutet dies, dass die Frau vom 40. bis zum 70. Lebensjahr im Durchschnitt etwa 40\% ihrer Knochenmasse verliert, wohingegen der Mann im gleichen Zeitraum nur etwa 12\% verliert. Aus diesem Grund ist eine hohe Spitzenknochenmasse (peak bone mass) vor beginnendem Knochenverlust, sowie die Aufrechterhaltung dieser bspw. durch eine gesunde Ernährung entscheidend, um das Osteoporose-Risiko zu minimieren (Bartl und Bartl 2011).

\subsection{Osteoporose}

\subsubsection{Definition}

Es gibt eine Vielzahl von unterschiedlichen Definitionen für die Osteoporose. Einen allgemeinen Überblick über das Krankheitsbild der Osteoporose liefert die Definition des NIH Consensus Development Planel on Osteoporosis aus dem Jahr 2001. Demnach handelt es sich bei der Osteoporose um eine systemische Skeletterkrankung, die durch eine unzureichende Knochenfestigkeit charakterisiert ist. Daraus geht wiederum ein erhöhtes Frakturrisiko hervor. Die Knochenfestigkeit spiegelt dabei primär das Zusammenwirken von Knochendichte und Knochenqualität wieder (Hofbauer et al. 2014).

Die Weltgesundheitsorganisation hat bereits im Jahre 1994 eine in Bezug auf die Diagnostik deutlich präzisere Definition festgelegt. Demnach liegt eine Osteoporose vor, wenn die Knochenmineraldichte (DXA-Methode) an der Lendenwirbelsäule (L2 - L4) und/ oder an der Hüfte (Gesamtareal oder Schenkelhals) um mehr als 2,5 Standardabweichungen (SD) vom statistischen Mittelwert einer gesunden prämenopausalen Frau abweicht (= T-Score) (WHO Study Group 1994).

Da die Einordnung sowie die Definition der Osteoporose auf den diagnostizierbaren T-Scores beruht (siehe Tabelle 1), ist es wichtig andere Erkrankungen, welche ebenfalls mit einer Verminderung des Knochenmineralgehaltes einhergehen können, auszuschließen. Wie bereits erwähnt, gilt 
die WHO-Definition nur für die Diagnose von postmenopausalen Frauen, zusätzlich jedoch auch für Männer ab dem 50. Lebensjahr.

Für Kinder, prämenopausale Frauen und Männer unter dem 50. Lebensjahr empfiehlt sich in der Diagnose die Anwendung des Z-Scores, welcher ein weiterer Parameter für die Knochendichtemessung darstellt. Hierbei wird die ermittelte Knochendichte mit knochengesunden Referenzwerten der entsprechenden Altersgruppe und des gleichen Geschlechts verglichen (Bartl und Bartl 2011, Hernlund et al. 2013).

Tab. 1: Osteoporose - Stadieneinteilung (modifiziert nach WHO, 1994)

\begin{tabular}{|c|c|c|}
\hline Stadium & DXA-Messung & Klinische Symptome \\
\hline $\begin{array}{l}\text { Osteopenie } \\
\text { (Grad 0) }\end{array}$ & T-Score: -1 bis $-2,5$ SD & $\begin{array}{l}\text { - verminderter Knochenmineralgehalt } \\
\text { - keine Frakturen }\end{array}$ \\
\hline $\begin{array}{l}\text { Osteoporose } \\
\text { (Grad 1) }\end{array}$ & T-Score* $:<-2,5$ SD & $\begin{array}{l}\text { - verminderter Knochenmineralgehalt } \\
\text { - keine Frakturen }\end{array}$ \\
\hline $\begin{array}{c}\text { Manifeste } \\
\text { Osteoporose } \\
\text { (Grad 2) }\end{array}$ & T-Score: $<-2,5$ SD & $\begin{array}{l}\text { - verminderter Knochenmineralgehalt } \\
\text { - bis zu } 3 \text { Wirbelkörperfrakturen }\end{array}$ \\
\hline $\begin{array}{l}\text { Fortgeschrittene } \\
\text { Osteoporose } \\
\text { (Grad 3) }\end{array}$ & T-Score: $<-2,5$ SD & $\begin{array}{l}\text { - verminderter Knochenmineralgehalt } \\
\text { - mehr als } 3 \text { Wirbelkörperfrakturen }\end{array}$ \\
\hline
\end{tabular}

\subsubsection{Epidemiologie}

Die Osteoporose, von der weltweit mehr als 200 Millionen Menschen betroffen sind, zählt laut der WHO zu den zehn bedeutendsten Volkskrankheiten (Lane 2006).

Es gibt mehrere Studien, in denen die Osteoporose-Prävalenz für Deutschland geschätzt wird, allerdings basieren sie auf unterschiedlichen Erhebungsmethoden, 
Daten, Altersgruppen und Populationen. Deswegen gibt es keine einheitlichen Angaben.

Bei einer Umfrage des Robert Koch-Instituts (RKI) stellte sich heraus, dass nur bei 11,9\% (5,2\% Männer, 17,6\% Frauen) der Befragten ab 50 Jahren ein Arzt Osteoporose festgestellt hat (Robert Koch-Institut 2011). Laut Häussler waren 2003 in Deutschland 7,8 Millionen Menschen im Alter von über 50 Jahren von Osteoporose betroffen. Die Prävalenz lag bei 26\%, welche sich zu 39\% bei den Frauen und zu 9,7\% bei den Männern zusammensetzte (Häussler et al. 2007). Im Jahr 2009 wurde die Prävalenz auf 14\% mit 6,3 Millionen Erkrankten in Deutschland in dieser Altersgruppe geschätzt (Hadji et al. 2013). Auffällig ist die Prävalenz der Frau in Bezug auf die verschiedenen Altersgruppen. Während sie zwischen 50 bis 54 Jahren noch bei 12\% liegt, fällt sie mit 32\% bei den 65 - bis 74 Jährigen deutlich höher aus. Bei der Altersgruppe über 74 Jahre liegt die Prävalenz sogar bei $48 \%$. So fällt der Anteil der erkrankten Frauen mit 5,2 Millionen auch deutlich höher aus als der Anteil der erkrankten Männer mit 1,1 Millionen. Laut Schätzungen (Bone Evaluation Study) für das Jahr 2009 geht man bei den über 50-Jährigen von jährlich rund 885.000 Neuerkrankungen aus (Hadji et al. 2013).

Auf Grundlage dieser Entwicklungen ist auch mit einem Anstieg osteoporotischer Frakturen zu rechnen. In Deutschland geht man z. B. in Bezug auf Hüftfrakturen von einem Anstieg von 117.000 Frakturen im Jahr 2000 auf über 240.000 im Jahr 2040 aus. Bedingt durch diese Entwicklungen werden sich höhere Kosten für das Gesundheitssystem ergeben. Laut Häussler betrugen die Osteoporose-bedingten Folgekosten in Deutschland bereits im Jahr 2003 ungefähr 5,4 Mrd. $€$ (Häussler et al. 2007).

Trotz der belegten Entwicklungen gilt Osteoporose unter vielen Experten noch immer als unterdiagnostizierte und untertherapierte Krankheit. Laut Schätzungen werden von ca. 7 Millionen Osteoporose-Patienten nur etwa 1,2 Millionen behandelt (Bartl und Bartl 2011).

\subsubsection{Einteilung}

Für Osteoporose gibt es eine Vielzahl unterschiedlicher Einteilungen. Die unter Punkt 1.3.1 von der WHO aufgestellte Einteilung nach Schweregrad ist nur ein 
Beispiel dafür. Im Folgenden werden weitere Einteilungen nach Ätiologie, Ausdehnung sowie Alter und Geschlecht vorgenommen (Bartl und Bartl 2011).

\section{Einteilung nach der Ätiologie:}

In Bezug auf die Krankheitsentstehung differenziert man zwischen den primären und sekundären Osteoporosen. Der Großteil wird hierbei von den primären oder idiopathischen Osteoporosen gebildet, welche sich vorwiegend aus postmenopausalen (Typ I) und senilen Osteoporosen (Typ II) zusammensetzen. Bei dieser Form der Erkrankung liegen keine anderen Grunderkrankungen vor, und die Pathogenese ist im Knochenstoffwechsel selbst vorzufinden. Der weitaus geringere Teil wird von den sekundären Osteoporosen eingenommen. Als Ursache werden hier bspw. endokrinologische, onkologische, hämatologische, kardiologische oder genetische Faktoren aufgeführt (Bartl und Bartl 2011, Lin und Lane 2004, Minne et al. 2002).

\section{Einteilung nach der Ausdehnung:}

Bei dieser Einteilung wird anhand des Skeletts zwischen lokalisierten Osteoporosen und der generalisierten Osteoporose unterschieden. Lokalisierte Osteoporosen treten örtlich beschränkt auf. Ein klassisches Beispiel hierfür sind Frakturen. Da Frakturen in der Regel mit einer Schienungstherapie behandelt und ruhiggestellt werden, ist in der Region der Fraktur ein deutlicher Knochenabbau zu verzeichnen. Dies ist besonders bei älteren Patienten mit ohnehin eingeschränktem Knochenstoffwechsel ein großes Problem (Bartl und Bartl 2011). Andere Ursachen für das Auftreten von lokalisierter Osteoporose sind Z. B. spezielle Syndrome wie das Gorham-Syndrom. Bei dieser Erkrankung findet eine vollständige osteoklastäre Resorption eines einzelnen Knochens statt. In der Folge werden auch benachbarte Skelettregionen resorbiert. Deutlich häufiger kommt es jedoch zu generalisierten (systemischen) Osteoporosen in Form von metabolischen Osteopathien. Auffällig ist, dass sie zunächst lokal, aber mit einem symmetrischen Skelettbefall auftritt (Bartl und Bartl 2011).

\section{Einteilung nach Alter und Geschlecht:}

Schon bei jungen Kindern zwischen dem 8. und 14. Lebensjahr kann es zum Auftreten einer Osteoporose kommen. Diese wird als idiopathische juvenile 
Osteoporose bezeichnet. Mögliche Folgen können schwere Rückenschmerzen und sogar Kompressionsfrakturen der Wirbelkörper sein. Zwischen dem 30. und 50. Lebensjahr spricht man von der idiopathischen Osteoporose junger Erwachsener. Auffällig ist, dass besonders Männer von dieser Erkrankung betroffen sind und es durch einen erhöhten Knochenabbau sehr oft $u$. a. zu Wirbelfrakturen am Achsenskelett kommt (Bartl und Bartl 2011, Fitzpatrick 2002). Die postmenopausale Osteoporose, welche als Typ I bezeichnet wird, ist die häufigste Form der Erkrankung. Aufgrund des Ausfalls der Ovarfunktion und dem daraus resultierenden Östrogenabfall tritt sie zwischen dem 51. und 75. Lebensjahr auf. Hierbei ist besonders der spongiöse Anteil des Knochens von Resorptionsvorgängen betroffen, wodurch es vor allem zu Oberschenkel- und Wirbelkörperfrakturen kommen kann. Die postmenopausale Osteoporose bezieht sich nur auf Frauen, jedoch führt ein vergleichbarer Hormonmangel (Testosteron) bei Männern, wenn auch in einer deutlich späteren Lebensphase, auch zu einer gesteigerten Knochenresorption (Bartl und Bartl 2011).

Ab dem 70. Lebensjahr geht die postmenopausale (Typ I) Osteoporose in die senile (Typ II) Osteoporose über. Frauen sind von dieser Erkrankung rund 2- mal häufiger betroffen als Männer. Im Rahmen des Alterungsprozesses kommt es zu einer Abnahme der Osteoblasten, oft auch in Kombination mit einem gesteigerten Knochenabbau. Neben Oberschenkeln und Wirbelkörpern sind auch Becken- und Röhrenknochen betroffen. Weitere Ursachen können z. B. auch ein gestörter Vitamin D-Stoffwechsel, ungenügende Calciumzufuhr oder Immobilität sein. Besonders problematisch ist, dass $\mathrm{zu}$ diesem Zeitpunkt auch Resorptionsvorgänge am kortikalen Knochen stattfinden. Aufgrund dieser Umstände treten in diesem Altersabschnitt mit ungefähr $80 \%$ auch die meisten Osteoporose-bedingten Frakturen auf. Eine klare Trennung zwischen der postmenopausalen und senilen Osteoporose im Alter ist jedoch nur von geringer praktischer Relevanz (Bartl und Bartl 2011, Marcus 1996).

\subsubsection{Risikofaktoren}

Neben der genetischen Prädisposition, welche Auswirkungen z. B. auf die maximale Knochendichte und die spätere Knochenverlustrate hat, gibt es eine Vielzahl von beeinflussbaren Risikofaktoren, die für die Entstehung einer 
Osteoporose in Frage kommen oder den Krankheitsverlauf einer bereits existierenden Erkrankung negativ beeinflussen können.

Einer der wichtigsten Risikofaktoren für die Entstehung einer Osteoporose stellt die Abnahme der körperlichen Aktivität dar (Hoidrup et al. 2001). Die Immobilisation z. B. einer Unterarmfraktur mit einem Gipsverband über 3 Wochen bedeutet für den Patienten einen Knochenverlust von ca. $6 \%$ in der betroffenen Region. Auch bei Astronauten kann man aufgrund der fehlenden Gravitationskraft im Weltall einen Knochenmasseverlust von etwa 1\% pro Monat feststellen. Andere Beispiele von Immobilität mit stark einhergehendem Knochenverlust sind z. B. Querschnittslähmung nach einem Halswirbelsäulen-Trauma, Paraplegie der unteren Körperhälfte oder mehrwöchige Bettruhe in der Schwangerschaft (Bartl und Bartl 2011). Den durch die Immobilität hervorgerufenen Knochenverlust kann man nur sehr schwer wieder kompensieren. Studien belegen, dass die Wiederherstellung der vorherigen Knochenverhältnisse etwa 3 - 4 mal so lange dauert (Ohshima 2010). Von daher ist eine schnelle Mobilisierung der Patienten anzustreben, um weiteren Knochenverlust und sich daraus ergebende Folgeschäden, wie z. B. Frakturen möglichst zu verhindern. Eine übertriebene sportliche Aktivität, gerade bei Frauen, ist jedoch auch als Osteoporosebegünstigend einzustufen, da sich hierbei das Risiko, eine Stressfraktur zu erleiden, erhöht (Bartl und Bartl 2011).

Ein weiterer Risikofaktor stellt ein zu geringes Körpergewicht dar. Laut der Global Longitudinal Study of Osteoporosis in Women-Studie, in der die Daten von mehr als 60.000 Frauen im Alter über 50 Jahren ausgewertet wurden, besteht ein direkter Zusammenhang zwischen niedrigem BMI und dem Risiko von Frakturen. Unter anderem findet in den Fettzellen eine verminderte Östrogenproduktion statt und auch die Knochendichte ist vermindert. Ferner werden die Knochen durch fehlendes Fettgewebe weniger gut geschützt (Hooven et al. 2009).

Auf der anderen Seite ist ein Übergewicht in Bezug auf den Knochenmetabolismus ebenfalls als kontraproduktiv anzusehen, da sich ein erhöhter Fettanteil im Knochenmark negativ auf die Osteoblastogenese auswirkt (Cao 2011).

Der Konsum von Zigaretten stellt einen zusätzlichen Risikofaktor dar. Weil Nikotin z. B. die Östrogenproduktion und Osteoblasten hemmt und zugleich den Östrogenabbau in der Leber fördert, verdoppelt sich das Osteoporose-Risiko. 
Auch eine Fehlernährung, bei der bspw. nicht genügend Calcium über die Nahrung zugeführt wird, erhöht das Risiko für die Entstehung einer Osteoporose. Als Konsequenz wird das im Knochen gespeicherte Calcium über das Parathormon freigesetzt, und es kommt zu einem negativen Knochenmetabolismus. Ebenso spielen Depressionen, Alkoholismus und die Einnahme von bestimmten Medikamenten eine nicht unerhebliche Rolle an Osteoporose zu erkranken. Hier ist vor allem die besonders schädigende Wirkung von Kortison und seiner Derivate, welche als Glukokortikoide bezeichnet werden, zu nennen (Bartl und Bartl 2011, Tella und Gallagher 2014).

\subsection{Diagnostik osteoporotischer Veränderungen}

Für die erfolgreiche Behandlung einer Osteoporose ist nicht nur das Erkennen und Vermeiden von Risikofaktoren von besonderer Relevanz, sondern auch eine frühzeitige Diagnosestellung entscheidend. Laut Empfehlung des Dachverbands Osteologie (DVO) besteht die Basisdiagnostik der Osteoporose aus Anamnese, klinischem Befund, einer DXA-Knochendichtemessung, einem Basislabor sowie ggf. einer bildgebenden Diagnostik (DVO-Leitlinie 2014).

\subsubsection{Anamnese und klinischer Befund}

Die Anamnese und der klinische Befund dienen für die Bestimmung des Osteoporose-Risikos und bilden die Grundlage für alle weiterführenden Behandlungen. Zugleich kann eine Differenzialdiagnose hinsichtlich einer primären oder sekundären Osteoporose oder ob es sich um eine andere Knochenerkrankung handelt, vorgenommen werden. Somit ist es wichtig, schon bei der Anamnese alle Frakturrisikofaktoren zu erfassen und diese individuell nach Nutzen und Risiko abzuwägen (DVO-Leitlinie 2014).

Neben einer ausführlichen Anamnese ist auch eine körperliche Untersuchung durchzuführen. Gerade bei Patienten mit bereits eingetretenen Frakturen ist es zudem wichtig, eine genaue Anamnese in Bezug auf die Intensität und Lokalisation des Schmerzes sowie funktionellen Einschränkungen, welche durch die Fraktur ausgelöst werden, vorzunehmen. Im Anschluss daran sollten eine 
Schmerztherapie, aber auch rehabilitative Maßnahmen in Erwägung gezogen werden (Bartl und Bartl 2011).

Bestehen bei den Patienten anamnestische oder klinische Hinweise für eine Beeinträchtigung von Koordination oder Muskelkraft, sollte zusätzlich eine Erfassung des Sturzrisikos durchgeführt werden (DVO-Leitlinie 2014).

\subsubsection{Osteodensitometrie}

Die Knochendichtemessung ist neben der konventionellen Röntgendiagnostik ein wichtiger Bestandteil bildgebender Untersuchungsmethoden in der Frühdiagnostik und Verlaufskontrolle osteoporotischer Veränderungen. Sie dient der Erfassung der Knochenmineraldichte (Bone Mineral Density, BMD) in $\mathrm{g} / \mathrm{cm}^{2}$ oder $\mathrm{g} / \mathrm{cm}^{3}$ und des Knochenmineralgehaltes (Bone Mineral Content, BMC) in g.

Grundsätzlich sind bei der Knochendichtemessung zwei methodische Ansätze zu differenzieren. Es besteht entweder die Möglichkeit die Messung mit energiereicher Strahlung mittels Röntgenenergie oder mit akustischen Messverfahren in Form von Ultraschall durchzuführen. Auf Grundlage der ermittelten Knochendichte können Erkenntnisse in Bezug auf das individuelle Frakturrisiko gewonnen werden. Laut Kann ermöglicht es dem Patienten zudem eine nützliche und mit Konsequenzen für sein zukünftiges Leben und seine Lebensqualität behaftete Therapieentscheidung zu treffen (Kann 2001).

\section{DXA/ DEXA-Methode (Dual Energy X-Ray Absorptiometry)}

Es gibt eine Vielzahl unterschiedlicher Messverfahren zur Knochendichtebestimmung. Derzeit wird jedoch nur die DXA-Methode von der Weltgesundheitsorganisation, der International Osteoporosis Foundation und auch von dem Dachverband Osteologie als anerkanntes Messverfahren zur Diagnostik der Osteoporose anerkannt (Issever und Link 2011).

Die DXA-Messung basiert auf dem Prinzip, dass zwei unterschiedliche Röntgenstrahlungsenergieniveaus, welche höher- und niedrigenergetisch sind, an der zu untersuchenden Körperregion erfasst werden. Die Messung erfolgt dabei auf Grundlage der energieabhängig, unterschiedlich starken Schwächung der Röntgenstrahlung durch Weichteilgewebe und Knochen. Als Resultat beider Energieniveaus erhält man ein Differenzbild, welches in seinen verbleibenden 
Werten aus den kalkdichten Knochenstrukturen der untersuchten Region besteht und somit Auskunft über den Mineralgehalt des Knochens gibt (Issever und Link 2011).

Zur Knochendichtemessung ist diese Methode weltweit am meisten verbreitet und erweist sich u. a. aufgrund der internationalen Standardisierung, Erfahrung in Therapiestudien, kurzen Messdauer, geringen Strahlenbelastung und schmerzlosen Messung als besonders vorteilhaft (Hadji et al. 2002, Wüster et al. 2001). Limitiert wird die DXA-Methode durch die integrale Messung der zu untersuchenden Skelettregion, welche zu erhöhten Knochenmineraldichtewerten führen kann (Bartl und Gradinger 2009, Grampp et al. 1999).

\section{Quantitative Computertomographie (QCT)}

Bei der quantitativen Computertomographie handelt es sich um ein Volumenmessverfahren zur dreidimensionalen Darstellung des Messfelds und Ermittlung der physikalischen Dichte in $\mathrm{mg} / \mathrm{cm}^{3}$. Es ermöglicht die selektive Messung von Spongiosa und Kortikalis an Wirbesäule, Unterarm und Tibia (Wüster et al. 2001).

Das QCT ist verglichen mit der DXA-Methode weniger anfällig für Falschmessungen, welche durch Überlagerungen, z. B. von Aortenkalk entstehen können, da es sich um ein tomographisches Verfahren handelt (Issever und Link 2011). Auch können Veränderungen im Bereich der Spongiosa präziser dargestellt werden, jedoch ist die Messvarianz größer. Ferner können Untersuchungen in der Skelettperipherie, welche als periphere quantitative Computertomographie bezeichnet werden, bei der Registrierung isolierter Schäden im Bereich der Oberschenkelhalsregion versagen (Minne et al. 2002).

Darüber hinaus sind die im Vergleich zur DXA hohe Strahlenbelastung (100 vs. 1 $10 \mu \mathrm{Sv}$ ) und Reproduktion als nachteilig anzusehen und nicht für regelmäßige Kontrolluntersuchungen geeignet (Hadji et al. 2002, Peters und Friebe 2005, Wüster et al. 2001).

\section{Quantitative Ultraschallmessung (QUS)}

Eine weitere Untersuchungsmethode zur Knochendichtemessung stellt die quantitative Ultraschallmessung (Quantitative Ultrasound) dar. 
Hierbei wird eine Messung der Ultraschallgeschwindigkeit (Speed of Sound, SOS, $\mathrm{m} / \mathrm{s}$ ) bzw. der Ultraschallabschwächung (Broadband Ultrasound and Attenuation, $\mathrm{BUA}, \mathrm{dB} / \mathrm{MHz}$ ) oder Kombination aus beiden an Tibia, Kalkaneus und Phalangen vorgenommen. Als vorteilhaft sind die Strahlenfreiheit und die geringe Belastung für die Patienten sowie die geringen Kosten anzusehen. Da die Messung bei diesem Verfahren nur an peripheren Orten stattfinden kann und sich die Standardisierbarkeit von unterschiedlichen Geräten und Messstellen als schwierig erweist, sollte die QUS in der Diagnostik der Osteoporose, Indikation zur Therapie und zur Verlaufskontrolle nur ergänzend zu den konventionellen Verfahren eingesetzt werden (Wüster et al. 2001).

\subsubsection{Röntgendiagnostik}

Die konventionellen Röntgenuntersuchungen der Brust- (BWS) und Lendenwirbelsäule (LWS) in 2 Ebenen nehmen bei Verdacht auf Osteoporose eine wichtige Rolle ein. Zudem können, bezogen auf die Differentialdiagnose, in Frage kommende Erkrankungen und sekundäre Osteoporose-Formen ausgeschlossen werden. Wirbelkörperdeformierungen, wie Keil-, Fisch- oder Plattwirbel, sind hierbei typische Anzeichen einer Osteoporose (Peters und Friebe 2005).

Auch hinsichtlich der Abschätzung des Frakturrisikos bei Osteoporose ist die Erfassung von prävalenten Wirbelkörperfrakturen mithilfe der konventionellen Röntgenuntersuchungen sehr hilfreich. So stellen Wirbelkörpersinterungen je nach Grad der Verformung und Zahl der Deformitäten unabhängig von der Knochendichtemessung ein hohes Risiko für weitere osteoporotische Frakturen dar (Braun und Pfeilschifter 2010).

\subsubsection{Basislabor}

Neben der Anamnese und dem klinischen Befund gehört die Durchführung eines Basislabors zum wesentlichen Bestandteil der Basisdiagnostik. Es dient dem Ausschluss wichtiger sekundärer Osteoporose-Formen und anderer differentialdiagnostisch in Frage kommender Osteopathien (Lange et al. 2011). 
Zusätzlich ermöglicht es Kontraindikationen für eine medikamentöse Therapie zu überprüfen (DVO-Leitlinie 2014).

Neben dem Blutbild, welches Hinweise auf entzündliche und maligne Erkrankungen geben kann, werden auch Serumcalcium und Serumphosphat analysiert. Des Weiteren werden die Parameter alkalische Phosphatase, GammaGT, Serumkreatinin, BSG/C-reaktives Protein, Serumeiweißelektrophorese und TSH untersucht.

\subsection{Prävention und Therapie der Osteoporose}

Für die Behandlung einer Osteoporose gibt es unterschiedliche Therapiestrategien. Diese kann man in allgemeine Basis- bzw. Prophylaxemaßnahmen und medikamentöse Therapieansätze differenzieren. Dabei steht sowohl die Verbesserung der Knochenqualität als auch die Optimierung des Knochenumbaus hinsichtlich einer Steigerung der Knochenmasse im Vordergrund. Ziel ist die Verhinderung der Krankheitsentstehung, sowie das Risiko von Frakturen zu reduzieren (Bartl und Gradinger 2009).

\subsubsection{Allgemeine Basis- und Präventionsmaßnahmen}

Neben nicht beeinflussbaren Risikofaktoren, wie die genetische Prädisposition und das Alter, gibt es eine Vielzahl an beeinflussbaren Risikofaktoren, an denen die allgemeinen Basis- bzw. Präventionsmaßnahmen anknüpfen. Sie stellen nichtmedikamentöse Möglichkeiten (Basistherapie) dar, um die Knochenfestigkeit zu verbessern und Knochenbrüche zu vermeiden (Kurth und Pfeilschifter 2007).

Als beeinflussbarer Risikofaktor nimmt besonders die körperliche Inaktivität eine schwerwiegende Bedeutung für Knochenschwund ein. So konnte man bspw. bei bettlägerigen Patienten innerhalb einer Woche mehr Knochenmasseverlust beobachten als bei mobilen Personen in einem ganzen Jahr. Im Rahmen der Basis- bzw. Präventionsmaßnahmen oder aber auch in der Rehabilitationsphase nach einer Fraktur kann durch körperliche Aktivität die Knochenmasse nicht nur erhöht werden, zudem stärkt es die Muskulatur und die Koordinationsfähigkeit. Daraus resultiert auf der einen Seite eine Reduktion der Sturzgefahr, auf der 
anderen Seite kommt es zu einer Verbesserung des Allgemeinzustands der Patienten (Bartl und Gradinger 2009).

Da Sturzereignisse im Alter eine der zentralen Hauptursachen für Frakturen sind, empfiehlt sich besonders bei Patienten ab dem 70. Lebensjahr die Durchführung einer jährlich stattfindenden Sturzanamnese zur Abklärung der Ursachen und Therapiemöglichkeiten (Kurth und Pfeilschifter 2007).

Um eine weitere Präventionsmaßnahme handelt es sich bei der Supplementierung von mindestens 1000 mg/Tag Calcium und 1 g/kg Körpergewicht Protein, sofern eine adäquate Aufnahme über die Nahrung nicht gewährleistet wird. Falls der Patient keine ausreichende Sonnenlichtexposition durchführen kann, ist ebenfalls die ergänzende Gabe von Vitamin D 3 (1000 - 2000 IE/Tag) möglich (Bartl und Bartl 2015, Neuerburg et al. 2015). In Bezug auf eine adäquate Prävention ist auch die kalorisch ausreichende Ernährung sicherzustellen. Ein Untergewicht $\left(\mathrm{BMI}<20 \mathrm{~kg} / \mathrm{m}^{2}\right)$ wirkt sich kontraproduktiv aus und begünstigt osteoporotische Frakturen (Joakimsen et al. 1998). Im Hinblick auf die Schaffung von knochenstoffwechselgesunden Verhältnissen sollte den Patienten ein Nikotinverzicht empfohlen werden. Es ist bewiesen, dass sich das Rauchen nicht nur negativ auf den Knochenmineralgehalt auswirkt, sondern ebenfalls für Durchblutungsstörungen und ein allgemein vorzeitiges Altern verantwortlich ist. Neben den bisher genannten Aspekten ist es zudem ratsam, eine regelmäßige Kontrolle der vom Patienten einzunehmenden Medikamente durchzuführen, da z.B. Sedativa, Antiepileptika oder Antidepressiva das Osteoporose- und Sturzrisiko erhöhen können (Minne et al. 2002).

\subsubsection{Indikationen für eine medikamentöse Behandlung}

Die DVO empfiehlt die medikamentöse Behandlung einer Osteoporose, wenn trotz Umsetzung der Basismaßnahmen in den kommenden 10 Jahren mit einer hohen Wahrscheinlichkeit (30\% und mehr) einer Wirbelkörperfraktur oder einer proximalen Femurfraktur zu rechnen ist. Unabhängig von der Frakturwahrscheinlichkeit kann eine Therapieentscheidung auch auf Grundlage des in der Knochendichtemessung ermittelten T-Werts, welcher in Relation zum Lebensalter, Geschlecht und bereits aufgetretener Frakturen unter Berücksichtigung von Risikofaktoren und klinischer Gesamtsituation gesetzt wird, 
getroffen werden. Studien zur Therapie der Osteoporose belegen eine medikamentöse Wirkung bei einer erniedrigten DXA-Knochendichte mit einem $T$ Score von unter -2,0 (DVO-Leitlinie 2014).

\subsubsection{Medikamentöse Behandlung}

Unter Berücksichtigung der aktuellen Studienlage erzielt eine individuell auf den Patienten abgestimmte medikamentöse Behandlung der Osteoporose positive Wirkung, so dass in der Folge bspw. auch eine Senkung der Frakturrate feststellbar ist (Braun und Pfeilschifter 2010). Bei gegebener Indikation sprechen sich demnach auch die entsprechenden Fachgesellschaften, wie z. B. die DVO, in Konsensus-Leitlinien für spezielle medikamentöse Therapien aus.

Neben der Basistherapie lassen sich die antiosteoporotischen Medikamente grundsätzlich in zwei Gruppen, die sich in Bezug auf ihren Wirkmechanismus differenzieren, einteilen. Auf der einen Seite gibt es Medikamente, welche den Prozess des Knochenumbaus stoppen und als Antiresorptiva bezeichnet werden. $\mathrm{Zu}$ diesen zählen z. B. Bisphosphonate, selektive Östrogen-RezeptorModulatoren, Calcitonin, Calcium und Vitamin D. Auf der anderen Seite gibt es osteoanabole Medikamente wie z. B. Parathormon, Fluoride, oder Strontium, die durch Stimulation von knochenbildenden Zellen den Knochenaufbau fördern (Bartl und Bartl 2011).

\subsubsection{Bisphosphonate}

Bei den Bisphosphonaten handelt es sich um antiresorptive Medikamente, welche bei der Behandlung von Osteoporose eine bedeutende Rolle einnehmen. Sie sind stabile Analoga der Pyrophosphate und werden seit Ende der 1960er Jahre eingesetzt.

Nach der Bindung an der mineralisierten Knochenoberfläche werden sie in der Folge von den Osteoklasten resorbiert, wodurch deren Formation und Rekrutierung inhibiert werden. Außerdem findet eine Herabsetzung der Stoffwechselaktivität statt. Darüber hinaus sind Bisphosphonate in der Lage, die Apoptose der Osteoklasten einzuleiten. Neben der Reduzierung der Knochenresorption wird durch unterschiedliche Wirkmechanismen zudem die Knochenneubildung gefördert. Dies bewirkt, dass der normalerweise im 
Gleichgewicht stehende Knochenumbauprozess zu Gunsten einer Knochenformation verändert wird und sich die Knochendichte erhöht (Reinsdorf et al. 2007).

$\mathrm{Zu}$ den derzeit verwendeten Bisphosphonaten gehören Alendronat, Risedronat, Ibandronat und Zoledronat. Diese können von den Patienten täglich, wöchentlich oder monatlich per os eingenommen werden. Ferner besteht die Möglichkeit einer monatlichen oder jährlich stattfindenden intravenösen Applikation (Braun und Pfeilschifter 2010).

Die aktuelle Studienlage (Horizon-Studie) demonstriert die hohe Effektivität der Bisphosphonattherapie (Black et al. 2007). Die Einnahme von Bisphosphonaten ist dennoch mit einer Reihe von Nebenwirkungen verbunden. Neben gastrointestinalen Beschwerden weisen Studien auf bisphosphonatassoziierte Knochennekrosen im Kieferbereich hin, welche besonders bei intravenöser Gabe von hochdosierten Bisphosphonaten auftreten (Lee et al. 2014, Mouri et al. 2009).

\subsubsection{Parathormon}

Parathormon (PTH) ist ein aus 84 Aminosäuren zusammengesetztes Polypeptid. Dieses wird in den Hauptzellen der Nebenschilddrüsen produziert und dient hauptsächlich der Regulierung der Calcium-Homöostase im Blutplasma (Deutzmann 2008).

In den Nieren stimuliert es die Calcium-Resorption und die Hydroxylierung von 25Hydroxycholecalciferol zu 1,25-Dihydroxycholecalciferol (Vitamin D), welches eine verstärkte Aufnahme von Calcium im Dünndarm bewirkt (Grodsky 2013, Jerosch et al. 2002). Bei intermittierender Gabe wirkt sich PTH anabol auf den Knochenstoffwechsel aus. Wird es kontinuierlich gegeben, wirkt es katabol, da die Osteoklastenaktivität erhöht wird (Hock und Gera 1992).

Studien belegen, dass die Applikation von PTH sowohl eine Zunahme der Knochenmineraldichte als auch eine Verbesserung der trabekulären Mikroarchitektur bewirkt, wodurch die Knochenstabilität und biomechanische Belastbarkeit gesteigert wird (Sehmisch et al. 2009, Tezval et al. 2010). Als Nebenwirkungen sind Übelkeit, Rückenschmerzen, orthostatische Hypotonie und Kopfschmerzen bekannt (Bartl und Bartl 2011). 


\subsection{Baicalein}

Bei Baicalein handelt es sich um ein Flavon des Baikal-Helmkrautes (Scrutellaria baicalensis), welches zu der Familie der Lippenblütler (Lamiaceae) gehört. Die Pflanze weist einen allgemein erhöhten Anteil von Flavonoiden auf. Neben Baicalein lassen sich z. B. auch Luteolin, Berberin, Wogonin, Oroxylin A und die Neurohormone Serotonin und Melatonin in Blättern und Stängeln nachweisen (Hübner 2012).

Die Heimat des Krautes liegt ursprünglich in Sibirien, allerdings reicht die Verbreitung bis nach China. Dort wird es als Bestandteil der traditionellen chinesischen Medizin z. B. für Herzkreislauferkrankungen, Bluthochdruck und verschiedene Knochenerkrankungen verwendet (Li-Weber 2009). Auch seine antikanzerogene und anti-inflammatorische Wirkung ist bekannt (Chen et al. 2013, Cheng et al. 2012, Gandhi 2013, Motoo und Sawabu 1994). So zeigen z. B. Invitro-Untersuchungen, dass Baicalein bei unterschiedlichen Tumorzelllinien nicht nur zu einer Inhibition der Proliferation sowie zu einem Stillstand des Zellzyklus führen kann, sondern auch die Apoptose verschiedener Tumorarten auslöst (Hübner 2012). Dabei zeigen Flavone wie Baicalein fast keine oder nur geringe Toxizität gegenüber normalen peripheren Blut, gewöhnlichen Epithel- und Knochenmarkzellen (Li-Weber 2009). Ferner belegen Untersuchungen, dass sich der oxidative Zellstress unter Applikation von Baicalein vermindern lässt (Gandhi 2013, Jin et al. 2007). Außerdem wird die Induktion der In-vitro-Differenzierung von Osteoblasten über den Wnt/beta-Catenin Signalweg ausgelöst (Kim et al. 2008).

Des Weiteren konnte nachgewiesen werden, dass es sich beim Baicalein um einen selektiven Inhibitor der 12/15-Lipoxygenase handelt (Deschamps et al. 2006, Mascayano et al. 2013). Bei erhöhter Expression dieser Lipoxygenase ist bekannt, dass ein Anstieg des pro-inflammatorischen Interleukin-6/TNF- $\alpha$ Spiegels resultiert (Wen et al. 2007). Daraus geht in der Folge eine Interleukinvermittelte Induktion der Osteoklasten (Kronke et al. 2009, Manolagas und Jilka 1995) und eine vermehrte adipozytäre Differenzierung aus mesenchymalen Vorläuferzellen der Osteoblasten hervor (Danks und Takayanagi 2013, Mori et al. 2013), wodurch eine verringerte Knochendichte resultiert (Kronke et al. 2009). 
Auf Grundlage der oben aufgeführten Effekte auf den Knochen stellt Baicalein in der Osteoporoseforschung möglicherweise eine Alternative gegenüber etablierter Therapieansätze dar. Als Gegenstand der vorliegenden Arbeit soll die Wirksamkeit der Substanz auf den Knochen am Beispiel des Femurs unter Verwendung des osteoporotischen Tiermodells näher untersucht werden.

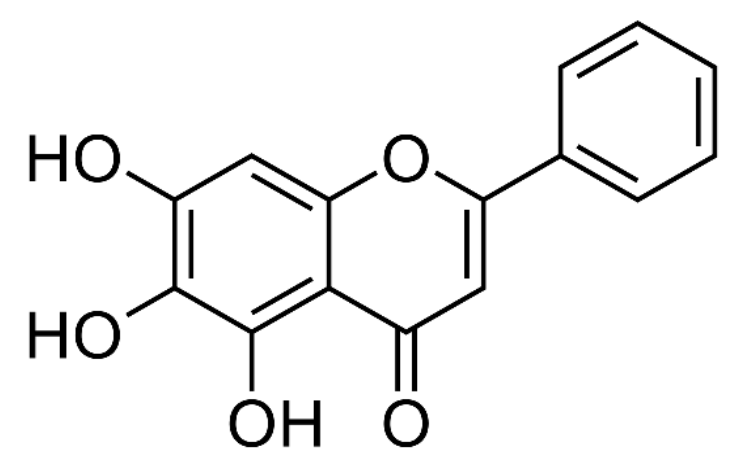

Abb. 1: Grundgerüst des Baicaleins 


\section{Material und Methoden}

Für die nachfolgend aufgeführten Tierversuche wurde durch die Bezirksregierung Braunschweig eine Genehmigung erteilt (AZ 14/1530). Das Projekt wurde durch die Elsbeth Bonhoff Stiftung mit der Projektnummer 114 gefördert.

\subsection{Versuchsablauf}

Die Gesamtdauer des Versuchs betrug 12 Wochen. Zu Versuchsbeginn wurden 61 weibliche Ratten in 5 Versuchsgruppen, je 10 - 13 Tiere pro Gruppe, eingeteilt (Tab. 2).

Nach einwöchiger Eingewöhnung der Tiere erfolgte bei den Versuchsgruppen 2 5 eine bilaterale Ovariektomie, wodurch ein Östrogenmangel und daraus hervorgehend eine Osteoporose induziert werden sollte. Die Tiere der Gruppe 1 wurden nicht ovariektomiert, da sie als Kontrollgruppe keine Osteoporose entwickeln sollten.

Tab. 2: Einteilung der Versuchstiere in Gruppen zu Beginn des Versuchs

\begin{tabular}{|c|c|c|}
\hline Gruppennummer & Gruppenbezeichnung & Anzahl der Tiere \\
\hline 1 & NON OVX & 10 \\
\hline $2-5$ & OVX & 51 \\
\hline
\end{tabular}

Nach der Ovariektomie wurde eine Standzeit von 8 Wochen eingehalten. Daraufhin wurde bei allen Versuchstieren (Gruppe 1 - 5) eine metaphysäre Osteotomie der Tibiae mit anschließender Plattenosteosynthese durchgeführt. Im Rahmen der Operationen verstarben insgesamt 11 Ratten, so dass für die medikamentöse Therapie insgesamt 50 Tiere, je 10 pro Gruppe, übrig blieben (Tab. 3).

Postoperativ wurde bei den Gruppen 3 - 5 eine medikamentöse Therapie mit Baicalein, welches in Dimethylsulfoxid (DMSO) gelöst war, über einen Zeitraum von 28 Tagen durchgeführt (Tab. 3). 
Tab. 3: Einteilung und Behandlungsart der Versuchstiere nach Ovariektomie und Osteotomie

\begin{tabular}{|c|c|c|c|}
\hline Gruppennummer & Gruppenbezeichnung & Behandlungsart & Tieranzahl \\
\hline \multirow{2}{*}{1} & \multirow{2}{*}{ NON OVX } & a) Osteotomie & a) 5 \\
\hline & & b) Osteotomie, DMSO & b) 5 \\
\hline \multirow{4}{*}{2} & \multirow{4}{*}{ OVX } & a) Ovariektomie, & a) 5 \\
\hline & & Osteotomie & \\
\hline & & b) Ovariektomie, & b) 5 \\
\hline & & Osteotomie, DMSO & \\
\hline 3 & OVX Baicalein Konz. 1 & $\begin{array}{l}\text { Ovariektomie, } \\
\text { Osteotomie, 1x tägl. } \\
\text { Baicalein (1 mg/ kg/ } \\
\text { KG), DMSO }\end{array}$ & 10 \\
\hline 4 & OVX Baicalein Konz. 2 & $\begin{array}{l}\text { Ovariektomie, } \\
\text { Osteotomie, 1x tägl. } \\
\text { Baicalein (10 mg/ kg/ } \\
\text { KG), DMSO }\end{array}$ & 10 \\
\hline 5 & OVX Baicalein Konz. 3 & $\begin{array}{l}\text { Ovariektomie, } \\
\text { Osteotomie, 1x tägl. } \\
\text { Baicalein (100 mg/ kg/ } \\
\text { KG), DMSO }\end{array}$ & 10 \\
\hline
\end{tabular}

Bei DMSO handelt es sich um ein organisches Lösungsmittel, welches zur Gruppe der Sulfoxide gehört. Es wirkt als Penetrationsverstärker, so dass in diesem Mittel gelöste Substanzen vom Organismus besser aufgenommen werden können. Darüber hinaus wirkt es analgetisch und antiphlogistisch (Kopp und Herschel 1985). Die tägliche Applikation des Medikaments erfolgte subkutan und in gruppenspezifischer Konzentration (Tab. 3).

Zur Validität der Versuchsergebnisse wurden Kontrollgruppen, bestehend aus den Tieren der Gruppen 1 und 2, eingeteilt. Während des gesamten Versuchszeitraums erhielt die Hälfte dieser Tiere keine Medikation, der andere Teil von ihnen wurde mit DMSO behandelt (Tab. 3). Zu unterschiedlichen 
Zeitpunkten der Versuchsdurchführung wurde eine fluorchrome Polysequenzmarkierung mit Xylenol-Orange, Calcein-Grün und Alizarin-Komplexon bei allen Tieren vorgenommen. Dadurch wird die Darstellung und Auswertung der im Rahmen der Frakturheilung stattfindenden Knochenumbauprozesse im Anschluss des Experiments ermöglicht.

Nach Abschluss der medikamentösen Therapie wurden die Versuchstiere in $\mathrm{CO}_{2}$ Sedierung durch Dekapitation getötet. Anschließend erfolgte eine Obduktion und es wurden verschiedene Proben für weitere Untersuchungen gewonnen.

\subsection{Versuchstiere und Haltung}

Die Durchführung des Experiments erfolgte mit 61 weiblichen Ratten des Stammes Sprague Dawley (Zuchtanstalt Fa. Winkelmann, Borken, Deutschland), die bei Versuchsbeginn drei Monate alt waren und ein Durchschnittsgewicht von $267,5 \pm 15,4 \mathrm{~g}$ hatten.

Während des gesamten Experiments wurden die Versuchstiere in der zentralen tierexperimentellen Einrichtung (ZTE) der Universitätsmedizin Göttingen gehalten. Sie waren in Gruppen von drei bis fünf Tieren in Makrolon®-Käfigen vom Typ IV untergebracht. Die fachgerechte Betreuung der Ratten wurde in Form von täglichen Kontrollen auf regelrechtes Verhalten und körperliche Integrität durch Tierpfleger und veterinärmedizinische Kontrollen gewährleistet.

Aus hygienischen Gründen wurden die Tiere einmal die Woche in neue Käfige umgesetzt, so dass eine Reinigung und Desinfektion der gebrauchten Käfige erfolgen konnte. Neben demineralisiertem Wasser stand auch sojafreies Futter (ssniff SM R/M, 10 mm Pellets, ssniff Spezialdiäten $\mathrm{GmbH}$, Soest, Deutschland) zur freien Verfügung. Das Futter wurde einmal pro Woche auf $1500 \mathrm{~g}$ pro Käfig wieder aufgefüllt, nachdem das Restfutter gewogen wurde. Ferner wurde auch das Körpergewicht der Ratten einmal wöchentlich erfasst.

Die Haltung erfolgte bei einer Raumtemperatur von $20^{\circ} \mathrm{C} \pm 1^{\circ} \mathrm{C}$ und einer relativen Luftfeuchtigkeit von 55\%. Mithilfe der Raumbeleuchtung wurde ein Tag-NachtZyklus von 12 Stunden simuliert. 


\subsection{Ovariektomie}

Bei der Ovariektomie handelt es sich um ein validiertes Experiment zur Induktion einer postmenopausalen Osteoporose. Es ist nachgewiesen, dass sie sich bei den Tieren bereits wenige Monate nach dem Eingriff entwickelt (Ishihara et al. 1999). Vor dem chirurgischen Eingriff wurden die Versuchstiere zunächst mit $\mathrm{CO}_{2}$ sediert. Anschließend erhielten sie eine intraperitoneale Anästhesie $(0,1 \mathrm{ml} / 100 \mathrm{~g}$ Körpergewicht), welche sich aus Ketamin (Hostaket ${ }^{\circledR}$, Firma Hoechst, Bad Soden, Deutschland) und Medetomidinhydrochlorid (Domitor $\AA$, Firma Orion Pharma, Espoo, Finnland) im 3:1 Gemisch zusammensetzte.

Nachdem das Operationsgebiet zwischen unterem Rippenbogen und Hinterläufen auf beiden Seiten rasiert und desinfiziert worden war, erfolgte ein paravertebraler Hautschnitt und die Präparation auf das Peritoneum (Abb. 2). Nach Eröffnung des Peritoneums konnten das Ovar und seine Nachbarstrukturen mithilfe einer Pinzette vorgelagert und dargestellt werden (Abb. 3).

Daraufhin wurde die Tuba uterina ligiert, so dass das Ovar mit einem Skalpell scharf abgetrennt werden konnte (Abb. 4). Nach der Rückverlagerung der Strukturen in den Bauchraum erfolgte der Peritoneal- und Bauchmuskulaturverschluss mit Vicrylfäden (Ethicon $\AA$, Johnson \& Johnson, Norderstedt, Deutschland) der Stärke 4.0. Die Wundränder der Haut wurden mit Klammern (Michel wound brackets $12 \times 3$ mm, Gebrüder Martin GmbH \& Co. KG, Tuttlingen, Deutschland) verschlossen und mit einem Wundantiseptikum (Braunol $\AA^{\circledR}$, Braun Melsungen AG, Melsungen, Deutschland) abgetupft (Abb. 5). Das beschriebene Operationsverfahren wurde zur Ektomie beider Ovarien angewendet. Um die Tiere postoperativ besser unterscheiden zu können, wurde nach der Ovariektomie jeder Ratte ein Transponder (UNO MICRO-ID-System, ISO-Transponder 12 mm, UNORoestvaststaal BV, Zevenaar, Niederlande) subkutan im Nacken injiziert. Zusätzlich erfolgte die Applikation von einer $3 \mathrm{ml}$ isotonischen Kochsalzlösung zur Verhinderung einer Hypovolämie.

Während der Aufwachphase wurden die Versuchstiere in einem mit Wärmeplatten ausgestatteten Käfig überwacht. Zum Schluss wurden sie in die festgelegten Gruppen eingeteilt und in die vorgesehenen Käfige verlegt. Da sichergestellt werden sollte, dass die Versuchstiere eine Osteoporose entwickeln, wurde nach der Ovariektomie eine Standzeit von 8 Wochen eingehalten (Ishihara et al. 1999). 


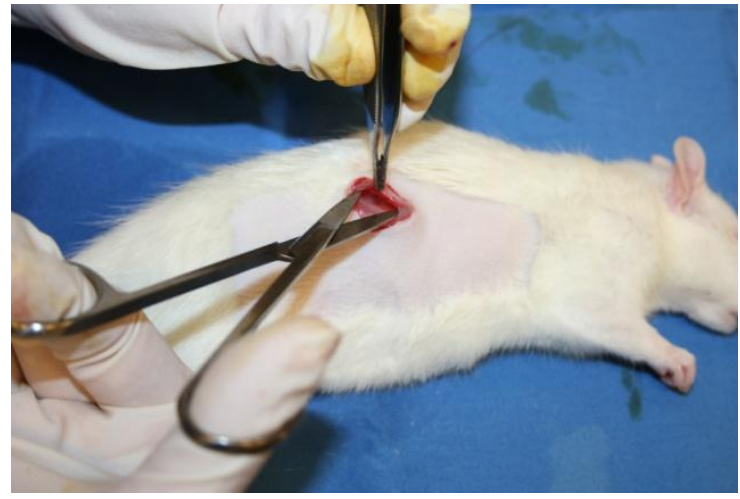

Abb. 2: Eröffnung des Peritoneums

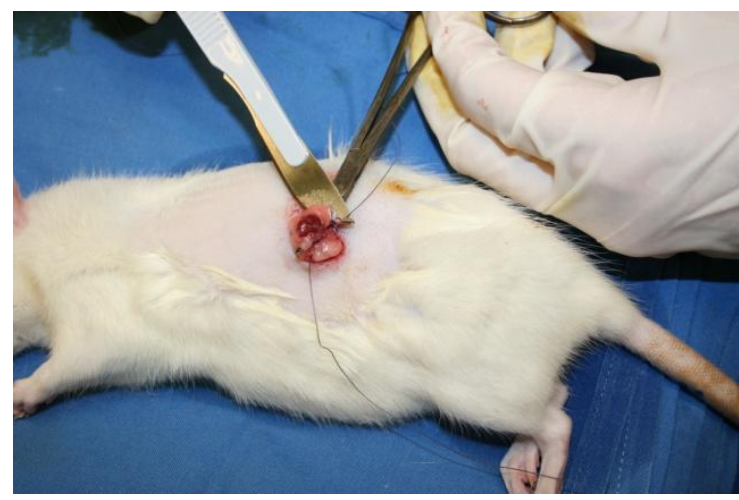

Abb. 4: Abtrennung des linken Ovars nach Ligatur der Tuba uterina

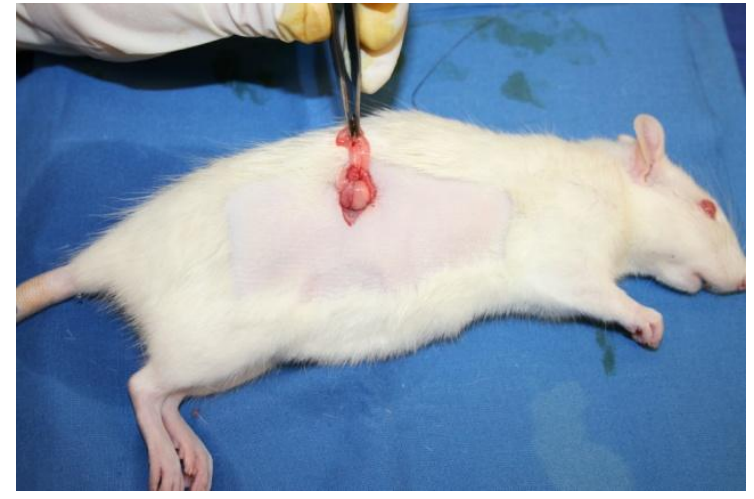

Abb. 3: Vorverlagerung des Ovars

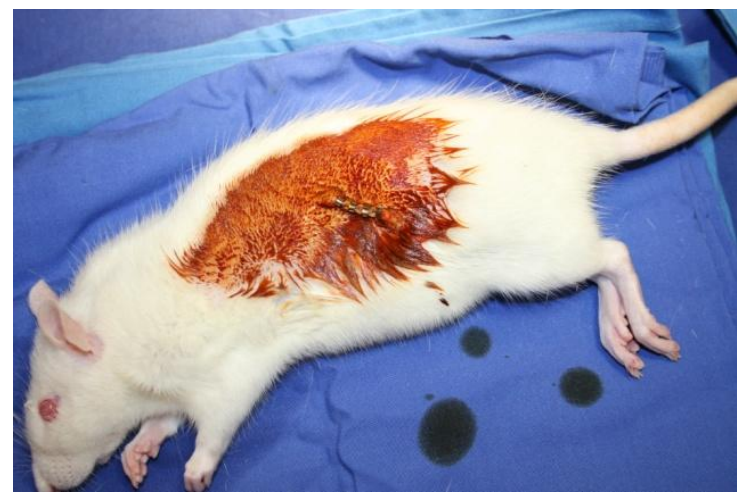

Abb. 5: Wundverschluss mit Klammern und Wunddesinfektion

\subsection{Osteotomie, Osteosynthese und medikamentöse Behandlung}

Neben der vorliegenden Studie sollte im Rahmen einer weiteren Untersuchung die Auswirkung der Applikation von Baicalein auf die Frakturheilung untersucht werden. Dazu erfolgte bei allen Versuchstieren eine beidseitige Osteotomie der Tibia, welche mithilfe einer Osteosyntheseplatte versorgt wurde (Stürmer et al. 2010). Postoperativ wurden die Ratten analog zu Punkt 2.3 überwacht und erhielten zusätzlich eine zweitägige Schmerzprophylaxe mit Carprofen $5 \mathrm{mg} / \mathrm{kg} / \mathrm{KG}$ (Rimady ${ }^{\circledR}$, Zoetis Schweiz GmbH, Zürich, Schweiz), welches intramuskulär appliziert wurde.

Ab dem ersten Tag nach der Operation erfolgte bei den Versuchstieren der Gruppen 3 - 5 die medikamentöse Behandlung mit Baicalein (Sigma-Aldrich, München) in gruppenspezifischer Konzentration (Tab. 3). Zur Applikation war der Wirkstoff in DMSO gelöst worden. Beim Ansatz der Wirkstofflösung wurde darauf 
geachtet, dass bei einem Spritzenvolumen von 0,6 $\mathrm{ml}$ die entsprechenden Baicalein-Konzentrationen von $1 \mathrm{mg} / \mathrm{kg} / \mathrm{KG}, 10 \mathrm{mg} / \mathrm{kg} / \mathrm{KG}$ und $100 \mathrm{mg} / \mathrm{kg} / \mathrm{KG}$ eingehalten werden konnten. Um mögliche Effekte des DMSO zu erkennen, wurde die Hälfte der Tiere der Kontrollgruppen 1 und 2 mit 0,6 ml reinem DMSO behandelt (Tab. 3).

Im Rahmen der medikamentösen Behandlung wurden die Versuchstiere aus inrem Haltungsraum in einem separaten Raum des ZTE gebracht. Um Stress während des Behandlungsablaufs zu vermeiden wurden die Käfige stets abgedeckt. Für die Applikation des Wirkstoffs wurde immer nur ein Tier aus dem Käfig entnommen und von einer Assistenz mit beiden Händen auf einer weichen Unterlage fixiert. Eine weitere Person führte mit einer $1 \mathrm{ml}$ Omnifix® Spritze (Braun Melsungen AG, Melsungen, Deutschland) und Kanüle des Typs Sterican® $0,45 \mathrm{~mm} \times 25 \mathrm{~mm}$ (Braun Melsungen AG, Melsungen, Deutschland) die Injektion durch. Zur besseren Unterscheidung der Tiere wurden die gespritzten Ratten vorübergehend in einen anderen bereitgestellten Käfig des gleichen Typs gesetzt. Sobald alle Tiere eines Käfigs behandelt worden waren wurden sie wieder in ihren ursprünglichen Käfig umgesetzt. Um einen immer gleichen Tagesrhythmus zu gewährleisten, erfolgte die Behandlung täglich zur gleichen Uhrzeit.

\subsection{Probenentnahme}

Nach einem Zeitraum von 28 Tagen wurden die Versuchstiere mit $\mathrm{CO}_{2}$ sediert und durch Dekapitation getötet. Anschließend erfolgte die Entnahme beider Femora nach Exartikulation aus Hüft- und Kniegelenk. Im Rahmen anderer Studien wurden den Ratten auch der Lendenwirbelkörper, die Tibiae mit ortständiger Muskulatur (M. gastrocnemius, M. soleus, M. longissimus) und Blut entnommen.

\subsection{Präparation und Lagerung der Femora}

Für die Durchführung der nachfolgenden Versuche wurden die entnommenen Femoraproben, jeweils zwei (linke und rechte Seite) pro Ratte, von dem restlichen Sehnengewebe und der Muskulatur freipräpariert.

Bis zur weiteren Verwendung erfolgte die Lagerung der Femoraproben bei $-20^{\circ} \mathrm{C}$, um die Knochenqualität zu erhalten. 


\subsection{Biomechanischer Kompressionstest}

Im Rahmen des biomechanischen Kompressionstests wurde eine zunehmend einwirkende Kraft orthogonal zur Längsachse des Femurs ausgeübt, bis es zu einer Fraktur des Schenkelhalses kam. Während des Versuchs wurden die einwirkenden Kräfte und Verformungen des Knochens in einem Kraft-WegDiagramm aufgezeichnet.

Dieser Test ermöglichte die Überprüfung der mechanischen Belastbarkeit der von den Versuchstieren gewonnenen Femora. Außerdem konnten durch den Vergleich der einzelnen Versuchsgruppen Rückschlüsse hinsichtlich der unterschiedlichen medikamentösen Therapie auf den osteoporotisch veränderten Knochen gezogen werden (Tezval et al. 2010).

\subsubsection{Validierung des Untersuchers}

Zur Validierung des Untersuchers wurde der komplette Ablauf des Kompressionstests wie in der Hauptuntersuchung an 20 Probeknochen, jeweils linker und rechter Femur von 10 Ratten, durchgeführt. Anhand dieser Voruntersuchungen wurden die Parameter Steigung und die Maximalkraft analysiert. Da eine annähernd gleiche Knochenbeschaffenheit beider Femora vorausgesetzt werden konnte, sprach eine intraindividuelle Abweichung von maximal $10 \%$ für einen durch den Prüfer korrekt durchgeführten Versuchsablauf.

\subsubsection{Aufbau und Ablauf}

Vor der Durchführung des Versuchs wurden die entsprechenden Knochenproben (linke Femora) etwa 15 - 20 min lang bei Raumtemperatur aufgetaut.

$\mathrm{Da}$ die Femora für die verschiedenen Versuche im Vorfeld präpariert werden mussten, führte dies bei einzelnen Knochen zur Beschädigung oder zum völligen Verlust des Kniegelenks. Um die Ergebnisse des biomechanischen Kompressionstests später besser auswerten und untereinander vergleichen zu können, entschied man sich vor Versuchsbeginn dafür, alle Kniegelenke von den Femura zu lösen. Ferner gewährleistet diese Maßnahme, dass ohne Beeinflussung des Kniegelenks nur die mechanische Stabilität des Knochens untersucht wird. 
Zu Versuchsbeginn wurde der zu prüfende Knochen zunächst auf einer speziell für diesen Versuch entwickelten Trägerplatte aus Aluminium positioniert, so dass ein Dreipunktkontakt über den Trochanter major, welcher in eine kugelförmige Senke gelegt wurde, und den beiden Kondylen zustande kam. Zusätzlich erfolgte eine Fixierung des Corpus femoris mit verstellbaren Schrauben. Dies sollte eine Positionsveränderung und daraus resultierende Falschmessung während des Versuchs verhindern (Abb. 6).

Im Anschluss konnte die Trägerplatte mit dem korrekt positionierten Knochen in die Werkstoffprüfmaschine (Typ 145660 Z020/ TND Zwick/ Roell, Ulm, Deutschland) eingespannt werden. Danach wurde über eine Software (testXpert@, Zwick/ Roell, Ulm, Deutschland) der zur Prüfmaschine gehörende Rollenstempel etwa mittig über dem Femurschaft positioniert. Anschließend wurde der Stempel auf den eingespannten Femur heruntergefahren (Abb. 7).

Erst wenn die ventrale Kante des Femurs genau mittig in der Nut des Stempels lag, wurde ein Knochenkontakt mit einer Vorkraft von $1 \mathrm{~N}$ hergestellt. Nach wiederholter Prüfung der Femur- und Stempelposition erfolgte die Durchführung des Kompressionstests. Durch das permanente Absenken (50 mm/min) des Stempels wurde ein zunehmender Druck auf den Knochen ausgeübt, bis daraus eine Fraktur des Schenkelhalses hervorging. Während des Versuchs führte die Software eine Messung durch und wandelte die erfassten Daten unmittelbar in ein Kraft-Weg-Diagramm um (Tezval et al. 2010, Stuermer et al. 2006).

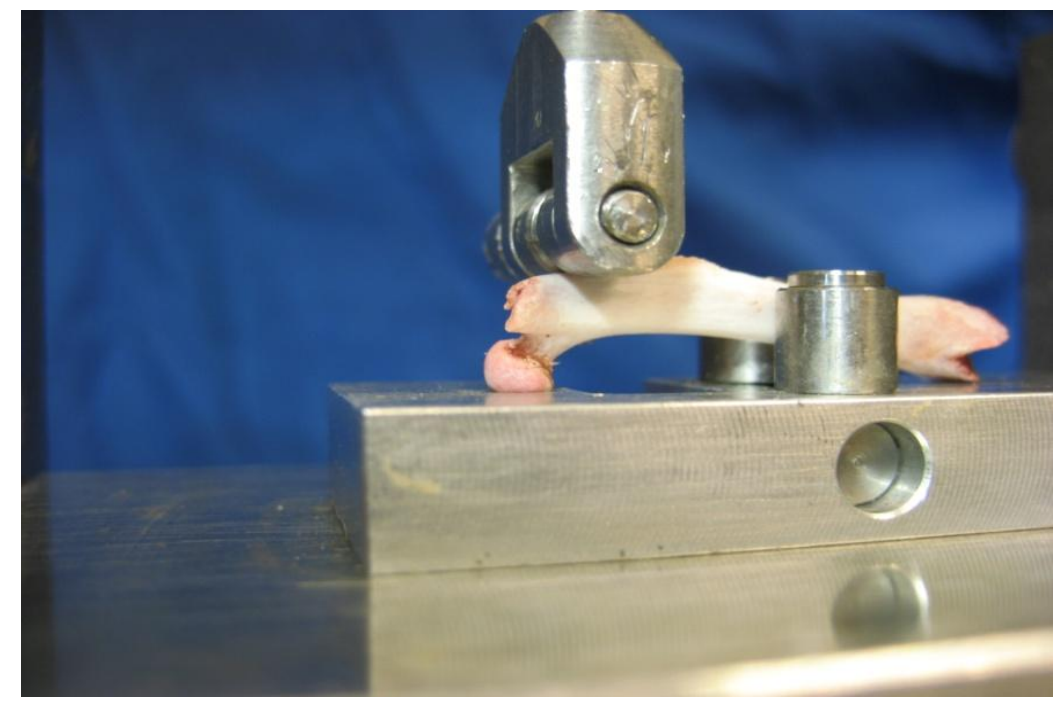

Abb. 6: Korrekte Lage des Femurs auf der Trägerplatte mit heruntergefahrenem Rollenstempel 


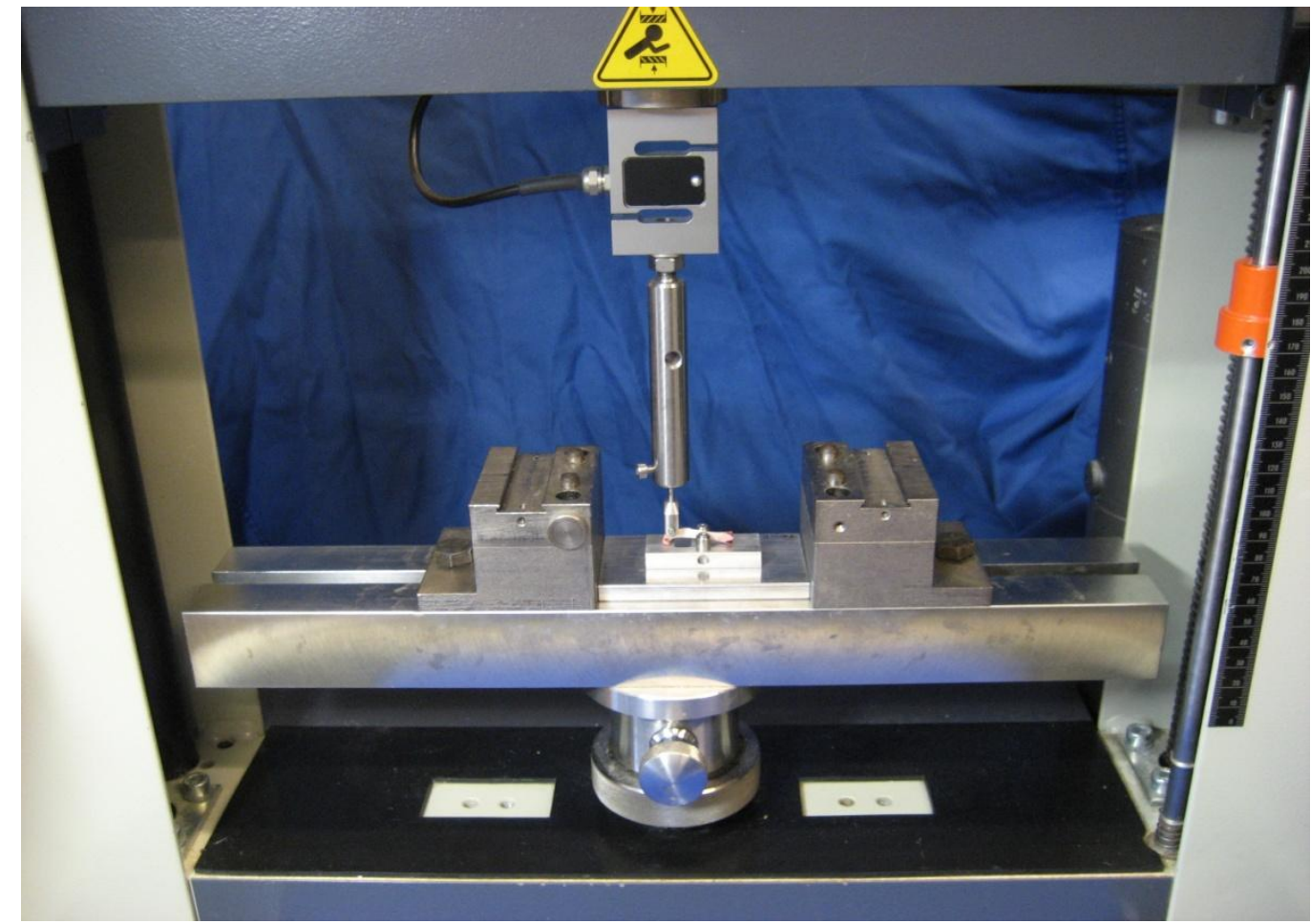

Abb. 7: Korrekte Position der Trägerplatte (inkl. darauf gelagertem Femur) in der Werkstoffprüfmaschine

\subsubsection{Messparameter}

\subsubsection{Steigung}

Die Steigung, welche in $\mathrm{N} / \mathrm{mm}$ angegeben wird, ist Maß für den linearen Kurvenverlauf im Kraft-Weg-Diagramm. Sie ist Ausdruck für die elastische Verformbarkeit des zu prüfenden Knochens während des Kompressionstests.

\subsubsection{Maximalkraft $\left(F_{\max }\right)$}

Bei der Maximalkraft handelt es sich um die größtmögliche Kraft, welche auf den Femur einwirken kann, bis eine Schenkelhalsfraktur hervorgerufen wird. Im Kurvenverlauf des Kraft-Weg-Diagramms ist diese Kraft als Scheitelwert erkennbar. Sie wird in N angegeben. 


\subsection{Veraschung}

\subsubsection{Bestimmung der organischen und anorganischen Knochensubstanz}

Zur Bestimmung des Anteils der organischen und anorganischen Knochensubstanz wurde nach dem biomechanischen Kompressionstest durch Veraschung der linken Femora ein Glührückstand erzeugt.

Zu Beginn des Versuchs wurde zunächst ein feuerfester Porzellantiegel analytisch gewogen, um ein Tara-Gewicht zu erhalten. Daraufhin wurde der zu prüfende Femur in diesen Tiegel gelegt und die Gesamtmasse analytisch gewogen. Mithilfe der Gesamtmasse abzüglich des Tara-Gewichts konnte die Masse des Femurs vor der Veraschung bestimmt werden (Gesamtmasse - Tara $=\mathrm{m}$ vor Veraschung). Im Anschluss wurde der Porzellantiegel mit dem Knochen über einen Zeitraum von 45 Minuten in einem Muffelofen einer Temperatur von $750^{\circ} \mathrm{C}$ ausgesetzt (Abb. 8).

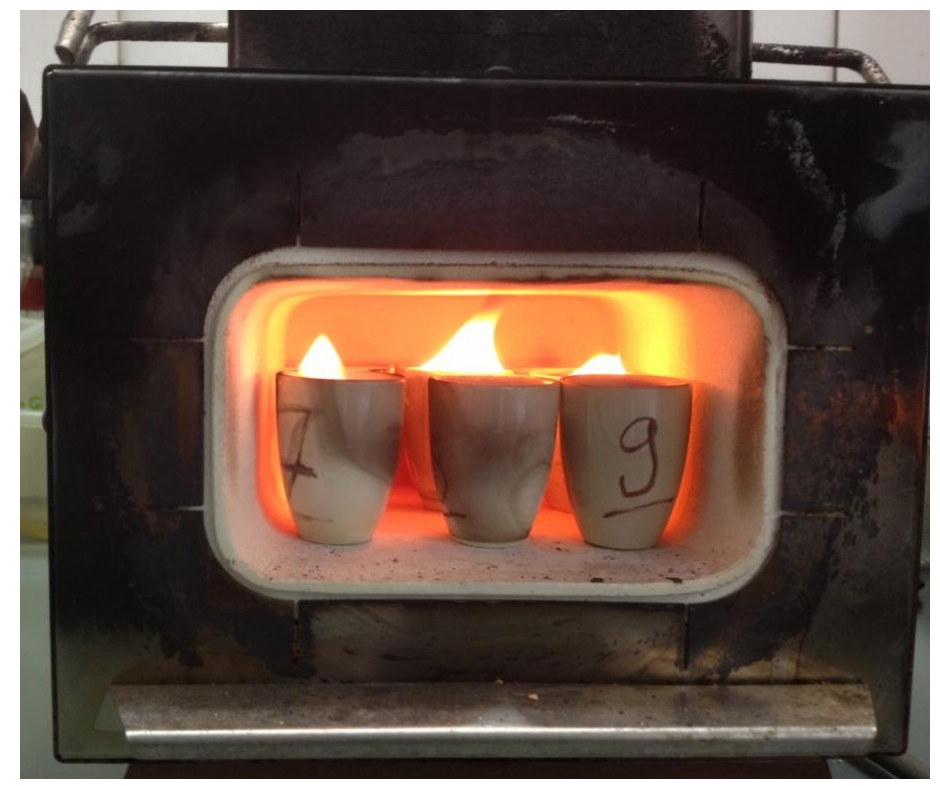

Abb. 8: Veraschung der Knochenproben in einem Muffelofen

Danach wurde der Glührückstand in einem Exsikkator über Kieselgel aufbewahrt, um eine Abkühlung auf Raumtemperatur ohne Bildung von Kondensationsfeuchtigkeit zu gewährleisten. Daraufhin erfolgte die Berechnung der Masse des Femurs nach der Veraschung, indem die analytisch gewogene Gesamtmasse 
wiederholt von dem Tara-Gewicht subtrahiert wurde (Gesamtmasse - Tara $=\mathrm{m}$ nach Veraschung).

Die Formel für die Berechnung des prozentualen Anteils der organischen Substanz an der Gesamtmasse des Knochens lautet:

$$
\% \text { organische Substanz }=\left(\left(m_{\text {vor Veraschung }}-m_{\text {nach Veraschung }}\right) * 100\right) / m_{\text {vor Veraschung }}
$$

Für die Berechnung des Anteils der anorganischen Substanz gilt folgende Formel:

$$
\% \text { anorganische Substanz }=100-\% \text { organische Substanz }
$$

\subsubsection{Bestimmung des Calcium- und Phosphatgehaltes}

Im Rahmen der Bestimmung des Calciumgehaltes der Knochensubstanz wurde eine Flamm-Atomabsorptionsspektroskopie (DIN EN ISO 7980:2000) angewendet. Ferner erfolgte die Phosphatbestimmung durch Photometrie des PhosphatMolybdänblau-Komplexes (DIN EN ISO 6878:2004). Beide Verfahren wurden jeweils nach Säureaufschluss des Glührückstandes mithilfe von 10\%Salpetersäure $\left(\mathrm{HNO}_{3}\right)$ durchgeführt. Im Anschluss wurden die Lösungen entsprechend verdünnt, da die erwarteten Konzentrationen im Vertrauensbereich des Messverfahrens liegen sollten.

Für den Säureaufschluss wurde der Glührückstand der zu prüfenden Knochenprobe in einem Mörser mit dem Pistill zunächst fein homogenisiert und davon $50 \mathrm{mg}$ analytisch genau ausgewogen $(\mathrm{m})$. Danach wurde diese Masse in einen Kolben überführt und mit 200 ml 10\%-Salpetersäure versetzt. In der Folge wurde diese Lösung erhitzt und 45 min lang auf Siedetemperatur gehalten. Der Aufschluss der erhitzten Lösung erfolgte über einen Rückflusskühler. Dann wurde die klare Aufschluss-Lösung in einen 1000-ml-Messkolben mit Wasser aufgefüllt. Anschließend erfolgte eine Probenentnahme $(5 \mathrm{ml})$, welche um den Faktor 1:20 verdünnt wurde, für die Herstellung einer Analysematrix zur Durchführung der Calcium- und Phosphatbestimmung.

Für die Bestimmung des Calciumgehaltes wurde der Atomabsorptionsspektrometer (FIAS 4100, Perkin-Elmer, Rodgau, Deutschland) zunächst gegen 
eine Verdünnungsreihe im Konzentrationsintervall zwischen 0,1 und $5 \mathrm{mg} / \mathrm{l}$ nach Vorgaben des akkreditierten Verfahrensprozesses kalibriert. Dann erfolgte die eigentliche Flamm-Atomabsorptionsspektrometrie, indem eine Probe $(5 \mathrm{ml}) \mathrm{der}$ Analysematrix in das Autosampler-Rack pipettiert und Lanthanchlorid $\left(\mathrm{LaCl}_{3}\right)$ als Matrix-Modifier zugegeben wurde. Dieses Gemisch wurde durch einen Zerstäuber permanent in die Luft-Acetylen-Flamme des Atomabsorptionsspektrometers befördert und darin aufgelöst. Dabei wurde die Extinktion der durch Calcium verursachten Flammenfärbung an der Calcium-Emissionsbande von 422,8 nm bestimmt.

Für die Phosphatbestimmung wurde $20 \mathrm{ml}$ der Analysematrix in einen $25 \mathrm{ml}$ Messkolben pipettiert und mit $4 \mathrm{ml}$ Phosphatreagenz ( $25 \mathrm{ml}$ Schwefelsäure, 7,5 ml Ammoniummolybdat, $15 \mathrm{ml}$ Ascorbinsäure, $2,5 \mathrm{ml}$ Kaliumantimonoxidtartrat) versetzt. Nach dem Auffüllen des Messkolbens $(25 \mathrm{ml})$ wurde eine Reaktionszeit von 10 min eingehalten. Anschließend erfolgte die photometrische Messung der Extinktion in einer Küvette der Schichtstärke $10 \mathrm{~mm}$ bei einer Messwellenlänge von $830 \mathrm{~nm}$ gegen eine Blindprobe mit destilliertem Wasser. Mithilfe einer Verdünnungsreihe im Konzentrationsverhältnis 0,1 bis $1,5 \mathrm{mg} / \mathrm{l}$ einer PhosphatStandardlösung wurde durch Messung der Extinktion eine Abgleichgerade erstellt.

Tab. 4: Einheiten und Messparameter der Calcium- und Phosphatbestimmung

\begin{tabular}{|c|l|}
\hline \multicolumn{1}{|c|}{ Abkürzung } & \multicolumn{1}{c|}{ Definition } \\
\hline $\mathrm{m}$ & Masse der Knochenprobe $(\mathrm{mg})$ \\
\hline $\mathrm{c}$ & Stoffmengenkonzentration $(\mathrm{mol} / \mathrm{m})$ \\
\hline $\mathrm{mol}$ & Stoffmenge \\
\hline Calcium-Gehalt \% & Prozentualer Anteil von $\mathrm{Ca}^{2+}$ an der Knochenprobe $(\mathrm{m})$ \\
\hline Phosphat-Gehalt \% & Prozentualer Anteil von $\mathrm{PO}^{3-}$ an der Knochenprobe $(\mathrm{m})$ \\
\hline $\mathrm{c}\left(\mathrm{Ca}^{2+}\right) / \mathrm{c}\left(\mathrm{PO}^{3-}\right)$ & Verhältnis der Stoffmengenkonzentration $(\mathrm{c})$ \\
& von Ca ${ }^{2+}$ und PO4 ${ }^{3-}$ an der Knochenprobe $(\mathrm{m})$ \\
\hline
\end{tabular}




\subsection{Mikro-Computertomographie}

Für die computertomographische Untersuchung der Femora (rechte Seite) wurde ein Quantum FX microCT des Herstellers Caliper Sciences (Hopkinton, Massachusetts, USA) verwendet. Dieses Gerät zeichnet sich besonders durch seine geringe Strahlenbelastung aus, welche pro Scan im Durchschnitt bei etwa 15 mGy liegt. Basierend auf einem Bildverstärkersystem, welche sich aus den Bestandteilen Optik, Kamera und Bildschirm zusammensetzt, werden die Prüfkörper in hochaufgelöste dreidimensionale Bilder dargestellt.

Während eines Scanvorgangs durchdringt die emittierte Röntgenstrahlung das Untersuchungsobjekt und trifft dabei auf eine Szintillatorschicht. Diese registriert die eintreffende Energie und wandelt sie in sichtbares Licht um. In der Folge werden die Lichtphotonen von einer Sensormatrix erfasst, dessen Elektronen das registrierte Strahlenprofil zur Bildverarbeitung weiterleiten.

Der gesamte Scanvorgang kann direkt über einen Bildschirm, welcher mit einer Digitalkamera verbunden ist, verfolgt werden. Die Durchführung der Scans erfolgte mithilfe von definierten Scanparametern, welche in Tabelle 5 aufgeführt sind.

Tab. 5: Scanparameter des Scanprotokolls

\begin{tabular}{|c|c|}
\hline Scan Parameter & Wert + Einheit \\
\hline Anzahl der Projektionen $\left(360^{\circ}\right.$ Scan) & 3600 \\
\hline Röhrenspannung & $70 \mathrm{kVp}$ \\
\hline Röhrenstrom & $200 \mu \mathrm{A}$ \\
\hline FOV (Field of View) & $20 \times 20 \mathrm{~mm}^{2}$ \\
\hline Scanzeit & $2 \mathrm{~min}$ \\
\hline Scanmode & Vollrotation $\left(360^{\circ}\right)$ \\
\hline Effektive „Voxel“-Größe & $40 \times 40 \times 40 \mu \mathrm{m}^{3}$ \\
\hline Detektor Frame Rate & $30 \mathrm{~Hz}$ \\
\hline Bildmatrix & $512 \times 512$ \\
\hline Datenpräsentation & $16 \mathrm{bit}$ \\
\hline
\end{tabular}




\subsubsection{Durchführung der Scans}

Um während des Scanvorgangs eine gleichmäßig intensive Röntgenstrahlung zu garantieren und die Röhre durch plötzliches An- und Ausschalten nicht zu beschädigen, wurde vor der Durchführung der Scans eine Aufwärmphase von ca. 15 min eingehalten.

Im Anschluss wurde der zu prüfende Knochen auf ein röntgentransparentes Schaumstoffstück positioniert, um während des Scanvorgangs eine sichere Lage zu gewährleisten. Für die bessere Vergleichbarkeit und Auswertung der einzelnen Aufnahmen wurde neben jedem Knochen zusätzlich ein Kalibrierungsphantom platziert.

Dieses Phantom beinhaltet insgesamt fünf verschiedene HydroxylapatitFestkörper. Jeder dieser einzelnen Festkörper weist eine dem System bekannte spezifische Mineraldichte auf. Dadurch dient es als Referenz für die durch den Prüfkörper abgeschwächten Röntgenstrahlen. Dadurch können die ermittelten Dichtewerte (Hounsfield-Skala) sehr detailgetreu in ein Graustufenbild umgewandelt werden.

Nach der stabilen Positionierung des Knochens konnte dieser in die Prüfkörperkammer des $\mu$-CT gelegt und der Fokus auf den Caput femoris inklusive des Phantoms ausgerichtet werden. Darauf erfolgte immer erst ein Testscan in niedriger Auflösung zur Überprüfung der Rekonstruktion am Bildschirm. Nur wenn die oberen Anteile des Knochens (Caput femoris, Collum femoris, Trochanter major, Trochanter minor) und das Phantom vollständig dargestellt wurden, erfolgte ein Scan in hoher Auflösung.

Der daraus resultierende Datensatz wurde mithilfe eines Filtered Back Projection (FBP)-Algorithmus und einer Kalibrierung durch Auswertung der Grauwerte der Referenzmaterialien (Kalibrierungsphantom) in eine 3-D-Rekonstruktion umgewandelt. 


\subsubsection{Auswertung der Scans}

Für die Auswertung wurde die Software 3D Osteoanalyze v 1.000 .4 benutzt. Mithilfe dieses Programms wurden Dichte, Volumen und Struktur der einzelnen Knochenbestandteile des Caput femoris analysiert und eine Kortikalismessung des Collum femoris vorgenommen.

\section{Arbeitsschritte}

\section{Transparenz- und Kontrasteinstellung}

Im Rahmen der Auswertung wurde bei jedem Knochen zunächst eine Anpassung der Einstellungen des 2-D- und 3-D-Sichtfensters vorgenommen, um eine detailgetreue Darstellung zu erhalten. Dieses Vorgehen sollte ebenfalls die bessere Vergleichbarkeit und Auswertung der einzelnen Femora sicherstellen.

Für die optimale 3-D-Darstellung der gesamten Knochenstruktur (Abb. 9) wurde das entsprechende Grauwerthistogramm in Bezug auf seine Transparenzfunktion, wie in Abb. 10 beschrieben, immer individuell angepasst.

Die 2-D-Darstellung (Abb. 11) wurde mithilfe der ebenfalls im dazugehörigen Grauwerthistogramm vorhandenen Kontrastfunktion (Abb. 12) angepasst, wodurch sowohl die Substantia compacta als auch das feine Trabekelwerk der Substantia spongiosa sichtbar und voneinander unterschieden werden konnten. 


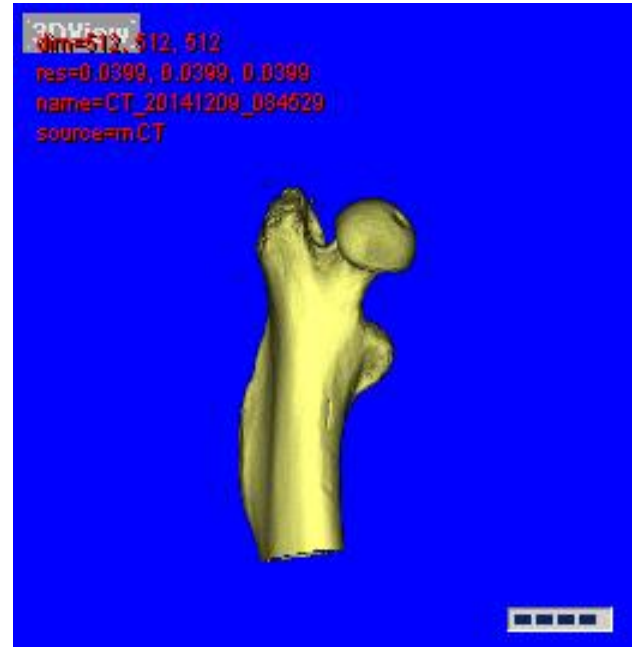

Abb. 9: 3-D-Darstellung eines Femurs mit optimal angepasster Transparenz

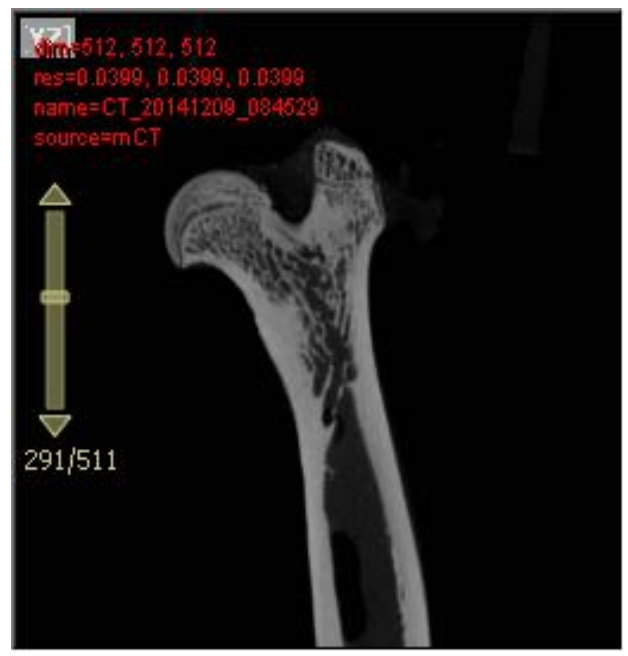

Abb. 11: 2-D-Darstellung eines Femurs mit optimal angepasstem Kontrast

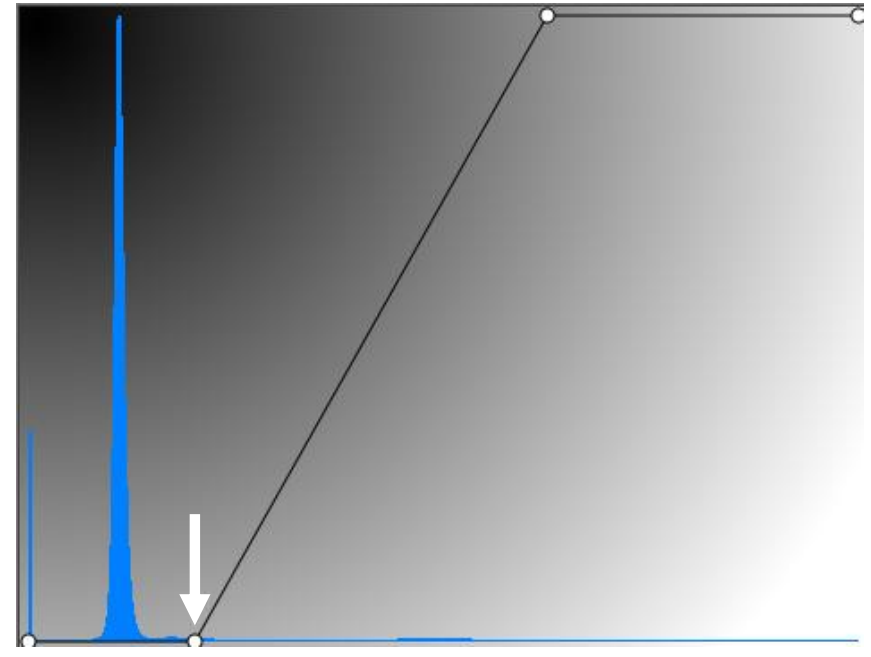

Abb. 10: Grauwerthistogramm der 3-DDarstellung (Abb. 9) für die optimale Anpassung der Transparenz; Pfeil (weiß) bezeichnet den Punkt, welcher verändert werden muss

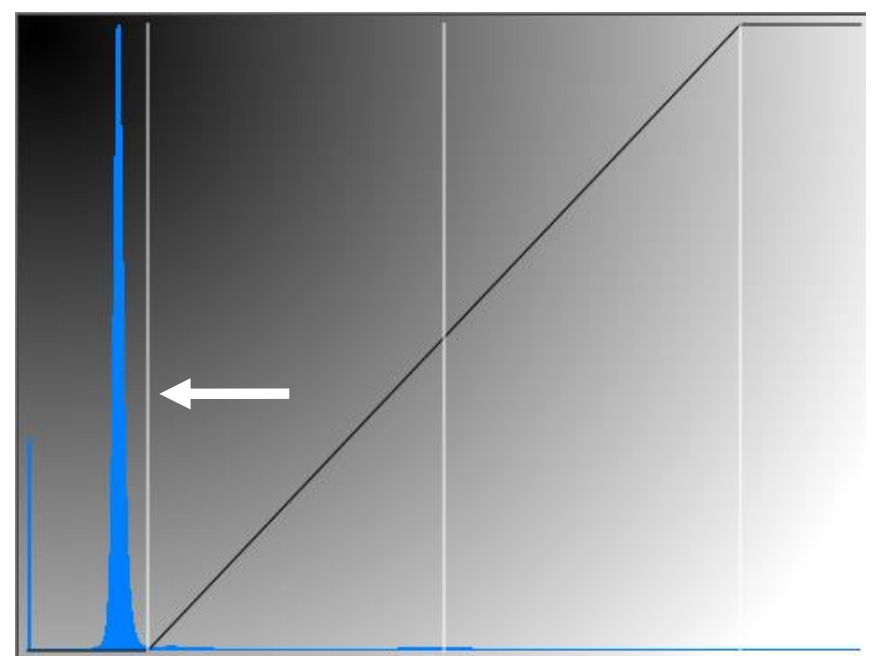

Abb. 12: Grauwerthistogramm der 2-DDarstellung (Abb. 11) für die optimale Anpassung des Kontrasts; Pfeil (weiß) bezeichnet die Linie, welche verschoben werden muss 


\section{Auswertung des Kalibrierungsphantoms}

Zur Validitätssicherung wurde vor der Analyse jedes einzelnen Knochens immer erst eine Dichte-Kalibrierung vorgenommen. Dazu wurde das Kalibrierungsphantom mithilfe der Software zunächst ausgeschnitten, um es separat vom Knochen darzustellen (Abb. 13).

Im Anschluss konnte die Erstellung eines Grauwerthistogramms erfolgen, wobei die Werte der x-Achse Ausdruck für die Röntgenschwächung (ansteigende Helligkeit) sind und die dazugehörigen Werte der y-Achse die Anzahl der Bildpunkte, die in den entsprechenden Grauwertbereich fallen, wiedergeben (Abb. 14).

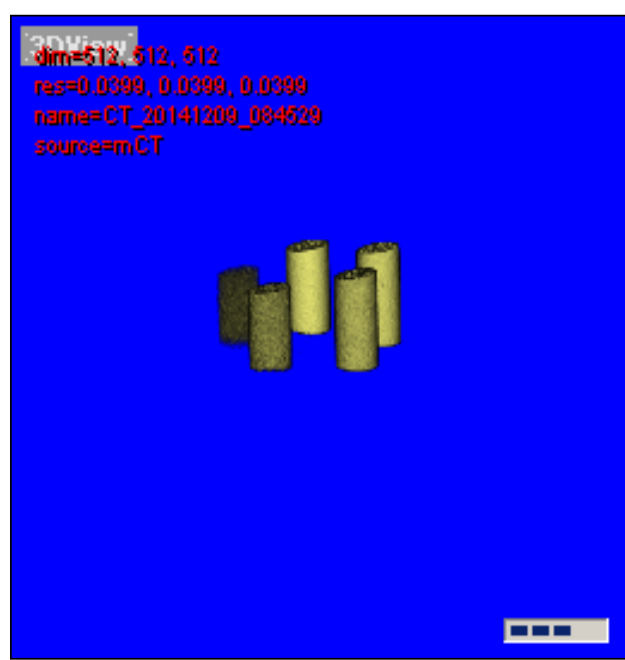

Abb. 13: 3-D-Darstellung des Kalibrierungsphantoms

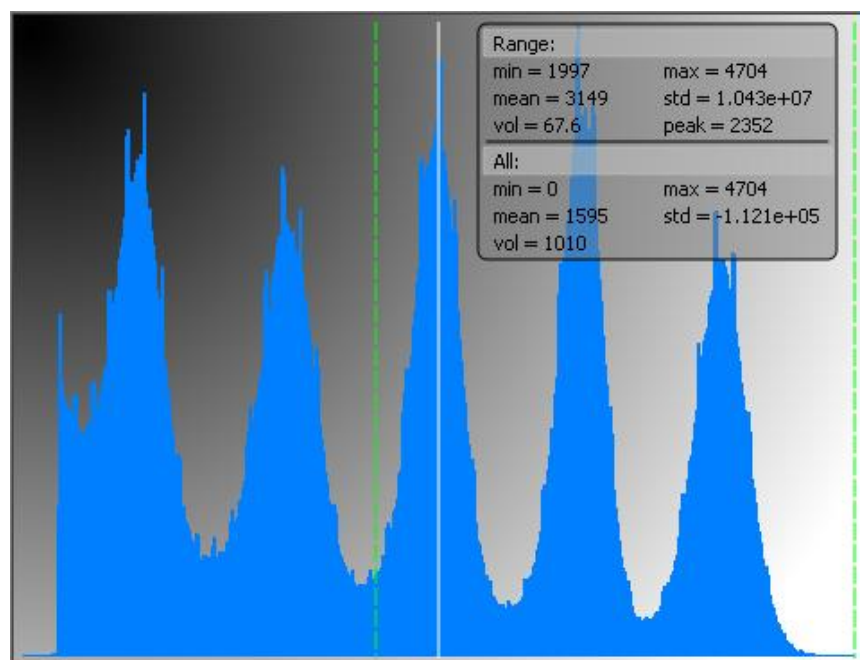

Abb. 14: Histogramm des Kalibrierungsphantoms

Da das Kalibrierungsphantom aus fünf verschiedenen Festkörpern mit jeweils unterschiedlichen Mineraldichte-Werten besteht, gehen daraus charakteristischerweise fünf Peaks im Histogramm hervor. Durch Kenntnis der einzelnen Materialzusammensetzungen, bzw. der spezifischen Elektronendichte, ergab sich ein Röntgenschwächungswert, woraus die Massendichte abgeleitet werden konnte. Dieses Vorgehen war von besonderer Bedeutung, da nur aus diesem Grund Rückschlüsse auf den Mineralisierungsgrad der verschiedenen Knochenkompartimente gezogen werden konnten. 
Zur Kalibrierung der Dichte wurden die Maximalwerte der Peaks erfasst und durch lineare Regression in eine Ausgleichsgerade, welche als Referenz für die spätere Knochenanalyse diente, umgewandelt.

\section{Dichte- und Volumenbestimmung}

Für die Dichte- und Volumenbestimmung der einzelnen Knochenbestandteile des Caput femoris wurde dieser zunächst so markiert und vom restlichen Knochen getrennt, dass ein gerader Schnitt im Bereich des Collum femoris am Übergang zum Trochanter major erzielt wurde (Abb. 15, Abb. 16).

Im Anschluss wurde die Luft in dem ausgeschnittenen Bereich entfernt, dass ein bereinigtes Histogramm nur in Bezug auf das Knochengewebe erstellt werden konnte. Dieses setzte sich aus Kortikalis, Trabekel und Weichgewebe zusammen.

$\mathrm{Da}$ die Peaks dieser Knochenbestandteile im Histogramm nicht immer klar voneinander abgegrenzt werden konnten, jedoch eine segmentspezifische und einheitliche Auswertung aller Knochen sichergestellt werden sollte, wurden vor der Analyse definierte untere Schwellenwerte festgelegt.

Dazu wurden aus jeder der fünf Versuchsgruppen (Tab. 3) zwei Femora untersucht, bei denen im Histogramm drei deutliche Grauwertbereiche, stellvertretend für die entsprechenden Knochenbestandteile (Kortikalis, Trabekel, Weichgewebe), mit ausgeprägten Peaks vorhanden waren. In der Folge wurden für jedes dieser 10 Histogramme der untere Schwellenwert des kortikalen Knochens (Übergang von Kortikalis zu Trabekel), sowie der untere Schwellenwert des trabekulären Knochens (Übergang von Trabekel zu Weichgewebe) festgelegt. Zur Festlegung des kortikalen Knochenanteils wurde dessen unterer Schwellenwert genau zwischen dem Kortikalispeak und den Peak des trabekulären Knochens verschoben. Parallel dazu wurde der untere Schwellenwert des trabekulären Knochens genau zwischen dem Trabekelpeak und den Peak des Weichgewebes verschoben. Auf diese Weise erhielt man insgesamt 10 untere Schwellenwerte, sowohl für den kortikalen als auch für den trabekulären Knochen. Anschließend wurden aus diesen Schwellenwerten Mittelwerte gebildet, welche in Tabelle 6 als definierte untere Schwellenwerte dargestellt sind. 


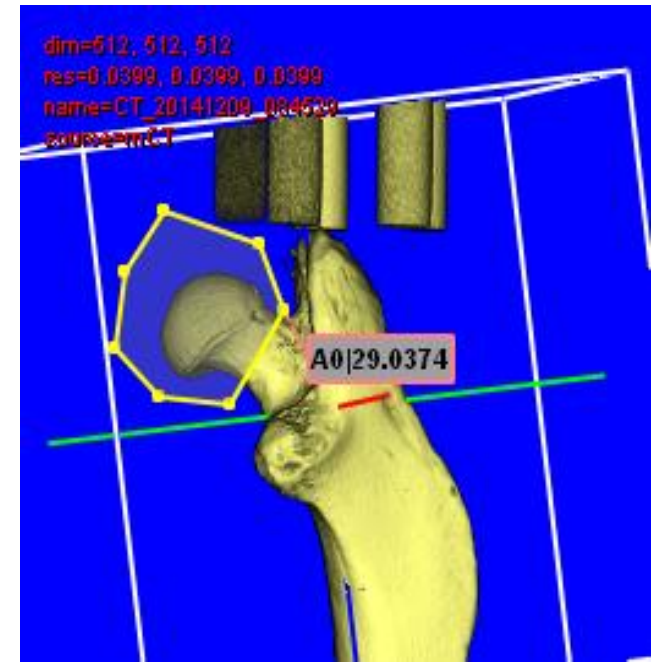

Abb. 15: 3-D-Darstellung von Kalibrierungsphantom und Femur (gelbe Markierung zeigt den Bereich um das Caput femoris an, welcher ausgeschnitten werden soll); Pfeil (weiß) zeigt auf den Trochanter major

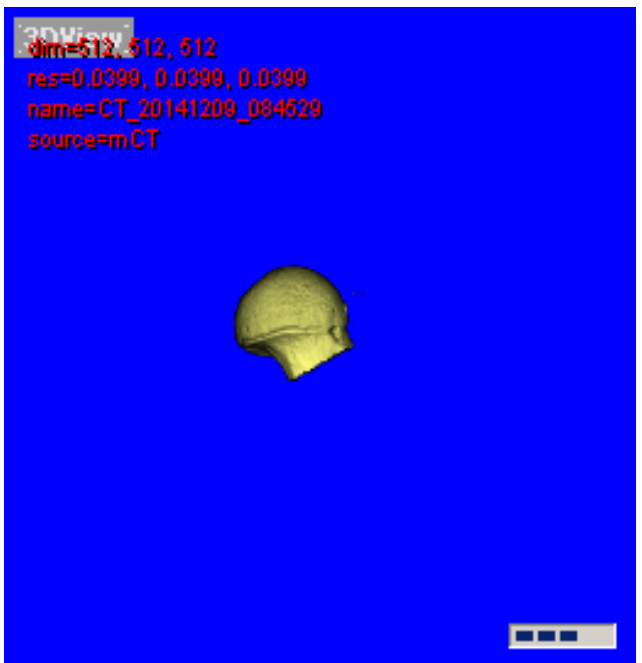

Abb. 16: Caput femoris in der 3-DDarstellung vor der Bestimmung der Knochendichte

Da der obere Schwellenwert eines Grauwertbereichs immer dem unteren Schwellenwert des angrenzenden Grauwertbereichs entsprach, musste dieser nicht zusätzlich definiert werden. Der untere Schwellenwert des Weichgewebes war durch den Beginn des Histogramms vorgegeben. Ebenso markierte das Ende des Histogramms den oberen Schwellenwert für den kortikalen Knochen.

Dadurch konnte bei jedem Knochen zwischen fünf verschiedenen Knochensegmenten, welche sich aus Gesamtknochen, Kortikalis, Kortikalis und Trabekel, Trabekel sowie Weichteilgewebe zusammensetzten, differenziert werden.

In der Folge wurde auf Grundlage der vorherigen Auswertung des Kalibrierungsphantoms (siehe Arbeitsschritt 2) bei jedem Knochen eine einheitliche Dichte- $\left(\mathrm{g} / \mathrm{cm}^{3}\right)$ und Volumenbestimmung $\left(\mathrm{mm}^{3}\right)$ der verschiedenen Messbereiche durchgeführt (Tab. 7). 
Tab. 6: Darstellung der ermittelten definierten unteren Schwellenwerte

\begin{tabular}{|l|l|l|}
\hline $\begin{array}{l}\text { Unterer Schwellenwert für die } \\
\text { Kortikalis (Range) }\end{array}$ & $\begin{array}{l}\text { Unterer Schwellenwert für den trabekulären } \\
\text { Knochen (Range) }\end{array}$ \\
\hline $0.8 \mathrm{~g} / \mathrm{cm}^{3}$ & & $0.45 \mathrm{~g} / \mathrm{cm}^{3}$ \\
\hline
\end{tabular}

Tab. 7: Messparameter der Dichte- und Volumenbestimmung

\begin{tabular}{|l|c|}
\hline \multicolumn{1}{|c|}{ Parameter } & Einheit \\
\hline Gesamtdichte & $\mathrm{g} / \mathrm{cm}^{3}$ \\
\hline Gesamtvolumen & $\mathrm{mm}^{3}$ \\
\hline Kortikalisdichte & $\mathrm{g} / \mathrm{cm}^{3}$ \\
\hline Kortikalisvolumen & $\mathrm{mm}^{3}$ \\
\hline Trabekeldichte & $\mathrm{g} / \mathrm{cm}^{3}$ \\
\hline Trabekelvolumen & $\mathrm{mm}^{3}$ \\
\hline Kortikalis- und Trabekeldichte (Knochendichte) & $\mathrm{g} / \mathrm{cm}^{3}$ \\
\hline Kortikalis- und Trabekelvolumen (Knochenvolumen) & $\mathrm{mm}^{3}$ \\
\hline $\begin{array}{l}\text { Kortikalis- und Trabekelvolumen (Knochenvolumen)/ } \\
\text { Gesamtvolumen }\end{array}$ & $\%$ \\
\hline Weichteilgewebedichte & $\mathrm{g} / \mathrm{cm}^{3}$ \\
\hline Weichteilgewebevolumen & $\mathrm{mm}^{3}$ \\
\hline
\end{tabular}

\section{Bestimmung der Kortikalis-Oberfläche}

Für die Bestimmung der Kortikalis-Oberfläche $\left(\mathrm{mm}^{2}\right)$ wurde das Caput femoris in der 3-D-Darstellung zunächst so gedreht, dass eine Ansicht von unten auf den Querschnitt des Collum femoris möglich war.

Im Anschluss erfolgte eine Berechnung der gesamten Knochenoberfläche dieses Querschnitts. Dazu wurde der äußere Rand des Knochens mithilfe der Software 
markiert (Abb. 17). Daraufhin wurde in gleicher Weise nur die Oberfläche des Trabekelwerks der Substantia spongiosa markiert und berechnet (Abb. 18). Durch Subtraktion der Fläche der Substantia spongiosa von der Gesamtoberfläche des Knochens konnte die Oberfläche der Kortikalis ermittelt werden.

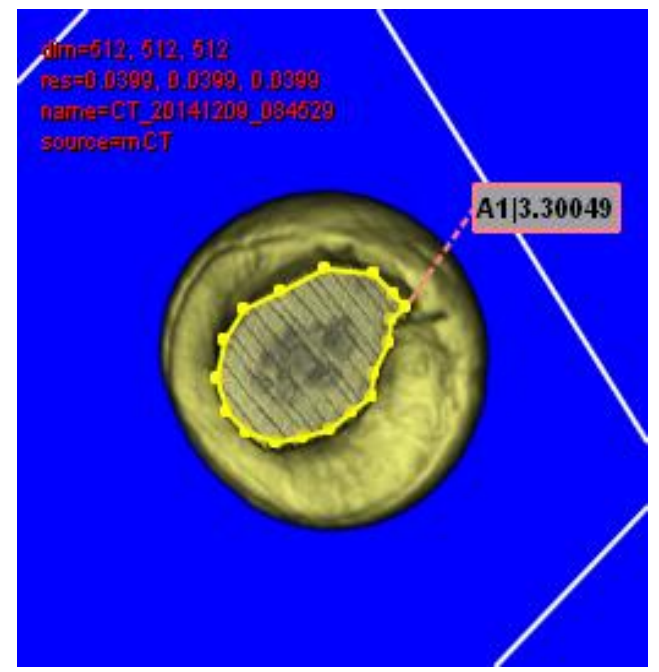

Abb. 17: 3-D-Darstellung von unten auf den Querschnitt des Collum femoris und Markierung der Knochenoberfläche

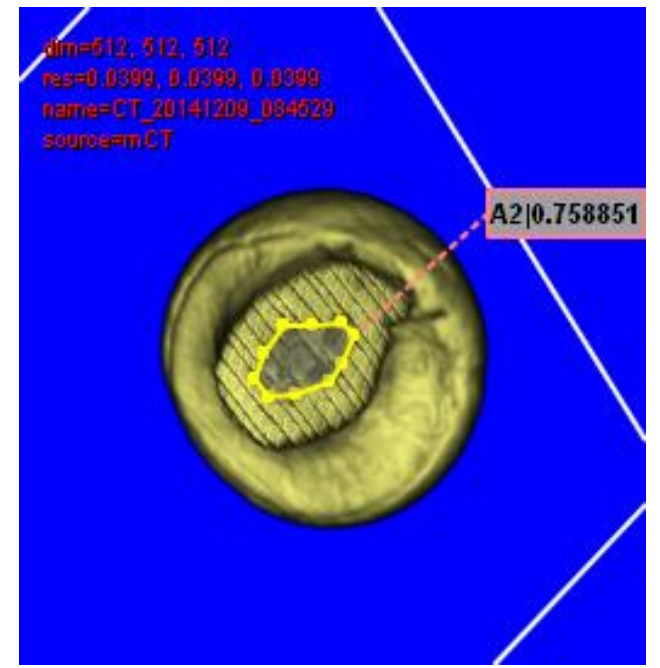

Abb. 18: 3-D-Darstellung von unten auf den Querschnitt des Collum femoris und Markierung der Substantia spongiosa

\section{Analyse der Substantia spongiosa}

Der letzte Arbeitsschritt der Auswertung sah eine Analyse des Caput femoris im Hinblick auf die Zusammensetzung des trabekulären Knochens vor.

Da mit der Software nur ein Teilbereich der Knochenstruktur ausgewertet werden konnte, wurde mithilfe eines Messrahmens (10 $\mathrm{mm} \times 0,2 \mathrm{~mm}$ ) zunächst ein möglichst zentraler und damit aussagekräftiger Untersuchungsabschnitt des Knochens ausgewählt (Abb. 19).

Um die zentrale Anpassung des Messrahmens an den Caput femoris zu gewährleisten, wurde er in der 3-D-Darstellung mehrmals in allen räumlichen Ebenen überprüft und gegebenenfalls angepasst (Abb. 20). Nach der Berechnung des ausgewählten Untersuchungsabschnitts konnte dieser in der 3-D-Darstellung betrachtet werden (Abb. 21). 


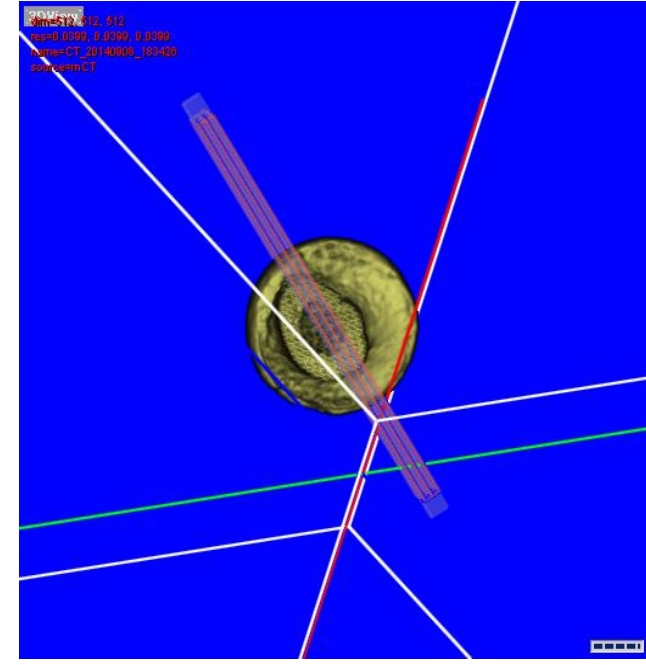

Abb. 19: 3-D-Ansicht von unten auf den Querschnitt des Collum femoris und zentrale Anpassung des Messrahmens

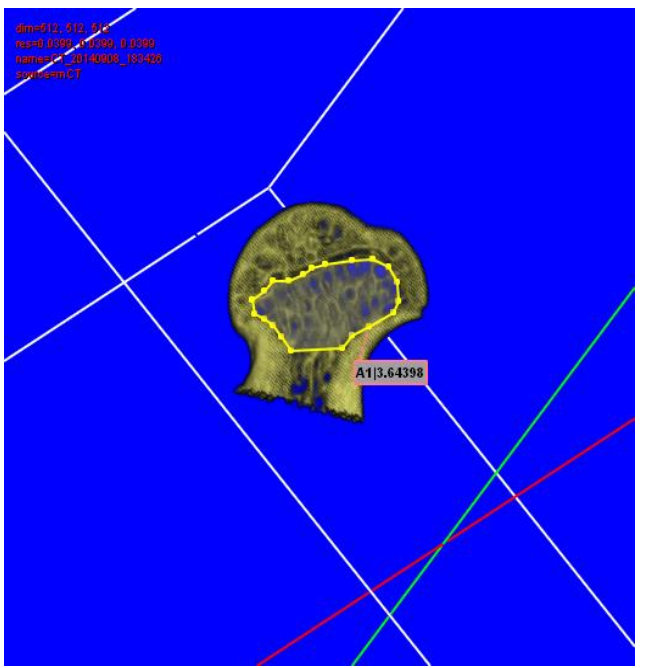

Abb. 21: 3-D-Ansicht von lateral auf den Untersuchungsabschnitt, welcher zuvor durch den Messrahmen ausgewählt wurde; Markierung der Substantia spongiosa

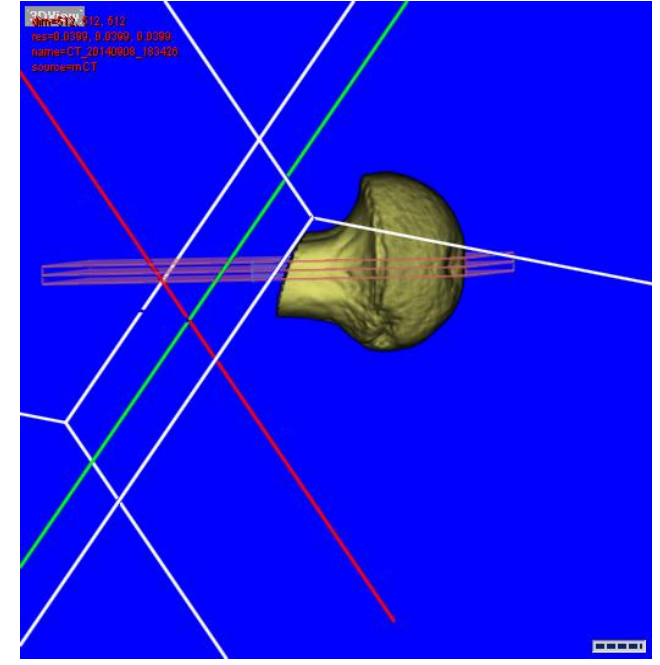

Abb. 20: 3-D-Ansicht von lateral zur Überprüfung und Anpassung des Messrahmens

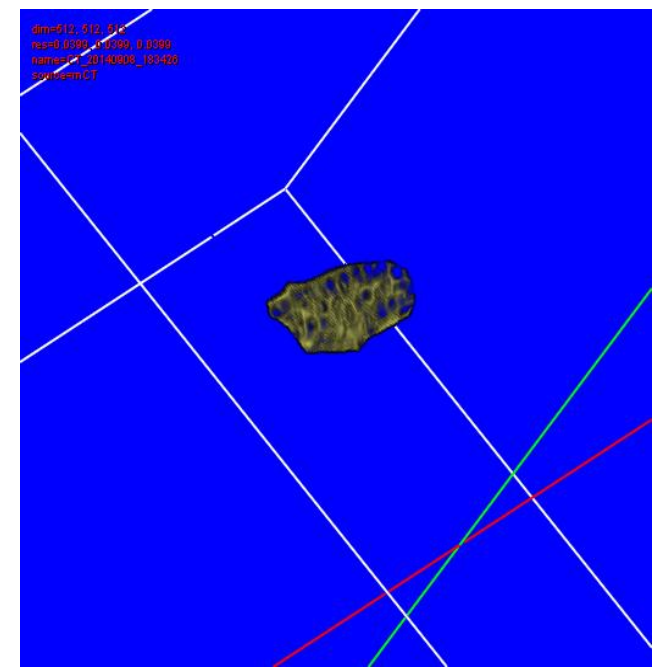

Abb. 22: 3-D-Ansicht von lateral auf die in Abb. 21 markierte trabekuläre Struktur der Substantia spongiosa

Für die Analyse der Substantia spongiosa wurde der gesamte trabekuläre Knochen unterhalb der Epiphysenfuge und oberhalb des Collum femoris markiert 
und ausgeschnitten (Abb. 21, Abb. 22). Anschließend konnte der ausgewählte Knochenbereich mit den Parametern, welche in Tabelle 8 dargestellt sind, untersucht werden.

Tab. 8: Messparameter für die Analyse der Substantia spongiosa

\begin{tabular}{|l|c|}
\hline \multicolumn{1}{|c|}{ Parameter } & Einheit \\
\hline Gesamtvolumen (Trabekel + Weichteilgewebe) & $\mathrm{mm}^{3}$ \\
\hline Trabekelvolumen & $\mathrm{mm}^{3}$ \\
\hline Trabekelvolumen/ Gesamtvolumen & $\%$ \\
\hline Mittlere Trabekeldicke & $\mathrm{mm}$ \\
\hline Mittlerer Trabekelabstand & $\mathrm{mm}$ \\
\hline
\end{tabular}

\subsection{Statistik}

Die statistische Auswertung der Versuchsergebnisse erfolgte mithilfe des Programms GraphPad Prism (Version 4.00, Graph Pad Software Inc., San Diego, USA). Es diente auch zur Erstellung der graphischen Abbildungen, welche im Ergebnisteil aufgeführt sind.

Basierend auf den Ergebnissen der einzelnen Versuche konnte für jeden Messparameter $(2.7 .3,2.8 .2,2.9 .2)$ eine gruppenspezifische Berechnung von Minimum und Maximum, Mittelwert, Standardabweichung und Standardfehler durchgeführt werden. Die Ergebnisse wurden zusätzlich einer Varianzanalyse (one-way-ANOVA) und einem Tukey-Kramer-post-hoc-Test unterzogen, um signifikante Unterschiede zwischen den einzelnen Versuchsgruppen feststellen zu können. Dabei wurde die maximale Irrtumswahrscheinlichkeit mit dem Signifikanzniveau $\alpha=\leq 0,05$ festgelegt. Diesbezüglich ging aus einem $p$-Wert (Ergebnis eines statistischen Signifikanztests), welcher kleiner als das festgelegte Signifikanzniveau war, eine statistische Signifikanz zum Niveau a hervor (Bender und Lange 2007). P-Werte von $\leq 0,05$ wurden als signifikant, $p$-Werte von $\leq 0,01$ als hoch signifikant und $p$-Werte von $\leq 0,001$ als höchst signifikant bezeichnet. 


\section{Ergebnisse}

Im Folgenden werden die Ergebnisse der Körpergewichtsbestimmung, der Futteraufnahme, der Uterusgewichte, des biomechanischen Kompressionstests, der Veraschung und der Mikrocomputertomographie präsentiert.

\subsection{Körpergewicht der Tiere im Verlauf}

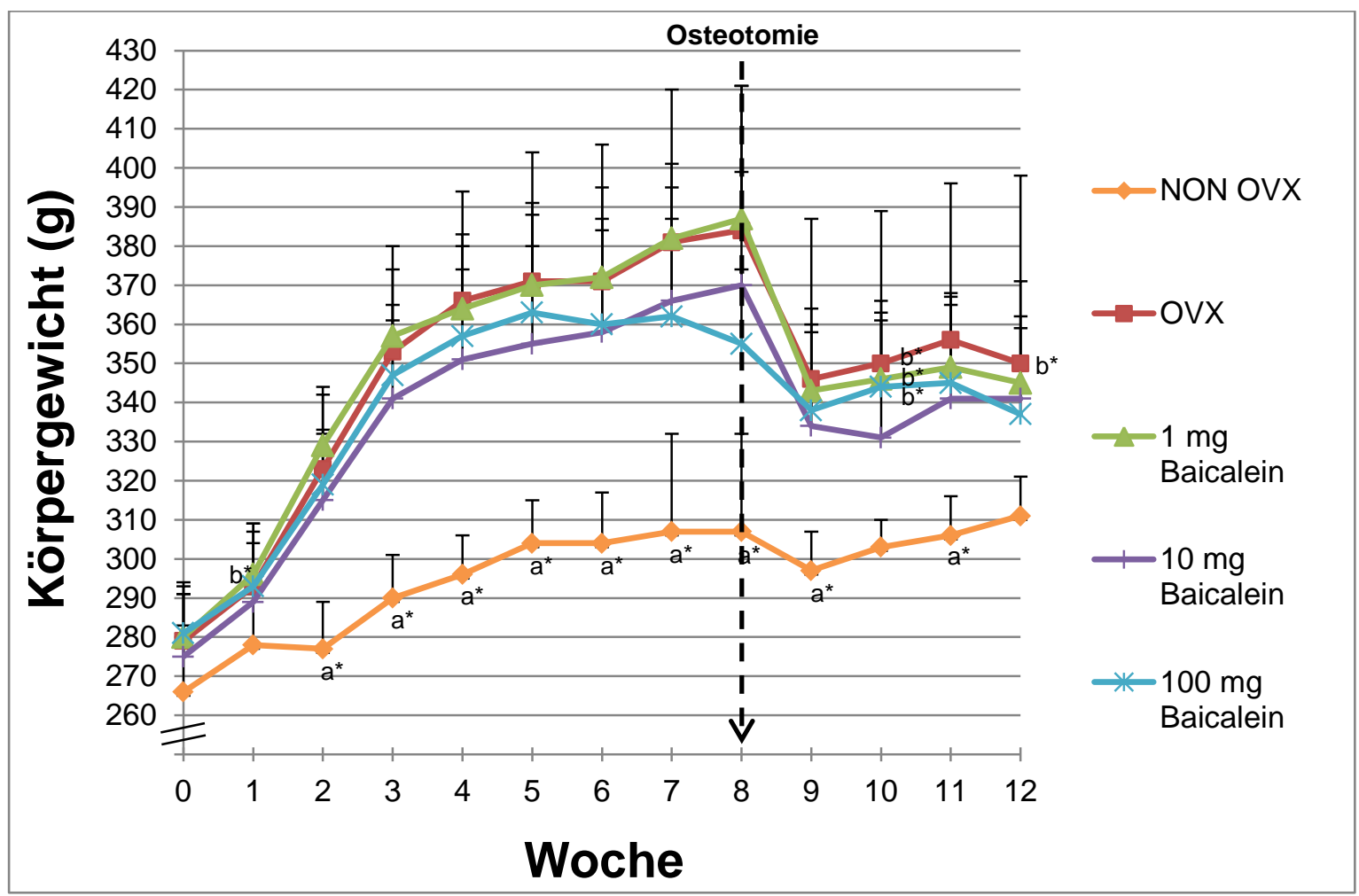

Abb. 23: Verlauf der wöchentlich ermittelten Körpergewichte als Mittelwert jeder einzelnen Versuchsgruppe; $a=$ signifikant $z u$ allen anderen Gruppen, $b=$ signifikant $z u$ NON OVX; * $=p \leq 0,05$

Die Auswertung der Ergebnisse in Bezug auf den Verlauf des Körpergewichts zeigte, dass zu Beginn des Versuchs keine deutlichen Gewichtsunterschiede zwischen den einzelnen Versuchsgruppen feststellbar waren.

Bei der Gesamtbetrachtung des Versuchs war jedoch das Körpergewicht der NON OVX-Gruppe auffällig, da es permanent unter denen der ovariektomierten Gruppen (OVX, $1 \mathrm{mg}$ Baicalein, $10 \mathrm{mg}$ Baicalein, $100 \mathrm{mg}$ Baicalein) blieb. Dennoch war über die gesamte Versuchsdauer bei allen Versuchsgruppen eine deutliche Gewichtszunahme zu erkennen. Hierbei ist anzumerken, dass bei den 
ovariektomierten Gruppen im Vergleich zu der NON OVX-Gruppe ein signifikant höherer Anstieg des Körpergewichts zu erkennen war. So lag bereits ab der zweiten Woche bei allen ovariektomierten Gruppen eine Signifikanz gegenüber der NON OVX-Gruppe vor.

Nach der Osteotomie in der 8. Woche konnte in der darauffolgenden Woche bei allen Versuchsgruppen ein Gewichtsverlust festgestellt werden. Bis zum Versuchsende wurde lediglich bei der NON OVX-Gruppe eine kontinuierliche Gewichtszunahme beobachtet. Die Körpergewichte der ovariektomierten Gruppen nahmen nach einer vorübergehenden Zunahme gegen Ende des Versuchs wieder ab oder blieben gleich (Abb. 23).

\subsection{Futteraufnahme der Tiere im Verlauf}

Die Erfassung der täglichen Futteraufnahme wurde ab der 2. Versuchswoche durchgeführt (Tab. 9). Bis zur Osteotomie in der 8. Woche nahm die Futteraufnahme ausschließlich bei der NON OVX-Gruppe kontinuierlich zu. Bei den ovariektomierten Gruppen konnte nur in den Anfangswochen ein Anstieg nachgewiesen werden, bereits nach der 4. Woche kam es bei ihnen zu einer Abnahme der Futteraufnahme.

Beim Vergleich der einzelnen Gruppen sind über den gesamten Versuchszeitraum nur in der 3. Woche signifikant höhere Werte bei den ovariektomierten Tieren der Gruppen $10 \mathrm{mg}$ Baicalein und $100 \mathrm{mg}$ Baicalein gegenüber der NON OVXGruppe erkennbar.

Unmittelbar nach der Osteotomie wurden die ovariektomierten Gruppen neu zusammengesetzt, daher fand in der 9. Woche keine Erhebung der täglichen Futteraufnahme statt. Diese erfolgte erst wieder ab der 10. Woche, in der es bei allen Tieren zu einer deutlichen Abnahme kam. Darüber hinaus erreichten zu diesem Zeitpunkt alle Tiere ihren niedrigsten Wert. In den letzten beiden Versuchswochen konnte gruppenübergreifend erneut eine Zunahme der Futteraufnahme festgestellt werden. 
Tab. 9: Verlauf der täglichen Futteraufnahme als Mittelwert \pm Standardabweichung pro Tier jeder einzelnen Versuchsgruppe; alle Werte in Gramm

\begin{tabular}{|c|c|c|c|c|c|}
\hline $\begin{array}{l}\text { Versuchs- } \\
\text { woche }\end{array}$ & $\begin{array}{l}\text { NON } \\
\text { OVX }\end{array}$ & ovx & $\begin{array}{c}1 \mathrm{mg} \\
\text { Baicalein }\end{array}$ & $\begin{array}{c}10 \mathrm{mg} \\
\text { Baicalein }\end{array}$ & $\begin{array}{c}100 \mathrm{mg} \\
\text { Baicalein }\end{array}$ \\
\hline 2 & $\begin{array}{c}19,53 \pm \\
1,28\end{array}$ & $\begin{array}{c}24,79 \pm \\
0,98\end{array}$ & $23,85 \pm 1,97$ & $25,07 \pm 2,52$ & $22,35 \pm 3,99$ \\
\hline 3 & $\begin{array}{c}19,24 \pm \\
1,03\end{array}$ & $\begin{array}{c}22,69 \pm \\
1,02\end{array}$ & $23,79 \pm 2,22$ & $\begin{array}{c}24,43 \pm 2,26 \\
\left(b^{\star}\right)\end{array}$ & $\begin{array}{c}24,33 \pm 1,87 \\
\left(b^{\star}\right)\end{array}$ \\
\hline 4 & $\begin{array}{c}24,08 \pm \\
0,55\end{array}$ & $\begin{array}{c}27,55 \pm \\
0,82\end{array}$ & $27,49 \pm 1,09$ & $26,81 \pm 2,27$ & $26,83 \pm 1,94$ \\
\hline 5 & $\begin{array}{c}22,85 \pm \\
1,51\end{array}$ & $\begin{array}{c}25,75 \pm \\
1,63\end{array}$ & $26,18 \pm 1,59$ & $25,12 \pm 2,03$ & $25,37 \pm 1,89$ \\
\hline 6 & $\begin{array}{c}22,89 \pm \\
0,66\end{array}$ & $\begin{array}{c}24,59 \pm \\
1,47\end{array}$ & $25,46 \pm 1,64$ & $24,59 \pm 1,59$ & $23,96 \pm 1,49$ \\
\hline 7 & $\begin{array}{c}22,74 \pm \\
0,88\end{array}$ & $\begin{array}{c}23,19 \pm \\
1,36\end{array}$ & $24,02 \pm 2,34$ & $23,20 \pm 2,24$ & $23,11 \pm 1,29$ \\
\hline 8 & $\begin{array}{c}22,44 \pm \\
0,29\end{array}$ & $\begin{array}{c}21,53 \pm \\
1,12\end{array}$ & $22,95 \pm 1,95$ & $21,42 \pm 1,78$ & $21,62 \pm 1,48$ \\
\hline 10 & $\begin{array}{c}19,18 \pm \\
1,44\end{array}$ & $\begin{array}{c}15,65 \pm \\
0,12\end{array}$ & $16,89 \pm 2,06$ & $17,06 \pm 1,91$ & $16,98 \pm 1,77$ \\
\hline 11 & $\begin{array}{c}20,33 \pm \\
2,73\end{array}$ & $\begin{array}{c}17,48 \pm \\
0,42\end{array}$ & $18,37 \pm 1,61$ & $17,64 \pm 1,65$ & $17,08 \pm 0,61$ \\
\hline 12 & $\begin{array}{c}22,08 \pm \\
2,49\end{array}$ & $\begin{array}{c}18,67 \pm \\
0,50\end{array}$ & $18,78 \pm 1,74$ & $19,89 \pm 2,87$ & $18,22 \pm 1,07$ \\
\hline
\end{tabular}

$\mathrm{b}=$ signifikant zu NON OVX; ${ }^{*}=p \leq 0,05$ 


\subsection{Uterusgewicht}

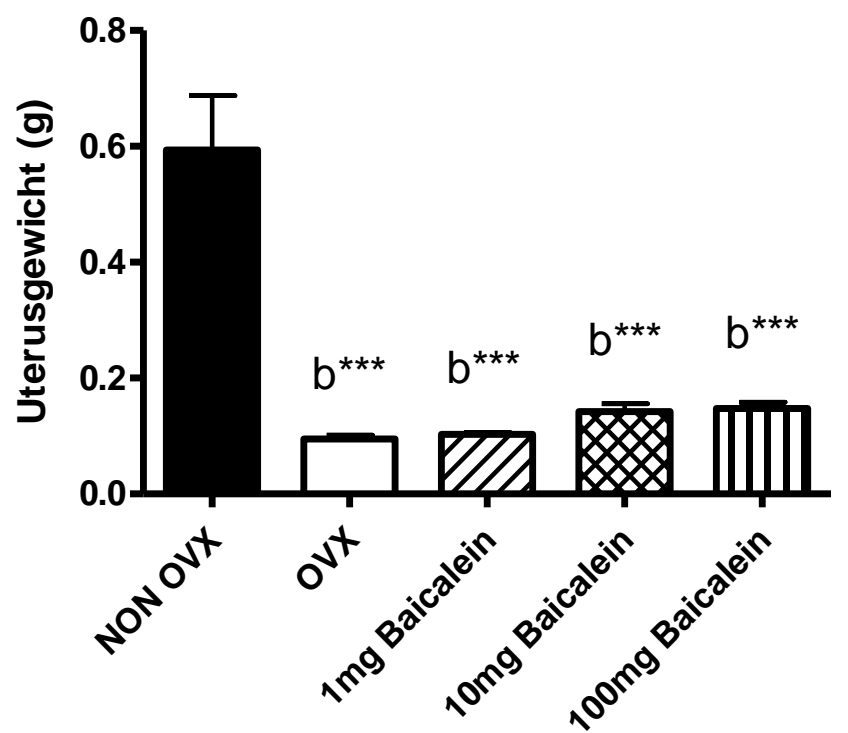

Abb. 24: Gruppenspezifische Darstellung des mittleren Uterusgewichtes \pm Standardabweichungen nach der Tötung; $b=$ signifikant zu NON OVX; ${ }^{* * *}=p \leq 0,001$

Beim Vergleich der gruppenspezifischen Uterusgewichte fiel auf, dass alle ovariektomierten Versuchsgruppen gegenüber der NON OVX-Gruppe ein niedrigeres Gewicht von höchster Signifikanz aufwiesen. Die Gewichte der 10-mgBaicalein- und 100-mg-Baicalein-Gruppen waren minimal höher als die der OVXund 1-mg-Baicalein-Gruppen. Dennoch konnten bei diesem und allen anderen Vergleichen keine weiteren Signifikanzen ermittelt werden (Abb. 24). 


\subsection{Ergebnisse des biomechanischen Kompressionstests}

\subsubsection{Elastizität}

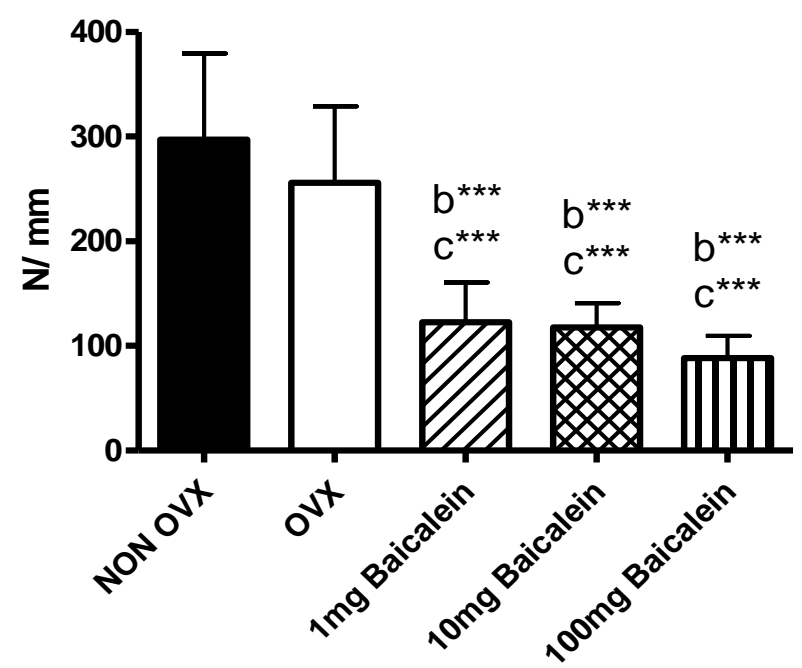

Abb. 25: Darstellung der gruppenspezifischen Mittelwerte \pm Standardabweichungen der Messgröße Elastizität; $b=$ signifikant zu NON OVX, $c=$ signifikant zu OVX; ${ }^{* * *}=p \leq$ 0,001

Die Auswertung der Ergebnisse des biomechanischen Kompressionstests zeigte, dass die Knochen der NON OVX-Gruppe mit 297,1 N/mm die mit Abstand größte Elastizität aufwiesen. Dahinter lagen die Versuchstiere der OVX-Gruppe mit 256,0 N/mm. Die Werte der medikamentös behandelten Gruppen lagen deutlich unter den beiden erstgenannten Gruppen (Abb. 25).

Mithilfe der Detailanalyse konnten zwischen den Gruppen $1 \mathrm{mg}$ Baicalein, $10 \mathrm{mg}$ Baicalein und $100 \mathrm{mg}$ Baicalein gegenüber der NON OVX-Gruppe und der OVXGruppe niedrigere Werte von höchster Signifikanz nachgewiesen werden. Weitere Gruppenvergleiche zeigten keine statistische Signifikanz.

$\mathrm{Zu}$ beachten waren die höheren Standardabweichungen bei der NON OVX- und OVX-Gruppe. Ferner konnte beobachtet werden, dass die elastische Verformung des Knochens umso niedriger ausfiel, je höher konzentriert die medikamentöse Therapie durchgeführt wurde (Abb. 25). 


\subsubsection{Maximalkraft}

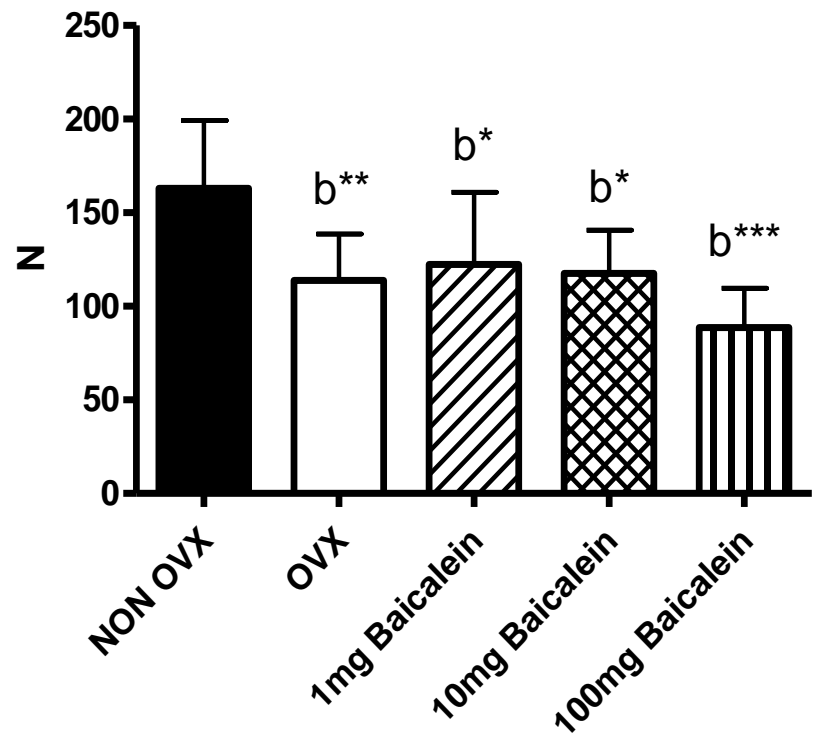

Abb. 26: Darstellung der gruppenspezifischen Mittelwerte \pm Standardabweichungen der Messgröße Maximalkraft; $b=$ signifikant zu NON OVX; * $=p \leq 0,05,{ }^{* *}=p \leq 0,01$, $* * *=p \leq 0,001$

Auch in Bezug auf die Maximalkraft konnte mit 163,1 $\mathrm{N}$ der höchste Wert bei der NON OVX-Gruppe nachgewiesen werden (Abb. 26).

Beim Gruppenvergleich zeigten sich signifikant niedrigere Mittelwerte bei den 1mg-Baicalein- und 10-mg-Baicalein-Gruppen gegenüber der NON OVX-Gruppe. Die Maximalkraft der OVX-Gruppe war sogar hoch signifikant, die der 100-mgBaicalein-Gruppe sogar höchst signifikant niedriger im Vergleich zu der NON OVX-Gruppe.

Die medikamentös behandelten Gruppen zeigten untereinander keine Signifikanzen. Beim Versuchskollektiv waren insgesamt hohe Standardabweichungen erkennbar (Abb. 26). 


\subsection{Ergebnisse der Veraschung}

\subsubsection{Organische und anorganische Masse}

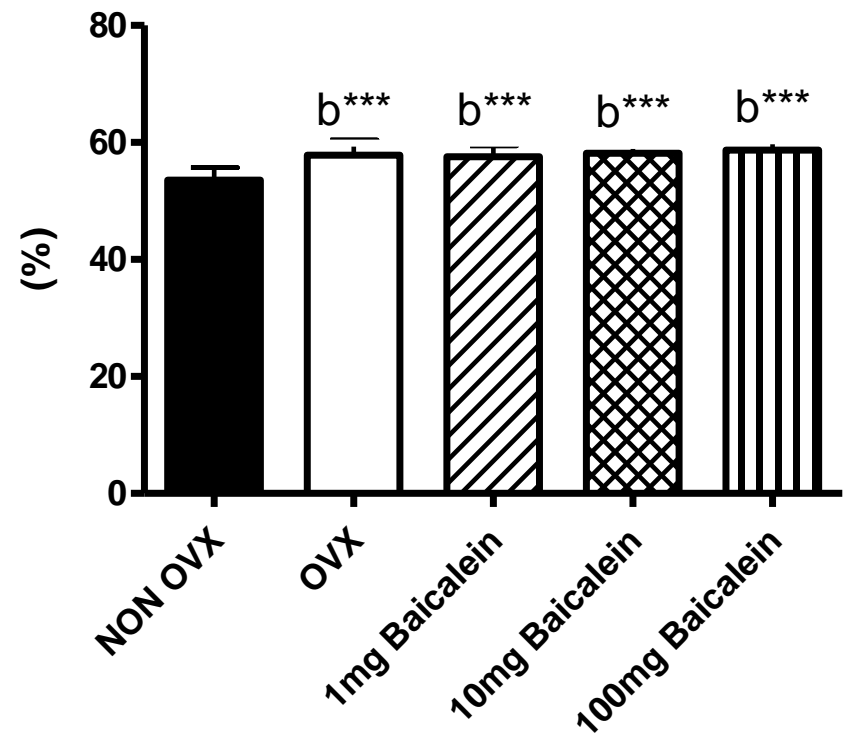

Abb. 27: Darstellung der gruppenspezifischen Mittelwerte \pm Standardabweichungen der organischen Masse; $b=$ signifikant zu NON OVX; ${ }^{* * *}=p \leq 0,001$

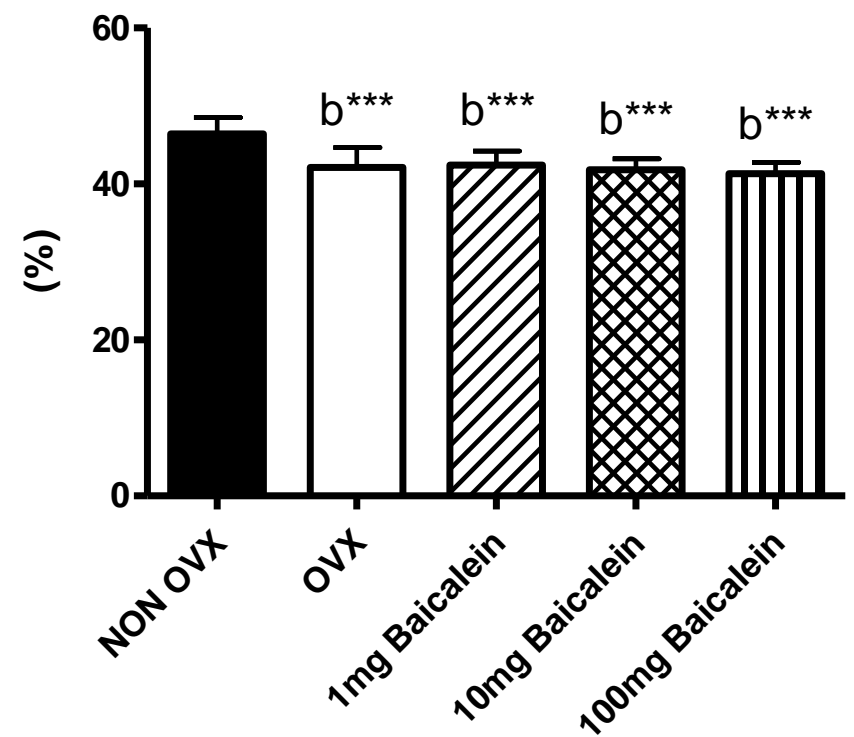

Abb. 28: Darstellung der gruppenspezifischen Mittelwerte \pm Standardabweichungen der anorganischen Masse; $b=$ signifikant zu NON OVX; ${ }^{* * *}=p \leq 0,001$ 
Bei der Auswertung der Ergebnisse der organischen Masse fiel auf, dass alle ovariektomierten Versuchsgruppen gegenüber der NON OVX-Kontrollgruppe höhere Werte von höchster Signifikanz aufwiesen. Alle anderen Vergleiche blieben ohne statistische Signifikanz (Abb. 27).

Auch in Bezug auf die anorganische Masse konnten Unterschiede von höchster Signifikanz nachgewiesen werden. Im Gegensatz zur organischen Masse waren die Werte der ovariektomierten Versuchsgruppen im Vergleich zu der OVXKontrollgruppe jedoch niedriger (Abb. 28). Alle anderen Vergleiche blieben ebenfalls ohne statistische Signifikanz.

\subsubsection{Calcium- und Phosphatgehalt}

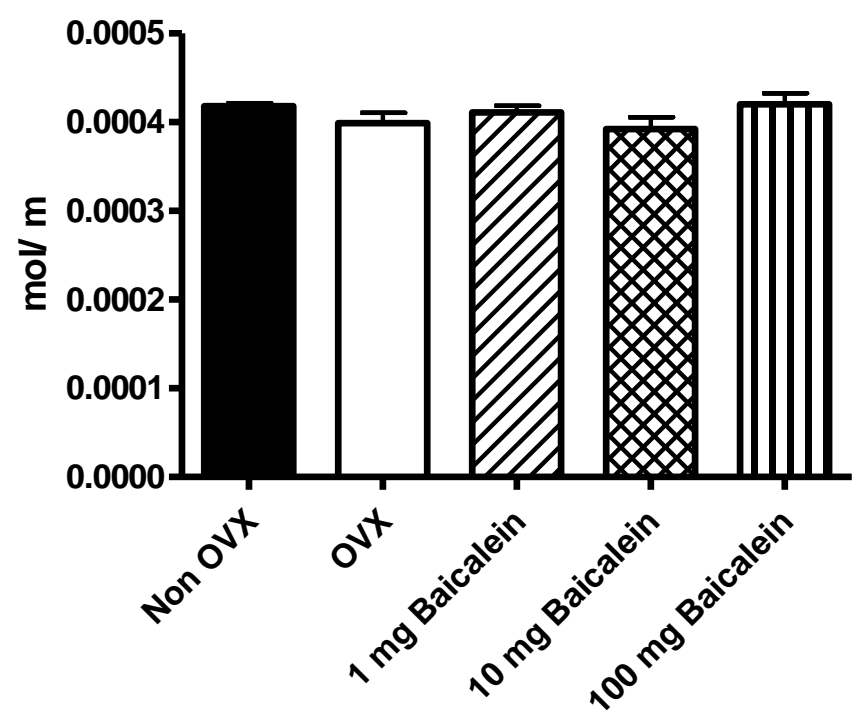

Abb. 29: Darstellung der gruppenspezifischen Mittelwerte \pm Standardabweichungen des Calcium-Gehaltes nach der Veraschung

Die Ergebnisse der Analyse des Calcium- und Phosphat-Gehaltes, sowie deren Verhältnis zueinander, zeigten keine signifikanten Unterschiede zwischen den Versuchsgruppen (Abb. 29, Abb. 30, Abb. 31). 


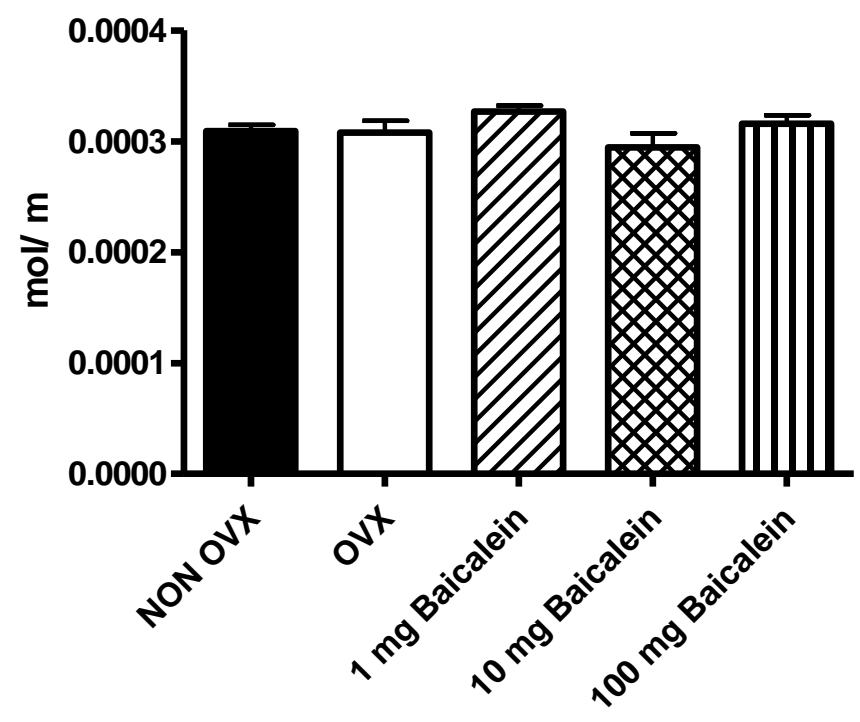

Abb. 30: Darstellung der gruppenspezifischen Mittelwerte \pm Standardabweichungen des Phosphat-Gehaltes nach der Veraschung

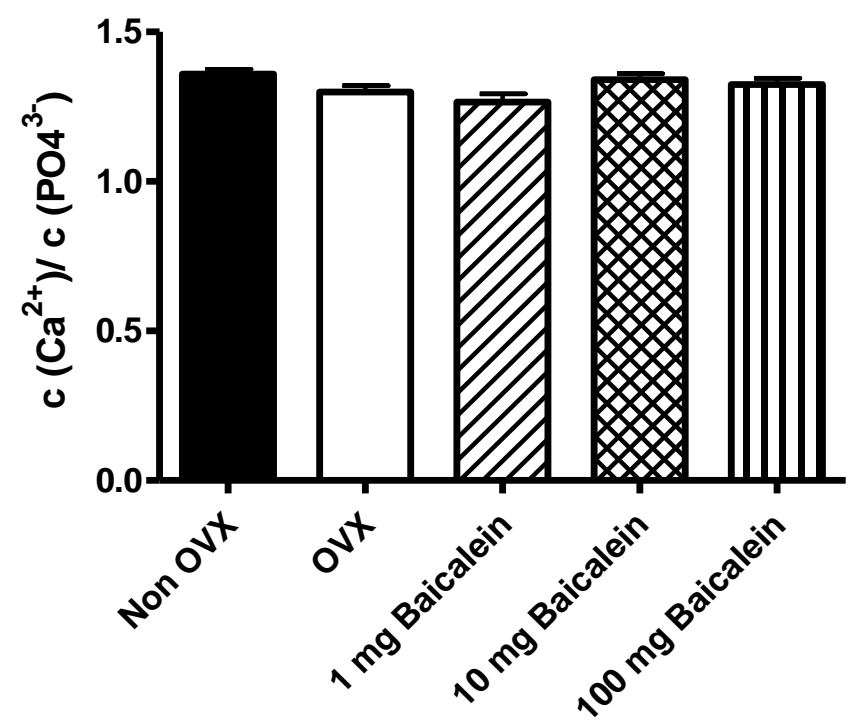

Abb. 31: Darstellung der gruppenspezifischen Mittelwerte \pm Standardabweichungen des Verhältnis von Calcium und Phosphat nach der Veraschung 
3.6 Ergebnisse der Mikro-Computertomographie

3.6.1 Dichte und Volumen des Gesamtknochens

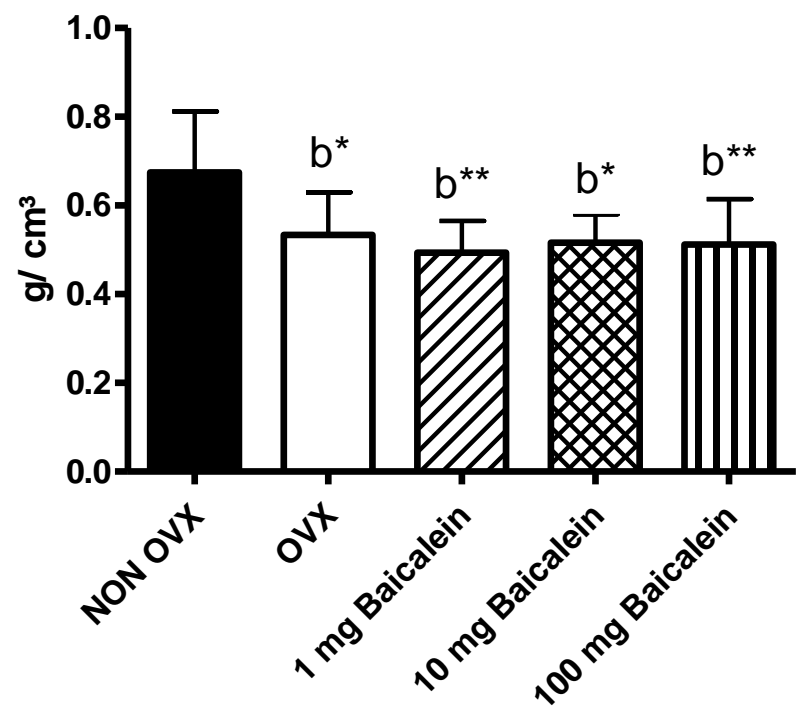

Abb. 32: Darstellung der gruppenspezifischen Mittelwerte \pm Standardabweichungen der Dichtebestimmung des Gesamtknochens; $b=$ signifikant zu NON OVX; * $=p \leq$ $0,05,{ }^{* *}=p \leq 0,01$

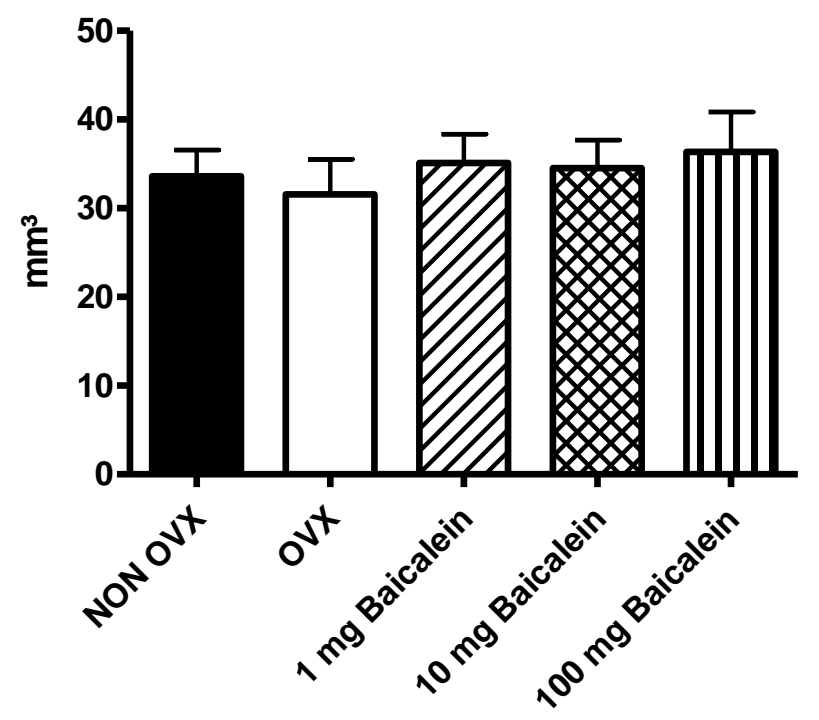

Abb. 33: Darstellung der gruppenspezifischen Mittelwerte \pm Standardabweichungen der Volumenbestimmung des Gesamtknochens 
Bei der Detailanalyse des Gesamtknochens konnten signifikante Unterschiede in Bezug auf die Dichte festgestellt werden. Sowohl bei der OVX-Gruppe als auch bei den mit Baicalein therapierten Versuchsgruppen lagen niedrigere Werte von unterschiedlicher Qualität im Vergleich zu der NON OVX-Gruppe vor (Abb. 32).

In Bezug auf die Ergebnisse der Volumenbestimmung konnten keine signifikanten Unterschiede ermittelt werden, jedoch wiesen alle medikamentös therapierten Versuchsgruppen einen höheren Wert als die NON OVX- und OVXKontrollgruppen auf (Abb. 33).

\subsubsection{Dichte und Volumen des kortikalen Knochens}

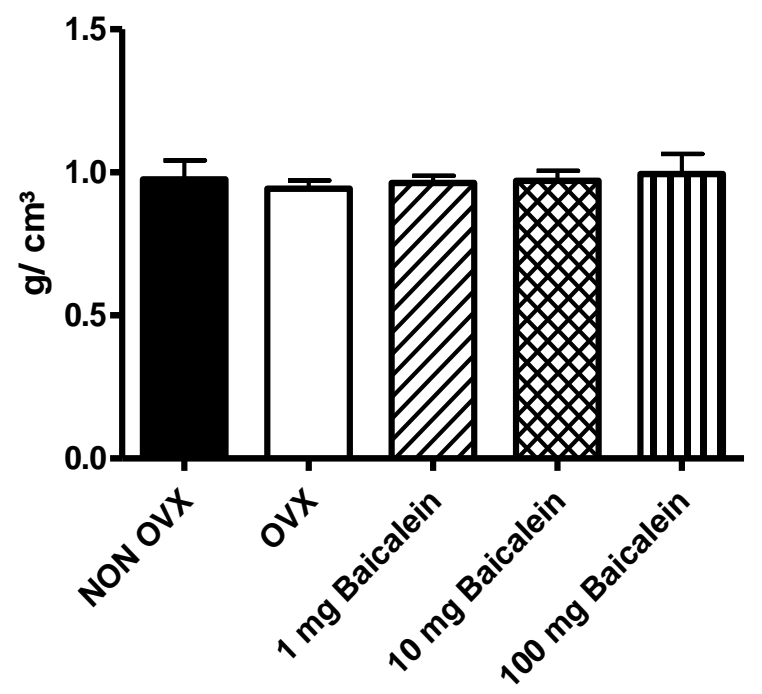

Abb. 34: Darstellung der gruppenspezifischen Mittelwerte \pm Standardabweichungen der Dichtebestimmung des kortikalen Knochens

Das Gesamtkollektiv zeigte in Bezug auf die Dichte des kortikalen Knochens nah beieinander liegende Werte ohne signifikante Unterschiede (Abb. 34).

Beim gruppenspezifischen Vergleich des kortikalen Knochenvolumens konnte mit $13,98 \mathrm{~mm}^{3}$ der höchste Wert bei der NON OVX-Gruppe nachgewiesen werden. Die Werte der 1-mg-Baicalein- und 100-mg-Baicalein-Gruppen waren hoch signifikant niedriger und die der OVX- und 10-mg-Baicalein-Gruppen sogar höchst signifikant niedriger im Vergleich zu der NON OVX-Gruppe. Darüber hinaus fiel bei den ovariektomierten Gruppen auf, dass die medikamentös behandelten Tiere im 
Vergleich zu den unbehandelten Tieren ein höheres Kortikalisvolumen aufwiesen (Abb. 35).

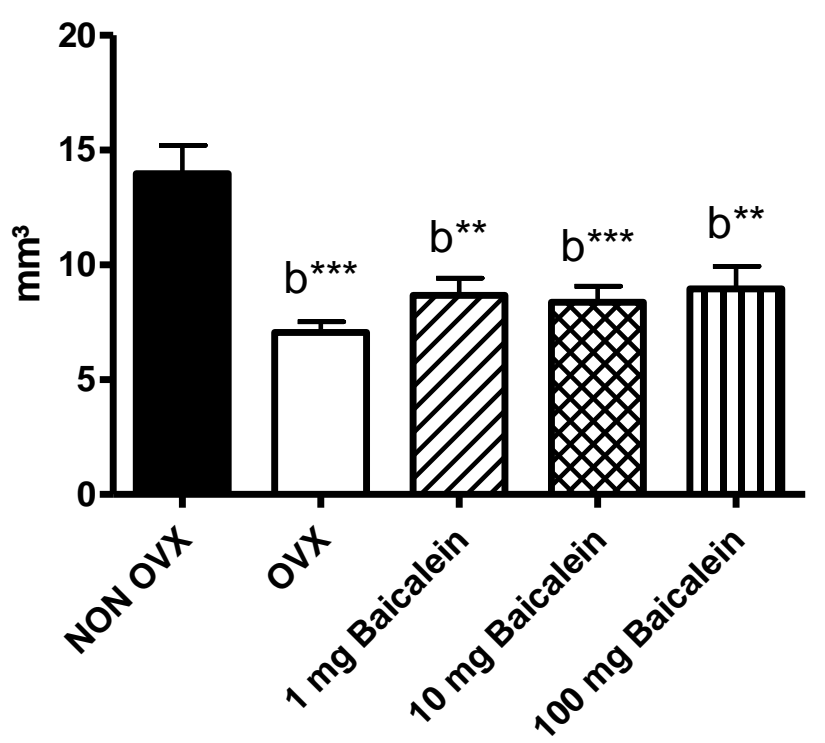

Abb. 35: Darstellung der gruppenspezifischen Mittelwerte \pm Standardabweichungen der Volumenbestimmung des kortikalen Knochens; $b=$ signifikant zu NON OVX; ${ }^{* *}=$ $p \leq 0,01,{ }^{* * *}=p \leq 0,001$

\subsubsection{Dichte und Volumen des trabekulären Knochens}

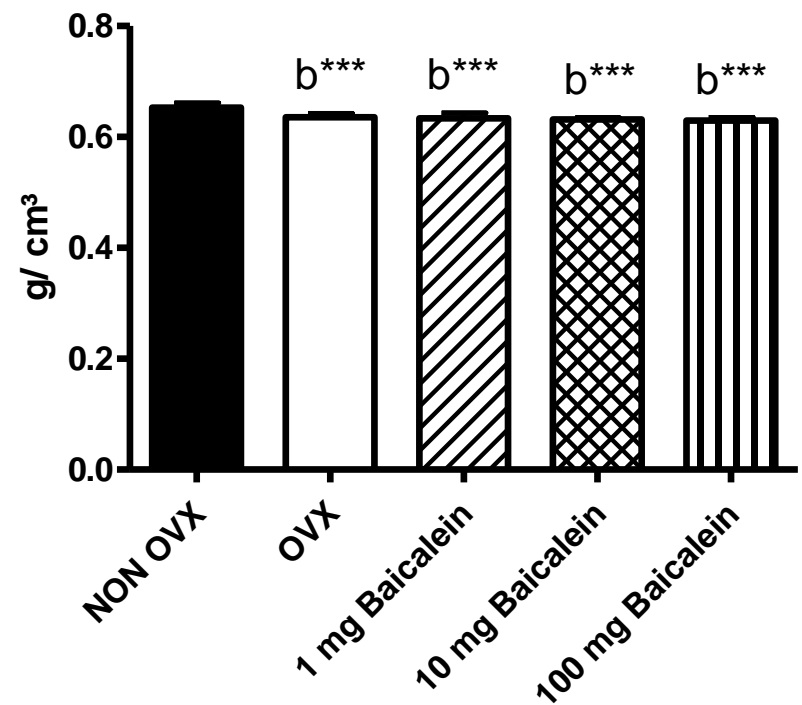

Abb. 36: Darstellung der gruppenspezifischen Mittelwerte \pm Standardabweichungen der Dichtebestimmung des trabekulären Knochens; $b=$ signifikant zu NON OVX; ${ }^{* * *}=$ $p \leq 0,001$ 


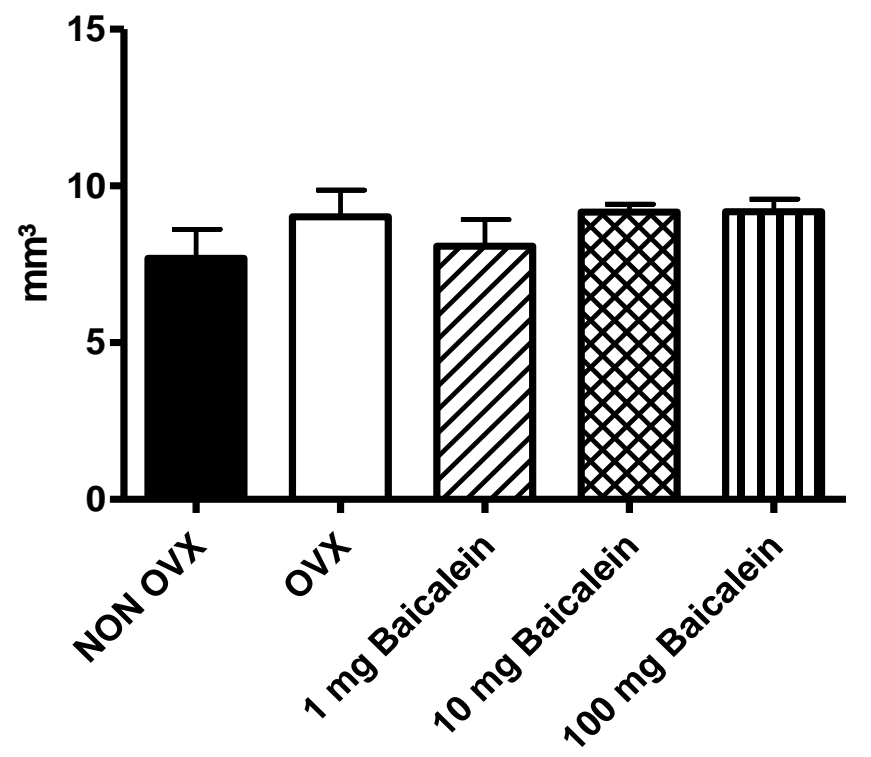

Abb. 37: Darstellung der gruppenspezifischen Mittelwerte \pm Standardabweichungen der Volumenbestimmung des trabekulären Knochens

Die Auswertung der Dichtebestimmung des trabekulären Knochens zeigte, dass bei allen ovariektomierten Versuchsgruppen niedrigere Werte von höchster Signifikanz im Vergleich zu der NON OVX-Gruppe vorlagen (Abb. 36).

In Bezug auf das Volumen konnten keine signifikanten Unterschiede festgestellt werden (Abb. 37). 
3.6.4 Dichte und Volumen von kortikalem und trabekulärem Knochen

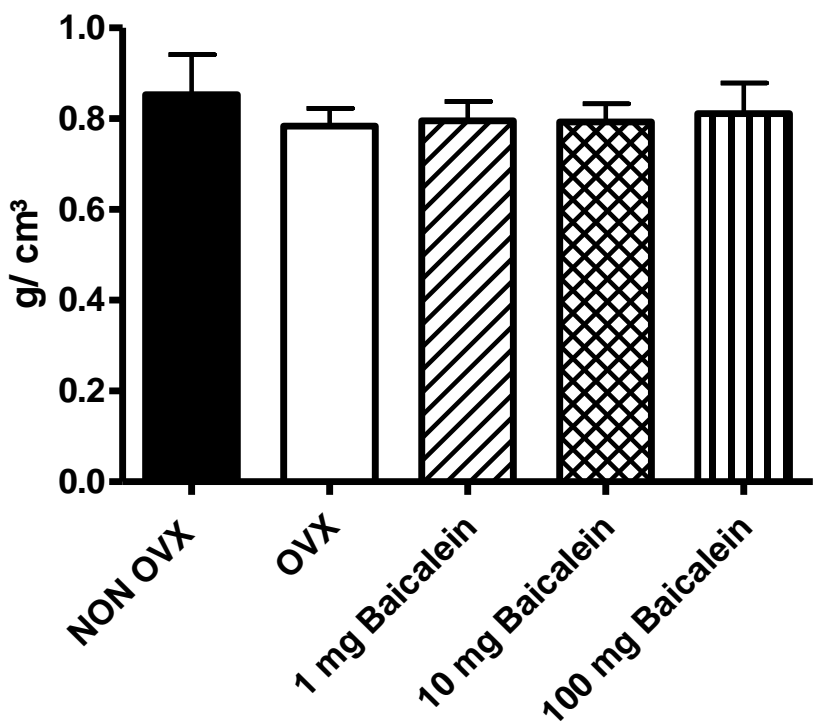

Abb. 38: Darstellung der gruppenspezifischen Mittelwerte \pm Standardabweichungen der Dichtebestimmung von Kortikalis und trabekulärem Knochen

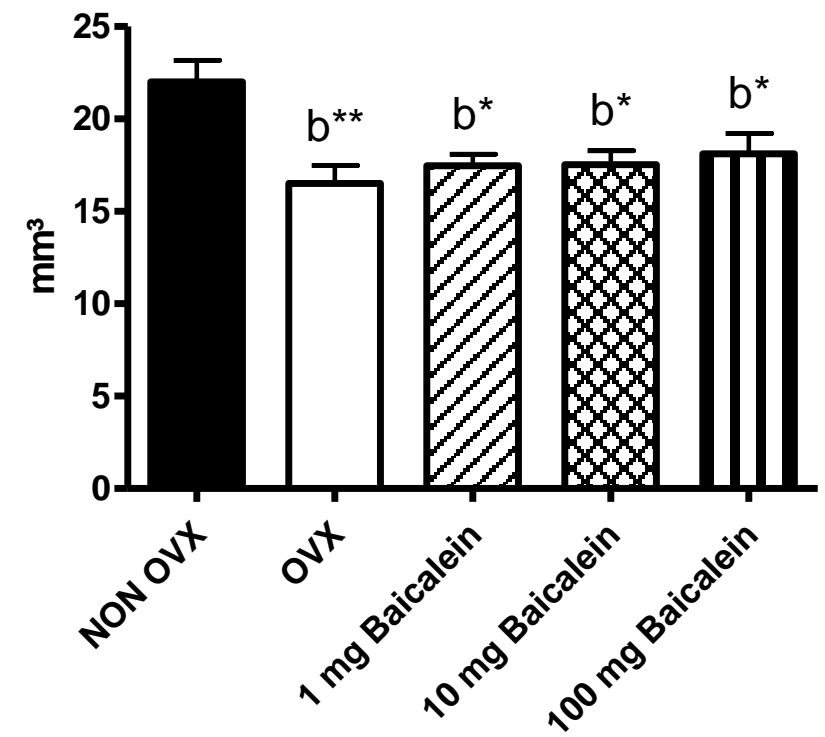

Abb. 39: Darstellung der gruppenspezifischen Mittelwerte \pm Standardabweichungen der Volumenbestimmung von Kortikalis und trabekulärem Knochen; $b=$ signifikant zu NON OVX; ${ }^{*}=p \leq 0,05,{ }^{* *}=p \leq 0,01$ 
In Bezug auf die Ergebnisse der Dichtebestimmung lag bei keiner Versuchsgruppe eine signifikante Differenz vor (Abb. 38).

Hinsichtlich des Volumens konnten allerdings bei allen medikamentös behandelten Versuchsgruppen signifikant niedrigere Werte gegenüber der NON OVX-Gruppe nachgewiesen werden. Die rein ovariektomierte Versuchsgruppe zeigte im Vergleich zu der NON OVX-Gruppe sogar einen niedrigeren Wert von hoher Signifikanz (Abb. 39).

\subsubsection{Dichte und Volumen des Weichteilgewebes}

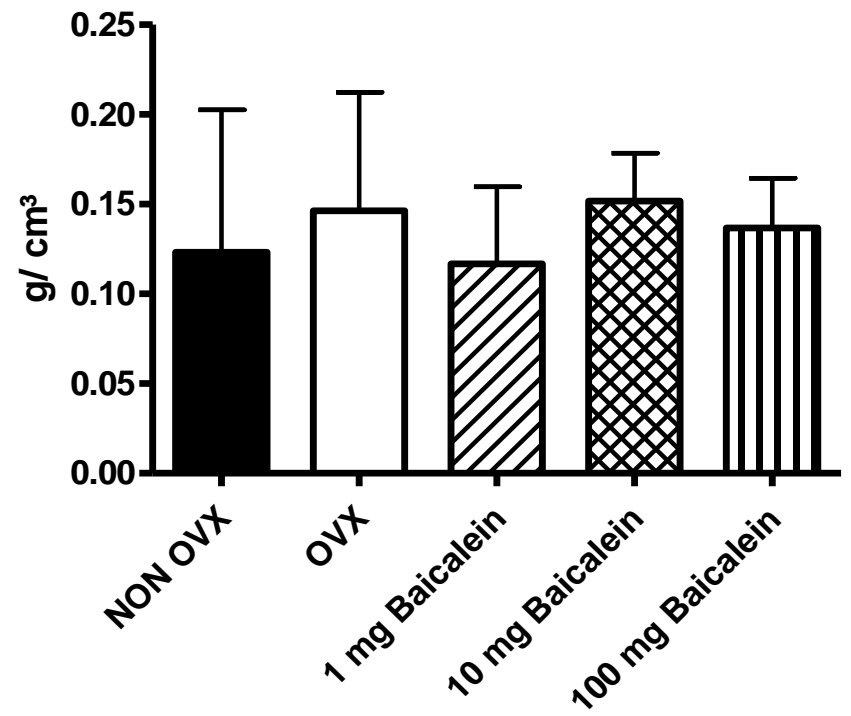

Abb. 40: Darstellung der gruppenspezifischen Mittelwerte \pm Standardabweichungen der Dichtebestimmung des Weichteilgewebes

Die Detailanalyse der Dichtewerte des Weichteilgewebes zeigte keine signifikanten Unterschiede. Man beachte jedoch die hohen Standardabweichungen, vor allem bei der NON OVX- und der OVX-Kontrollgruppe. Die Dichte der medikamentös behandelten Versuchsgruppen variierte deutlich. Mit $0,15 \mathrm{~g} / \mathrm{cm}^{3}$ lag der höchste Wert bei der 10-mg-Baicalein-Gruppe vor (Abb. 40). 


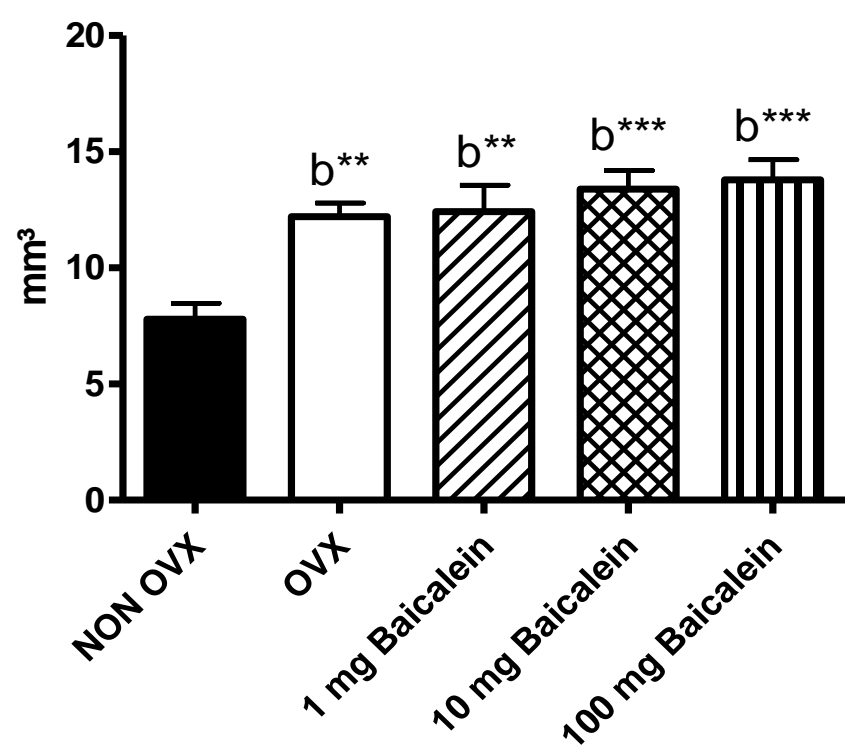

Abb. 41: Darstellung der gruppenspezifischen Mittelwerte \pm Standardabweichungen der Volumenbestimmung des Weichteilgewebes; $b=$ signifikant zu NON OVX; ${ }^{* *}=p \leq$ $0,01,{ }^{* * *}=p \leq 0,001$

In Bezug auf das Volumen zeigten sich bei allen ovariektomierten Versuchsgruppen erhöhte Werte von hoher (OVX, $1 \mathrm{mg}$ Baicalein) und höchster (10 mg Baicalein, 100 mg Baicalein) Signifikanz gegenüber der NON OVXGruppe (Abb. 41). 


\subsubsection{Fläche des kortikalen Knochens}

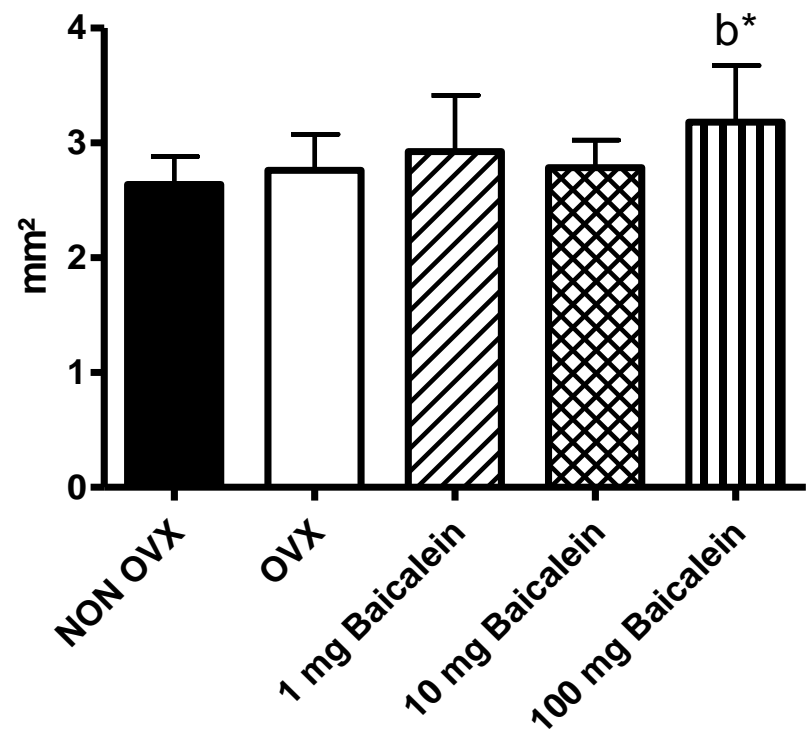

Abb. 42: Darstellung der gruppenspezifischen Mittelwerte \pm Standardabweichungen der Flächenbestimmung des kortikalen Knochens; $b=$ signifikant zu NON OVX; ${ }^{*}=p$ $\leq 0,05$

Bei der Analyse der kortikalen Knochenoberfläche waren bei allen medikamentös behandelten Versuchsgruppen im Vergleich zu den NON OVX- und OVXKontrollgruppen höhere Mittelwerte erkennbar. Mit 3,18 $\mathrm{mm}^{2}$ lag der höchste Wert bei der 100-mg-Baicalein-Gruppe vor. Außerdem konnte bei dieser Versuchsgruppe eine signifikante Differenz im Vergleich zu der NON OVXGruppe festgestellt werden (Abb. 42). 


\subsubsection{Substantia spongiosa}

Tab. 10: Ergebnisse der Analyse der Substantia spongiosa

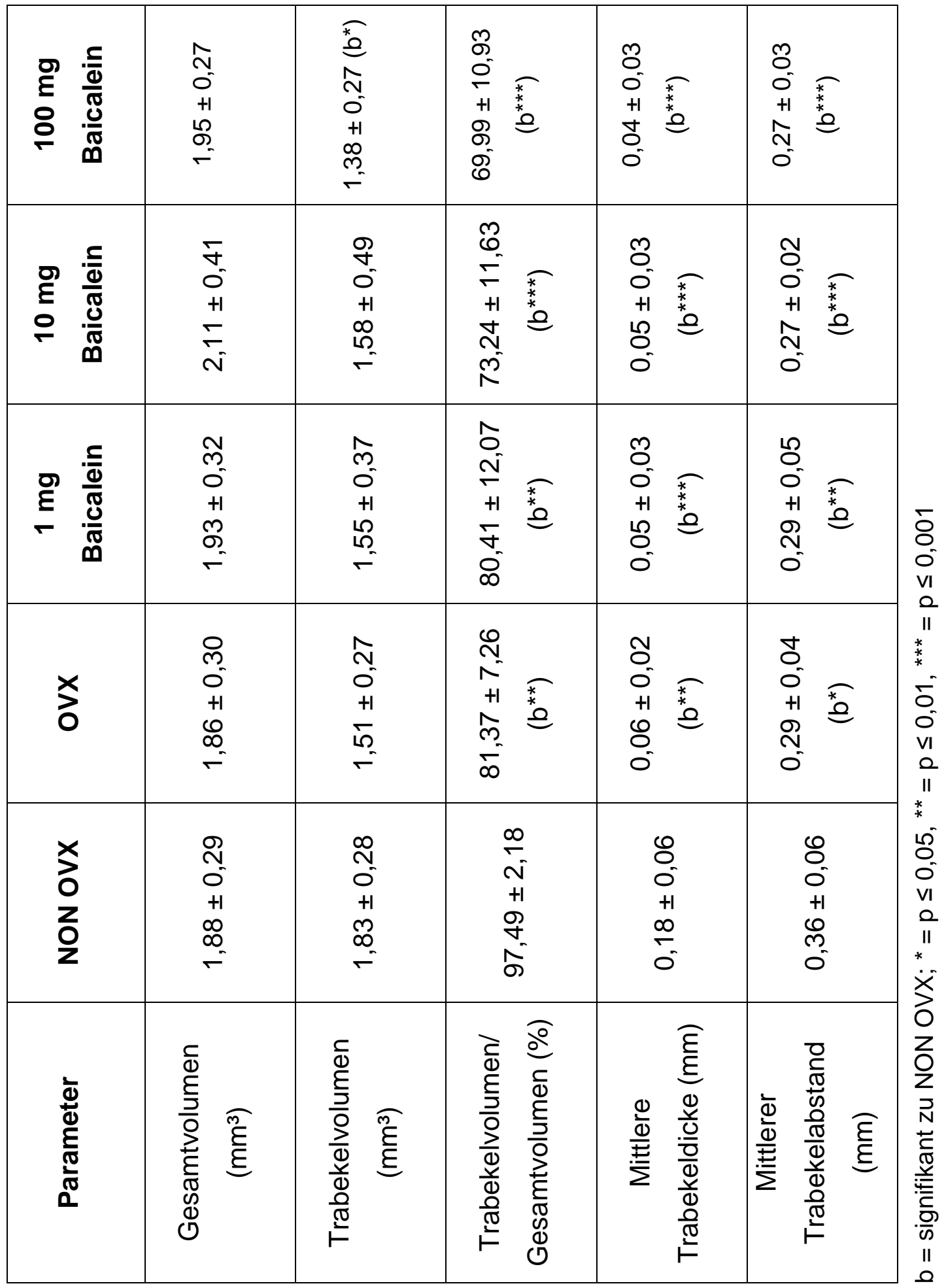




\section{Diskussion}

Ziel der vorliegenden Dissertationsarbeit war es herauszufinden, inwiefern sich die Applikation von Baicalein auf den osteoporotischen Knochen am Tiermodell der ovariektomierten Ratte auswirkt.

Da es sich bei Baicalein um einen selektiven Inhibitor der 12/15-Lipoxygenase handelt, wurde bislang ein positiver Effekt auf den osteoporotischen Knochen angenommen. Weil diesbezüglich jedoch keine experimentellen Untersuchungsergebnisse vorliegen, sollte die Studie neue Erkenntnisse liefern, möglicherweise auch in Bezug auf die Therapie der Osteoporose.

Für die Durchführung der einzelnen Experimente wurden insgesamt fünf unterschiedliche Versuchsgruppen gebildet. Davon wurden drei Gruppen ovariektomiert und über einen Zeitraum von 28 Tagen täglich mit Baicalein, welches in einer gruppenspezifischen Konzentration von $1 \mathrm{mg} / \mathrm{kg} / \mathrm{KG}$ (1 mg Baicalein), $10 \mathrm{mg} / \mathrm{kg} / \mathrm{KG}$ (10 mg Baicalein) und $100 \mathrm{mg} / \mathrm{kg} / \mathrm{KG}$ (100 mg Baicalein) verabreicht wurde, therapiert. Zusätzlich fungierten eine nicht ovariektomierte Versuchsgruppe (NON OVX) sowie eine ovariektomierte Versuchsgruppe (OVX), welche jedoch beide nicht medikamentös therapiert wurden, als Kontrollgruppen.

\subsection{Die ovariektomierte Ratte als Tiermodell für die postmenopausale Osteoporose der Frau}

In der Wissenschaft werden verschiedene Tierarten wie Hund, Schwein, Schaf, Maus, Ratte und der nichtmenschliche Primat zur Osteoporose-Forschung eingesetzt. Da bei diesen Tieren allerdings keine natürliche Menopause stattfindet, werden verschiedene Methoden, wie z. B. die Ovariektomie, durchgeführt, um einen Östrogenabfall zu induzieren. Dies führt in der Folge zu einem osteoporotischen Knochenverlust, welcher in seinen charakteristischen Eigenschaften mit dem der postmenopausalen Frau verglichen werden kann (Kalu 1991).

Für die Versuche der vorliegenden Studie wurde das Tiermodell der ovariektomierten Ratte gewählt, da es weltweit als etabliert und anerkannt gilt und am häufigsten für Studien zur postmenopausalen Osteoporose verwendet wird (Cortet 2011, Lelovas et al. 2008). 
Im Vergleich zu anderen Tiermodellen ist die Haltung von Ratten als vorteilhaft anzusehen. Sie ist nicht nur leichter und kostengünstiger, sondern genießt auch eine größere ethische Akzeptanz gegenüber der Verwendung von großen Tieren (Lelovas et al. 2008, Oheim et al. 2016).

Studien belegen, dass sowohl bei der Ratte als auch beim Menschen ähnliche pathophysiologische Veränderungen des Knochenstoffwechsels vorliegen (Frost und Jee 1992). Diese sind besonders durch eine erhöhte Knochenumsatzrate in Verbindung mit einer gesteigerten Resorption und dem damit einhergehendem Knochenverlust, vor allem im Bereich der Spongiosa, gekennzeichnet (Wronski et al. 1989a, Kalu et al. 1989, Yamazaki und Yamaguchi 1989).

Kritiker gingen bei der Ratte lange Zeit von einem nicht vorhandenen remodeling und einem lebenslangen Skelettwachstum aus, was das Tiermodell zur Osteoporose-Forschung unbrauchbar machte. In der Spongiosa und der Kortikalis der Ratte konnte allerdings, wie auch beim Menschen, ein altersabhängiger und sukzessiv fortschreitender Prozess hin zum remodeling nachgewiesen werden (Dennison et al. 2005). Ferner konnte Erben sogar einen Stopp des Längenwachstums im Lendenwirbelkörper von 12 Monate alten Ratten nachweisen (Erben 1996).

Andere Studien verdeutlichen zudem, dass Ratten auf etablierte Therapieformen, welche bei der Behandlung einer Osteoporose beim Menschen angewendet werden, in ähnlicher Weise ansprechen. Dies ist z. B. bei Östrogen (Aitken et al. 1972), Bisphosphonaten (Storm et al. 1990, Wronski et al. 1989b) und Parathormon (Kalu et al. 1989, Liu und Kalu 1990) der Fall. Dies unterstreicht die Aussagekraft von Erkenntnissen, welche bei der Anwendung von neuen Medikamenten an diesem Tiermodell gewonnen werden.

Mithilfe der im Anschluss des Versuchs ermittelten Uterusgewichte konnte belegt werden, dass bei allen ovariektomierten Versuchsgruppen im Vergleich zu der NON OVX-Gruppe höchst signifikant niedrigere Werte und somit unterentwickelte Uteri vorlagen (Abb. 24). Dies bestätigt die Ovariektomie als eine erfolgreiche Methode zur Induktion eines Östrogenmangels und Simulation einer Osteoporose bei Ratten.

Auch wenn es kein Tiermodell gibt, welches gänzlich auf den Menschen übertragen werden kann, liegen unter Berücksichtigung der oben aufgeführten Belege sehr viele Gemeinsamkeiten in Bezug auf den Knochenverlust der 
ovariektomierten Ratte und der postmenopausalen Frau vor. Das Modell der Ratte ermöglicht nicht nur die Zusammenhänge des postmenopausalen Knochenverlusts zu analysieren, sondern ist auch dazu geeignet neue Behandlungsmethoden für die Osteoporose-Therapie zu erforschen.

\subsection{Körpergewicht und tägliche Futteraufnahme}

Wie auch schon in vorherigen Studien (Komrakova et al. 2009, Komrakova et al. 2010, Komrakova et al. 2015) beobachtet werden konnte, nahmen während des Versuchszeitraums alle Tiere an Körpergewicht zu. Da die Ratten zu Versuchsbeginn 3 Monate alt waren, konnte dies unter anderem mit einem generellen Wachstum begründet werden.

Bei genauerer Betrachtung der einzelnen Gruppen fiel auf, dass alle ovariektomierten Tiere gegenüber der NON OVX-Gruppe zu Beginn des Versuchs deutlich schneller an Gewicht zunahmen (Abb. 23). Dies konnte mit einer höheren Futteraufnahme bis zur Osteotomie in der 8. Woche erklärt werden (Tab. 9).

Darüber hinaus wiesen alle ovariektomierten Versuchsgruppen im Vergleich zu der NON OVX-Gruppe ein höheres Körpergewicht am Ende des Versuchs auf (Abb. 23). Dieses Ergebnis konnte neben der anfangs erhöhten Futteraufnahme auf die Auswirkungen der Ovariektomie zurückgeführt werden. Es ist nämlich bekannt, dass durch den Abfall des Östrogenspiegels eine Abnahme der körperlichen Aktivität resultiert (Izumo et al. 2012) bzw. umgekehrt die Gabe von Östrogenen eine Zunahme der körperlichen Aktivität bewirkt (Diaz-Veliz et al. 1991, Thomas et al. 1986). Ein weiterer Grund für das erhöhte Körpergewicht der ovariektomierten Tiere war vermutlich auch ein Anstieg der Fettmasse, der häufig bei postmenopausalen Frauen beobachtet werden kann und ebenfalls zu einem Abfall des Östrogenspiegels führt (Lovejoy 2003, Kim et al. 2014).

Nach der Osteotomie konnte bei allen Versuchsgruppen eine Abnahme der Futteraufnahme und des Körpergewichts festgestellt werden. Dieser Zusammenhang wurde auch schon in anderen Studien beschrieben (Komrakova et al. 2009, Komrakova et al. 2010). Möglicherweise könnten dafür postoperative Schmerzen, die durch die Schmerzprophylaxe möglichst verhindert werden sollten, oder Nachwirkungen der Narkose verantwortlich gewesen sein. Nach der 10. Versuchswoche nahm die Futteraufnahme bei allen Gruppen bis zum Ende 
des Versuchs kontinuierlich zu. Ebenfalls wurde eine gruppenübergreifende Zunahme des Körpergewichts beobachtet. Lediglich bei der OVX-, 1-mg- und 100mg-Baicalein-Gruppe stellte sich am Versuchsende eine erneute Abnahme des Körpergewichts ein. Möglicherweise stand dies im Zusammenhang mit der täglichen Applikation des Medikaments, genauer gesagt an den unerwünschten Nebenwirkungen des Penetrationsverstärkers DMSO. So konnten wir bei den Tieren dieser Gruppen im entsprechenden Applikationsareal der Haut die Bildung von Entzündungen beobachten.

In Bezug auf die unmittelbaren Auswirkungen der medikamentösen Gabe von Baicalein auf die tägliche Futteraufnahme und das Körpergewicht waren keine Aussagen möglich.

\subsection{Biomechanischer Kompressionstest}

Die Belastbarkeit von Knochen hängt von verschiedenen Faktoren wie z. B. der Größe, der Masse, der Geometrie, der Mikroarchitektur oder der Matrixzusammensetzung ab. Um die mechanische Belastbarkeit bzw. das individuelle Frakturrisiko von osteoporotischen Knochen zu bestimmen, wird in der Regel die Überprüfung der Knochenmineraldichte vorgenommen. Ein häufig verwendetes Verfahren stellt die DEXA-Methode dar. Da hierbei allerdings wichtige Faktoren wie z. B. die Geometrie oder die trabekuläre Mikroarchitektur des Knochens in der Analyse nicht berücksichtigt werden, eignet sich dieses Verfahren leider nur begrenzt, um die mechanische Belastbarkeit von osteoporotischen Knochen zu bestimmen (Ammann und Rizzoli 2003). So wurde bereits nachgewiesen, dass ein hoher Wert für die Knochenmineraldichte nicht zwangsläufig mit einer verbesserten mechanischen Belastbarkeit des Knochens korreliert, weshalb die Einschätzung des realen individuellen Frakturrisikos auch nur bedingt möglich ist (Stürmer et al. 2006).

Da mithilfe des biomechanischen Kompressionstests eine Fraktur hervorgerufen wird, die maßgeblich $u$. a. von den oben genannten Faktoren abhängt, gilt der Versuch im Rahmen von Tiermodellen als besonders geeignet, um die mechanische Belastbarkeit von Knochen zu überprüfen bzw. therapeutische Auswirkungen zu erfassen. 
Weil die proximale Femurfraktur eine der häufigsten Frakturen des osteoporotischen Skeletts beim Menschen darstellt und von großer sozioökonomischer Bedeutung ist, wurde bei den Ratten genau dieser Bereich des Knochens als Ansatzpunkt für den biomechanischen Kompressionstest gewählt. Darüber hinaus ist es als vorteilhaft anzusehen, dass beim proximalen Femur von Mensch und Ratte einige Gemeinsamkeiten vorliegen. Neben ähnlichen Zellen und Stoffwechselvorgängen setzt sich der Knochen in dieser Region bei beiden Individuen sowohl aus trabekulären als auch aus kortikalen Bestandteilen zusammen (Tezval et al. 2010). Dies gewährleistet eine Analyse der gesamten Knochenstruktur hinsichtlich möglicher Auswirkungen der medikamentösen Therapie mit Baicalein.

Zur Überprüfung der mechanischen Belastbarkeit werden in biomechanischen Kompressionstests vor allem axiale Kräfte ausgeübt (Shimano und Volpon 2007, Zhang et al. 2005). In dieser Arbeit sollte jedoch der klinische Aspekt, dass Femurfrakturen in der Regel durch laterale Stürze hervorgerufen werden, im Vordergrund stehen. Deswegen wurde ein Test, welcher auf einer lateralen Kraftausübung basiert und bereits in einer vorherigen Studie (Tezval et al. 2010) etabliert wurde, gewählt. Ferner zeigt die Studie von Zhang et al., dass der laterale Belastungstest für die durch Östrogenmangel herabgesetzte mechanische Belastbarkeit eine höhere Sensitivität aufweist als der axiale Belastungstest (Zhang et al. 2005).

Es ist hinlänglich bekannt, dass osteoporotische Knochenveränderungen zu einer verringerten Stabilität und somit zu einer erhöhten Frakturgefahr führen. Dieser Zusammenhang kann im biomechanischen Kompressionstest in Form von erniedrigten Werten für die Parameter Elastizität und Maximalkraft nachgewiesen werden.

Bislang liegen noch keine wissenschaftlichen Studien zu den Auswirkungen von Baicalein, speziell in Bezug auf die Belastbarkeit des osteoporotischen Knochens, vor. Die von uns ermittelten Ergebnisse des biomechanischen Kompressionstests machten allerdings deutlich, dass in Bezug auf die Elastizität bei den medikamentös behandelten Versuchstieren gegenüber der OVX-Kontrollgruppe keine positiven Auswirkungen erkennbar waren. Während bei der OVX-Gruppe ein um 13,83\% verringerter Durchschnittswert gegenüber der NON OVX-Gruppe festgestellt werden konnte, lagen die Werte der 1-mg-Baicalein-Gruppe um 
52,19\%, der 10-mg-Baicalein-Gruppe um 54,02\% und der 100-mg-BaicaleinGruppe sogar um 65,37\% unter dem Durchschnittswert der OVX-Kontrollgruppe (Abb. 25). Demnach nahm die elastische Verformbarkeit des Knochens umso stärker ab, je höher die Konzentration des Baicaleins war.

In Bezug auf die Ergebnisse der Maximalkraft konnte bei der OVX-Gruppe ein um $30,17 \%$ verringerter Durchschnittswert gegenüber der NON OVX-Gruppe ermittelt werden, wohingegen die Werte der 1-mg-Baicalein-Gruppe um 7,46\% und der 10mg-Baicalein-Gruppe um 3,34\% höher ausfielen als der Durchschnittswert der OVX-Kontrollgruppe. Nur die Maximalkraft der 100-mg-Baicalein-Gruppe lag 22,17\% unter der der OVX-Gruppe (Abb. 26). Da die Werte der Maximalkraft aller Baicalein-Gruppen jedoch deutlich unter dem Durchschnittswert der NON OVXKontrollgruppe lagen, konnte insgesamt nicht nachgewiesen werden, dass die medikamentöse Behandlung mit Baicalein $\mathrm{zu}$ einer Verbesserung der biomechanischen Eigenschaften von osteoporotischen Knochen führt.

\subsection{Veraschung}

Die Veraschung stellt eine geeignete Ex-vivo-Methode dar, um die Knochen gezielt in Bezug auf ihre organische und anorganische Zusammensetzung zu untersuchen, da durch die hohen Temperaturen bei der Verbrennung alle organischen Bestandteile aufgelöst werden. Leider resultiert daraus auch ein struktureller Zusammenbruch des Knochens, weshalb in der Analyse keine Differenzierung zwischen den beiden Knochenkompartimenten Kortikalis und trabekulärem Netzwerk erfolgen kann.

Die Auswertung der Ergebnisse der organischen und anorganischen Masse zeigte, dass die Applikation von Baicalein keine Auswirkungen hatte. Da die Werte der OVX-Kontrollgruppe und der medikamentös behandelten Gruppen sehr nah beieinander lagen, konnten weder statistische Signifikanzen ermittelt, noch Tendenzen abgeleitet werden. Leider konnten unsere Ergebnisse nicht mit anderen Studien verglichen werden, da es bisher keine Veröffentlichungen zu diesem Thema gibt.

Verglichen mit der NON OVX-Kontrollgruppe waren bei allen ovariektomierten Gruppen höchst signifikant niedrigere Werte für den prozentualen Anteil der anorganischen Masse und höhere Werte von höchster Signifikanz für den 
prozentualen Anteil der organischen Masse erkennbar (Abb. 27, Abb. 28). Vorherige Studien der Arbeitsgruppe konnten bereits ähnliche Veränderungen im osteoporotischen Knochen präsentieren (Neuerburg 2015).

Die ermittelten Signifikanzen zwischen der NON OVX- und den ovariektomierten Gruppen standen wahrscheinlich im Zusammenhang mit der Ovariektomie. Es ist bekannt, dass die Umsatzgeschwindigkeit des remodelings den Grad der Knochenmineralisierung bestimmt. Bedingt durch die Ovariektomie kommt es zu einer erhöhten Aktivitätsrate der Knochenumbaueinheiten (BMUs), wodurch die sekundäre Mineralisation der neu gebildeten Knochenmatrix (BSU) verkürzt wird (Boivin und Meunier 2003). In der Folge wird immer mehr, nicht mineralisierte organische Masse aufgebaut, so dass der Anteil der anorganischen Knochenmasse abnimmt.

Zur Überprüfung der genauen Zusammensetzung der anorganischen Masse wurde der Calcium- und Phosphatgehalt ermittelt. In vorherigen Studien der Arbeitsgruppe konnte bereits nachgewiesen werden, dass ein osteoporotischer Knochenmetabolismus nicht zwangsläufig mit einer Veränderung des Calciumund Phosphatgehaltes einhergeht (Döll 2010, Eimer 2014). Dies wurde mit unseren Ergebnissen bestätigt, da in Bezug auf den Calciumgehalt die NON OVXGruppe mit 31,11\% und die OVX-Gruppe mit 29,89\% relativ nah beieinander lagen (Abb. 29). Auch im Hinblick auf den Phosphatgehalt waren die ermittelten Werte annähernd gleich (Abb. 30). Die Therapie mit Baicalein zeigte ebenfalls keine Auswirkungen auf die mineralische Zusammensetzung des Kochens, da beim Vergleich mit den Kontrollgruppen keine signifikanten Unterschiede oder Tendenzen des Calcium- und Phosphatgehaltes festgestellt werden konnten.

\subsection{Mikro-Computertomographie}

$\mathrm{Da}$ die mechanischen Eigenschaften des Knochens wesentlich von seiner mikrostrukturellen Architektur abhängen, nimmt die Erfassung der knöchernen Strukturen in der Osteoporose Forschung einen zentralen Bestandteil ein. Daher wurde in der vorliegenden Studie neben dem biomechanischen Kompressionstest und der Veraschung eine mikro-computertomographische Analyse der Knochenproben durchgeführt. 
Auch wenn die Histomorphometrie des Knochens seit Jahrzehnten als etablierte Methode zur quantitativen Untersuchung des trabekulären Netzwerks eingesetzt wird (Merz und Schenk 1970, Thomsen et al. 2005) und mit ihr eine hohe Ortsauflösung von $1 \mu \mathrm{m}$ möglich ist, besitzt sie den großen Nachteil, dass nur ein zweidimensionaler Datensatz erhoben werden kann. Die Umrechnung dieser Daten in ein dreidimensionales Modell beruht lediglich auf Annahmen. Ferner ist die invasive Gewinnung, die aufwendige Präparation und die Destruktion der Proben als nachteilig anzusehen (Engelke et al. 1999). Basierend auf diesen Erkenntnissen eignet sich die Histomorphometrie nur begrenzt, um die möglichen strukturellen Veränderungen des Knochens zu untersuchen.

Seit den frühen 70er- Jahren konnte die Bildgebung durch die Einführung der Computertomographie (Hounsfield 1973) und deren Weiterentwicklung in den 80er- Jahren als Mikro-Computertomographie $(\mu \mathrm{CT}$ ) (Kujoory et al. 1980, Sato et al. 1981) deutlich verbessert werden. Das computertomographische Messverfahren besitzt gegenüber der Histomorphometrie den bedeutenden Vorteil, dass die dreidimensionale Knochenstruktur analysiert werden kann und die Erfassung der mikrostrukturellen Parameter nicht auf Modellannahmen beruht. Darüber hinaus handelt es sich um eine nicht invasive Methode, so dass sogar Invivo-Messungen von kleinen Labortieren erfolgen können. Zudem gilt die Versuchsdurchführung als einfach und setzt im Vorfeld keine aufwendige Präparation der Proben voraus. Da bei kleinen Labortieren wie z. B. der Ratte hohe Auflösungen für die Erfassung der Knochenstruktur aufgebracht werden müssen, sind Mikro-CT-Anlagen mit 5 - $50 \mu \mathrm{m}$ Auflösung besser geeignet im Vergleich zu klinischen Spiral-CT-Scannern, welche nur eine isotrope Ortsauflösung von 0,25 - 1,00 mm ermöglichen. Auch wenn die Auflösung der MikroCT nicht so gut ist wie bei der Histomorphometrie, kann sie dennoch als geeignet angesehen werden, um z. B. bei Ratten die trabekuläre Dicke (ca. 100 - $150 \mu \mathrm{m}$ ) oder den trabekulären Abstand (ca. $100-1000 \mu \mathrm{m}$ ) zu ermitteln. Als nachteilig erweisen sich die langen Scanzeiten, welche bislang im Bereich von Minuten bis Stunden liegen und die relativ hohe Strahlenexposition. Ferner ist das Messfeld auf kleine Probengrößen von nur wenigen Zentimetern begrenzt. Aus diesen Gründen eignet sich das Mikro-CT bislang nicht zur klinischen Diagnostik (Engelke et al. 1999). 
Aufgrund der Tatsache, dass mithilfe von Baicalein eine selektive Inhibition von Lipoxygenasen nachgewiesen werden konnte (Deshamps et al. 2006, Mascayano et al. 2013), wurde bislang ein anaboler Effekt auf den Knochenstoffwechsel angenommen. Dies konnte bereits mit der Studie von Kim et al., welche einen stimulierenden Effekt von Baicalein auf die Osteoblastendifferenzierung von Mäuseknochen festgestellt haben, bestätigt werden (Kim et al. 2008). Die Auswertung der Ergebnisse unserer mikro-computertomographischen Analyse zeigte für Baicalein, insgesamt betrachtet, allerdings einen inhomogenen Effekt auf den osteoporotischen Femur der Versuchstiere.

In Bezug auf die Dichte des Gesamtknochens konnten bei allen BaicaleinGruppen im Vergleich mit der OVX-Kontrollgruppe geringfügig niedrigere Werte ermittelt werden, auch wenn deren Knochenvolumina etwas höher ausfielen (Abb. 32, Abb. 33). Beim Vergleich mit der NON OVX-Kontrollgruppe fiel zunächst der signifikant niedrigere Wert der OVX-Kontrollgruppe auf. Bei der 10-mg-BaicaleinGruppe lag ebenfalls ein signifikant niedrigerer Wert vor, die Werte der 1-mg- und 100-mg-Baicalein-Gruppen waren gegenüber der NON OVX-Kontrollgruppe sogar hoch signifikant niedriger.

Die Analyse des kortikalen Knochens ergab gruppenübergreifend sehr nah beieinander liegende Werte für die Dichte, so dass keine statistischen Unterschiede ermittelt werden konnten (Abb. 34). Die Volumina der medikamentös behandelten Gruppen waren höher als das Volumen der ovariektomierten Kontrollgruppe, dennoch wurden keine statistischen Signifikanzen ermittelt. Im Vergleich mit der NON OVX-Kontrollgruppe lagen bei den Baicalein-Gruppen hoch und höchst signifikant niedrigere Werte vor (Abb. 35). Interessant war die Tatsache, dass die Fläche des kortikalen Knochens im Bereich des Collum femoris bei allen medikamentös behandelten Versuchsgruppen zunahm. Am deutlichsten wurde dies bei der 100-mg-Baicalein-Gruppe, da hier sogar ein signifikant höherer Wert im Vergleich mit der NON OVX-Kontrollgruppe festgestellt werden konnte (Abb. 42).

In einer von $\mathrm{Li}$ et al. veröffentlichten Studie wurden die Auswirkungen einer 3monatigen Therapie mit Baicalein auf die Knochenbildung von ovariektomierten Mäusen untersucht. Verglichen mit einer rein ovariektomierten Kontrollgruppe konnte bei den mit Baicalein behandelten Mäusen eine signifikant höhere trabekuläre Knochendichte gemessen werden (Li et al. 2015). Diese 
Beobachtungen konnten anhand von unseren Ergebnissen nicht bestätigt werden, da bei der Untersuchung des trabekulären Knochens bei den Parametern Dichte und Volumen keine signifikanten Unterschiede zwischen der OVX-Kontrollgruppe und den Baicalein-Gruppen vorlagen (Abb. 36, Abb. 37). Darüber hinaus wurde bei allen ovariektomierten Versuchsgruppen im Vergleich mit der NON OVXKontrollgruppe ein höchst signifikant niedrigerer Wert für die Dichte des trabekulären Knochens festgestellt (Abb. 36).

Die Ergebnisse der mikro-computertomographischen Untersuchung der Substantia spongiosa machten deutlich, dass für die medikamentöse Gabe von Baicalein in Bezug auf das Trabekelvolumen keine positiven Auswirkungen nachgewiesen werden konnten. Während sich die Werte der 1-mg- und 10-mgBaicalein-Gruppen nicht nennenswert von der OVX-Kontrollgruppe unterschieden, lag ein verringertes Trabekelvolumen bei der 100-mg-Baicalein-Gruppe vor. Zusätzlich ergab sich für diese Versuchsgruppe ein erniedrigter Wert von statistischer Signifikanz gegenüber der NON OVX-Kontrollgruppe. Unter Berücksichtigung des Gesamtvolumens wurde deutlich, dass je höher die Konzentration des Baicaleins war, desto geringer fiel der prozentuale Anteil des Trabekelvolumens aus (Tab. 10).

In der oben aufgeführten Studie von Li et al. wurde ebenfalls nachgewiesen, dass eine Therapie mit Baicalein zu einer erhöhten mittleren Trabekeldicke führte (Li et al. 2015). Im Gegensatz dazu konnte in der vorliegenden Studie keine Verbesserung hinsichtlich der mittleren Trabekeldicke durch die medikamentöse Therapie mit Baicalein erzielt werden. Zwischen der ovariektomierten Kontrollgruppe und den medikamentös behandelten Gruppen lagen keine Unterschiede vor. Zusätzlich konnten bei diesen Versuchsgruppen gegenüber der NON OVX-Kontrollgruppe insgesamt niedrigere Werte von höchster Signifikanz gemessen werden (Tab. 10).

Ein ähnliches Ergebnis lag auch bei dem Parameter mittlerer Trabekelabstand vor, da hier zwischen den medikamentös behandelten Versuchsgruppen und der OVXKontrollgruppe keine Unterschiede beobachtet werden konnten. Gleichzeitig wiesen alle ovariektomierten Gruppen gegenüber der NON OVX-Gruppe niedrigere Werte von statistischer Signifikanz auf (Tab. 10). 


\subsection{Schlussfolgerung}

Bisherige Studienergebnisse belegen, dass Baicalein zu einer positiven Beeinflussung des Knochens führt. Im Gegensatz dazu konnten in der vorliegenden Studie durch die medikamentöse Therapie mit Baicalein leider keine Verbesserungen auf den osteoporotischen Knochenmetabolismus nachgewiesen werden. Interessant war allerdings die Tatsache, dass die im Rahmen einer weiteren Studie durchgeführte Untersuchung an der Skelettmuskulatur der Ratten ergab, dass Baicalein die Angiogenese in der Skelettmuskulatur stimuliert und folglich der durch Östrogenmangel induzierten Atrophie entgegenwirkt (Kling 2016, Saul et al. 2016).

Unter Berücksichtigung unserer Untersuchungsergebnisse gilt es, in weiteren Studien herauszufinden, ob gegebenenfalls eine länger gewählte Applikationsdauer zu Auswirkungen auf den osteoporotischen Knochen führt. Aufgrund der im Zusammenhang mit der gewählten Applikationsform aufgetretenen Komplikationen sollten eventuell alternative Möglichkeiten, wie beispielsweise die enterale Gabe, gewählt werden. 


\section{Zusammenfassung}

Bei der Osteoporose handelt es sich schon jetzt um eine ernstzunehmende Volkskrankheit in Deutschland. Vor dem Hintergrund einer immer älter werdenden Bevölkerung und stetig zunehmender Kosten für das Gesundheitssystem stellt die Therapie der Osteoporose in der Zukunft eine große sozio-ökonomische Herausforderung für die Gesellschaft dar. Etablierte Behandlungsmethoden, wie beispielsweise die Gabe von Bisphosphonaten, führen im klinischen Alltag zu nicht unerheblichen Nebenwirkungen. Aufgrund dessen besteht Forschungsbedarf nach alternativen Lösungen.

Als Bestandteil der traditionellen chinesischen Medizin wird Baicalein seit Jahrhunderten für verschiedene Herz-, Kreislauf- und Knochenerkrankungen eingesetzt. Besonders die bereits nachgewiesene geringe Toxizität gegenüber körpereigenem Gewebe macht Baicalein für die Osteoporose-Forschung interessant.

In der vorliegenden Studie wurden die Auswirkungen der medikamentösen Behandlung mit Baicalein in unterschiedlichen Konzentrationen auf den osteoporotisch veränderten Knochen am Beispiel des Femurs untersucht. Hierfür wurden 61 weibliche Ratten, welche zu Versuchsbeginn 3 Monate alt waren, in 5 Versuchsgruppen eingeteilt. Zur Induktion einer Osteoporose wurde bei den Gruppen 2 - 5 eine bilaterale Ovariektomie durchgeführt. Die nicht operierten Tiere der Gruppe 1 dienten als Kontrollgruppe. Nach Einhaltung einer 8-wöchigen Standzeit und Entwicklung einer manifesten Osteoporose erfolgte bei allen Versuchsgruppen eine metaphysäre Osteotomie mit anschließender Osteosynthese beider Tibiae. Die entsprechenden Untersuchungen zur Frakturheilung waren Bestandteil einer anderen Studie.

Im Anschluss wurde die medikamentöse Behandlung mit Baicalein bei der Gruppe 3 (1 mg/kg/KG), der Gruppe 4 (10 mg/kg/KG) und der Gruppe 5 (100 mg/kg/KG) durchgeführt. Nach 28 Tagen wurden alle Versuchstiere durch Dekapitation getötet. Die nicht medikamentös behandelte Gruppe 2 fungierte als ovariektomierte Kontrollgruppe. Nach der Biopsie wurden die zu untersuchenden Femora einem biomechanischen Kompressionstest unterzogen, um ihre mechanische Belastbarkeit zu überprüfen. Außerdem wurden die Knochenproben nach Veraschung hinsichtlich ihrer organischen und anorganischen 
Zusammensetzung sowie deren Calcium- und Phosphatgehalt untersucht. Zuletzt erfolgte eine mikro-computertomographische Analyse zur Überprüfung des trabekulären Netzwerks im Bereich des Caput femoris.

Die Auswertung der Ergebnisse ergab in Bezug auf den biomechanischen Kompressionstest eine signifikante Abnahme für den Parameter Elastizität bei den mit Baicalein behandelten Versuchsgruppen. Ferner konnte eine geringfügige Verbesserung der Maximalkraft bei der 1-mg- und 10-mg-Baicalein-Gruppe beobachtet werden, auch wenn keine statistische Signifikanz gemessen werden konnte.

Nach der Veraschung zeigten sich zwischen der OVX-Kontrollgruppe und den Baicalein-Gruppen sowohl bei der organischen als auch bei der anorganischen Masse keine Unterschiede. Zudem lagen die Werte des Calcium- und Phosphatgehaltes gruppenübergreifend sehr nah beieinander.

Bezogen auf die Ergebnisse der mikro-computertomographischen Analyse lagen bei den medikamentös behandelten Versuchsgruppen inhomogene Ergebnisse vor. Während keine Verbesserung im Hinblick auf die Dichte der einzelnen Knochenkompartimente registriert werden konnte, lag eine Zunahme der kortikalen Fläche im Bereich des Collum femoris, besonders bei der 100-mgBaicalein-Gruppe vor. Im Bereich der Substantia spongiosa ergab die medikamentöse Therapie mit Baicalein keinen Vorteil gegenüber der OVXKontrollgruppe.

In der vorliegenden Studie konnte gezeigt werden, dass die medikamentöse Behandlung mit Baicalein kaum messbaren Einfluss auf den osteoporotischen Knochen zur Folge hatte. Aufgrund inhomogener Effekte sind weitere Untersuchungen mit modifiziertem Versuchsaufbau erforderlich. 


\section{Literaturverzeichnis}

Aitken JM, Armstrong E, Anderson JB (1972): Osteoporosis after oophorectomy in the mature female rat and the effect of oestrogen and-or progestogen replacement therapy in its prevention. J Endocrinol $\underline{55}, 79-87$

Ammann P, Rizzoli R (2003): Bone strength and its determinants. Osteoporos Int 14 Suppl 3, 13-18

Bartl R, Bartl C: Osteoporose: Prävention, Diagnostik, Therapie. 4. Auflage; Georg Thieme Verlag, Stuttgart 2011

Bartl R, Bartl C (2015): Aktuelle Osteoporoseprophylaxe und -therapie. Internist $\underline{56}, 1445-1457$

Bartl R, Gradinger R (2009): Aktuelle Diagnostik und Therapie der Osteoporose auf der Basis der "European guidance 2008". Orthopäde 38, 365-379

Batge B, Diebold J, Stein H, Bodo M, Muller PK (1992): Compositional analysis of the collagenous bone matrix. A study on adult normal and osteopenic bone tissue. Eur J Clin Invest 22, 805-812

Bender R, Lange S (2007): Was ist der p- Wert? Dtsch Med Wochenschr 132 Suppl 1, 15-16

Black DM, Delmas PD, Eastell R, Reid IR, Boonen S, Cauley JA, Cosman F, Lakatos P, Leung PC, Man Z et al. (2007): Once-yearly zoledronic acid for treatment of postmenopausal osteoporosis. N Engl J Med 356, 1809-1822

Boivin G, Meunier PJ (2003): The mineralization of bone tissue: a forgotten dimension in osteoporosis research. Osteoporos Int 14 Suppl 3, 19-24 
Braun J, Pfeilschifter J (2010): Leitliniengerechte Diagnostik und Therapie der Osteoporose 2010. Z Rheumatol $\underline{69}$, 327-339

Brückle W: Was bedeutet Osteoporose, Osteoporose: Stabil durchs Leben. TRIAS Verlag, Stuttgart 2014

Cao JJ (2011): Effects of obesity on bone metabolism. J Orthop Surg Res $\underline{6}, 30$

Chen YJ, Wu CS, Shieh JJ, Wu JH, Chen HY, Chung TW, Chen YK, Lin CC (2013): Baicalein Triggers Mitochondria-Mediated Apoptosis and Enhances the Antileukemic Effect of Vincristine in Childhood Acute Lymphoblastic Leukemia CCRF-CEM Cells. Evid Based Complement Alternat Med 2013, 124747

Cheng YH, Li LA, Lin P, Cheng LC, Hung CH, Chang NW, Lin C (2012): Baicalein induces $\mathrm{G} 1$ arrest in oral cancer cells by enhancing the degradation of cyclin D1 and activating AhR to decrease Rb phosphorylation. Toxicol Appl Pharmacol 263, 360-367

Cortet B (2011): Bone repair in osteoporotic bone: postmenopausal and cortisone-induced osteoporosis. Osteoporos Int 22, 2007-2010

Danks L, Takayanagi H (2013): Immunology and bone. J Biochem 154, 29-39

Deller T: Gewebe. In: Welsch U, Kummer C (Hrsg.): Lehrbuch Histologie. 4. Auflage; Urban und Fischer in Elsevier, München 2014, 81-232

Dennison E, Cole Z, Cooper C (2005): Diagnosis and epidemiology of osteoporosis. Curr Opin Rheumatol 17, 456-461

Deschamps JD, Kenyon VA, Holman TR (2006): Baicalein is a potent in vitro inhibitor against both reticulocyte 15-human and platelet 12-human lipoxygenases. Bioorg Med Chem 14, 4295-4301 
Deuss U: Einleitung. In: Peters KM, Deuss U (Hrsg.): Osteoporose: Leitliniengerechte Diagnostik und Therapie. Steinkopff, Darmstadt 2005, 1-4

Deutzmann R: Hormone. In: Rassow J, Hauser K, Netzker R, Deutzmann R (Hrsg.): Duale Reihe Biochemie. 3. Auflage; Georg Thieme Verlag, Stuttgart 2008, 557-626

Diaz-Veliz G, Urresta F, Dussaubat N, Mora S (1991): Effects of estradiol replacement in ovariectomized rats on conditioned avoidance responses and other behaviors. Physiol Behav $\underline{50}$, 61-65

Döll C: Einfluss der vertikalen Ganzkörpervibration unterschiedlicher Frequenz auf den osteoporotischen Lendenwirbelkörper der Ratte. Med. Diss. Göttingen 2010

DVO-Leitlinie 2014 zur Prophylaxe, Diagnostik und Therapie der Osteoporose bei Männern ab dem 60. Lebensjahr und bei postmenopausalen Frauen. Kurzfassung und Langfassung.

[http://www.dv-osteologie.org/uploads/Leitlinie\%202014/DVO-

Leitlinie\%20Osteoporose\%202014\%20Kurzfassung\%20und\%20Langfassung\%20

Version\%201a\%2012\%2001\%202016.pdf]

Eimer C: Einfluss der vertikalen Ganzkörpervibration in Kombination mit Strontiumrenalat und Parathormon auf das osteoporotische Rattenfemur. Med. Diss. Göttingen 2014

Engelke K, Karolczak M, Lutz A, Seibert U, Schaller S, Kalender W (1999): Mikro-CT Technologie und Applikation zur Erfassung von Knochenarchitektur. Radiologe 39, 203-212

Erben RG (1996): Trabecular and endocortical bone surfaces in the rat: modeling or remodeling? Anat Rec $\underline{246}, 39-46$

Fitzpatrick LA (2002): Secondary causes of osteoporosis. Mayo Clin Proc $\underline{77}$, 453-468 
Frost HM, Jee WS (1992): On the rat model of human osteopenias and osteoporoses. Bone Miner $\underline{18}$, 227-236

Gandhi NM (2013): Baicalein protects mice against radiation-induced DNA damages and genotoxicity. Mol Cell Biochem 379, 277-281

Grampp S, Henk CB, Imhof H (1999): Die klinische Anwendung der Densitometrie. Radiologe $\underline{39}, 222-227$

Grodsky GM: Chemie und Wirkung von Hormonen. In: Harper HA, Martin DW, Mayes PA, Rodwell VW (Hrsg.): Medizinische Biochemie. 2. Auflage; Springer Verlag, Berlin 2013, 566-585

Hadji P, Bock K, Emons G, Wüster C, Schulz K (2002): Früherkennung und Prävention der Osteoporose. Gynäkologe $\underline{35}$, 518-526

Hadji P, Klein S, Häussler B, Kless T, Schmidt T, Steinle T, Verheyen F, Linder R (2013): The Epidemiology of Osteoporosis - Bone Evaluation Study (BEST). Dtsch Arztebl Int 110(4), 52-57

Häussler B, Gothe H, Gol D, Glaeske G, Pientka L, Felsenberg D (2007): Epidemiology, treatment and costs of osteoporosis in Germany--the BoneEVA Study. Osteoporos Int $\underline{18}, 77-84$

Hernlund E, Svedbom A, Ivergard M, Compston J, Cooper C, Stenmark J, McCloskey EV, Jonsson B, Kanis JA (2013): Osteoporosis in the European Union: medical management, epidemiology and economic burden. A report prepared in collaboration with the International Osteoporosis Foundation (IOF) and the European Federation of Pharmaceutical Industry Associations (EFPIA). Arch Osteoporos $\underline{8}, 136$

Hock JM, Gera I (1992): Effects of continuous and intermittent administration and inhibition of resorption on the anabolic response of bone to parathyroid hormone. $J$ Bone Miner Res $\underline{7}, 65-72$ 
Hofbauer LC, Jakob FJ, Tsourdi E: Primäre und sekundäre Osteoporoseformen. In: Lehnert H (Hrsg.): Rationelle Diagnostik und Therapie in Endokrinologie, Diabetologie und Stoffwechsel. 4. Auflage; Georg Thieme Verlag, Stuttgart 2014, 171-185

Hoidrup S, Sorensen TI, Stroger U, Lauritzen JB, Schroll M, Gronbaek M (2001): Leisure-time physical activity levels and changes in relation to risk of hip fracture in men and women. Am J Epidemiol 154, 60-68

Hooven FH, Adachi JD, Adami S, Boonen S, Compston J, Cooper C, Delmas P, Diez-Perez A, Gehlbach S, Greenspan SL et al. (2009): The Global Longitudinal Study of Osteoporosis in Women (GLOW): rationale and study design. Osteoporos Int 20, 1107-1116

Hounsfield GN (1973): Computerized transverse axial scanning (tomography). 1. Description of system. Br J Radiol 뜨, 1016-1022

Hübner J: Scutellaria. In: Hübner J: Komplementäre Onkologie - Supportive Maßnahmen und evidenzbasierte Empfehlungen. 2. Auflage; Schattauer Verlag, Stuttgart 2012, 308-311

Ishihara A, Sasaki T, Debari K, Furuya R, Kawawa T, Ramamurthy NS, Golub LM (1999): Effects of ovariectomy on bone morphology in maxillae of mature rats. $\mathrm{J}$ Electron Microsc $\underline{48}, 465-469$

Issever AS, Link TM (2011): Radiologische Diagnostik der Osteoporose. Z Rheumatol $\underline{70}, 135-144$

Izumo N, Ishibashi Y, Ohba M, Morikawa T, Manube T (2012): Decreased voluntary activity and amygdala levels of serotonin and dopamine in ovariectomized rats. Behav Brain Res $\underline{227}$, 1-6

Jerosch J, Bader A, Uhr G: Knochen: Curasan Taschenatlas spezial. Georg Thieme Verlag, Stuttgart 2002 
Jin XQ, Xu H, Shi HY, Zhang JM, Zhang HQ (2007): Fluoride-induced oxidative stress of osteoblasts and protective effects of baicalein against fluoride toxicity. Biol Trace Elem Res 116, 81-89

Joakimsen RM, Fonnebo V, Magnus JH, Tollan A, Sogaard AJ (1998): The Tromso Study: body height, body mass index and fractures. Osteoporos Int $\underline{8}$, 436-442

Junqueira LCU, Carneiro J, Gratzl M: Histologie. 6. Auflage; Springer Verlag, Heidelberg 2005

Kalu DN (1991): The ovariectomized rat model of postmenopausal bone loss. Bone Miner $\underline{15}, 175-191$

Kalu DN, Liu CC, Hardin RR, Hollis BW (1989): The aged rat model of ovarian hormone deficiency bone loss. Endocrinology 124, 7-16

Kann PH (2001): Osteodensitometrie und Ultraschalluntersuchungen des Knochens. Orthopäde $\underline{30}$, 437-443

Kim JH, Cho HT, Kim YJ (2014): The role of estrogen in adipose tissue metabolism: insights into glucose homeostasis regulation. Endocr J $\underline{61}, 1055-1067$

Kim JM, Lee SU, Kim YS, Min YK, Kim SH (2008): Baicalein stimulates osteoblast differentiation via coordinating activation of MAP kinases and transcription factors. J Cell Biochem 104, 1906-1917

Kling JH: Einfluss des Lipoxygenaseinhibitors Baicalein in unterschiedlicher Dosierung auf den Skelettmuskel der ovariektomierten Ratte. Med. Diss. Göttingen 2016 
Komrakova M, Werner C, Wicke M, Nguyen BT, Sehmisch S, Tezval M, Stuermer KM, Stuermer EK (2009): Effect of daidzein, 4-methylbenzylidene camphor or estrogen on gastrocnemius muscle of osteoporotic rats undergoing tibia healing period. J Endocrinol 201, 253-262

Komrakova M, Stuermer EK, Werner C, Wicke M, Kolios L, Sehmisch S, Tezval M, Daub F, Martens T, Witzenhausen P et al. (2010): Effect of human parathyroid hormone hPTH (1-34) applied at different regimes on fracture healing and muscle in ovariectomized and healthy rats. Bone $\underline{47}, 480-492$

Komrakova M, Weidemann A, Dullin C, Ebert J, Tezval M, Stuermer KM, Sehmisch S (2015): The Impact of Strontium Ranelate on Metaphyseal Bone Healing in Ovariectomized Rats. Calcif Tissue Int $\underline{97}, 391-401$

Kopp $\mathbf{H}$, Herschel $\mathbf{M}$ : Dolobene-Gel in der Klinik bei verschiedenen Venenerkrankungen. In: Jacob SW, Herschler RJ, Schmellenkamp H (Hrsg.): DMSO: Die Anwendung in der Medizin The Use of DMSO in Medicine. Springer Verlag, Berlin 1985, 78-83

Kronke G, Uderhardt S, Katzenbeisser J, Schett G (2009): The 12/15lipoxygenase pathway promotes osteoclast development and differentiation. Autoimmunity $\underline{42}, 383-385$

Kujoory MA, Hillman BJ, Barrett HH (1980): High-resolution computed tomography of the normal rat nephrogram. Invest Radiol $\underline{15}, 148-154$

Kunczik T, Ringe J (1994): Osteoporose: Eine Herausforderung für die Zukunft. Dtsch Arztebl $\underline{91}, 1126-1129$

Kurth AA, Pfeilschifter J (2007): Diagnostik und Therapie der postmenopausalen Osteoporose und der Osteoporose des Mannes. Orthopade 즈, 683-692

Lane NE (2006): Epidemiology, etiology, and diagnosis of osteoporosis. Am J Obstet Gynecol 194, S3-11 
Lange U, Muller-Ladner U, Pfeilschifter J (2011): Osteoporose: Leitliniengerechte Prophylaxe, Diagnostik und Therapie. Internist (Berl) $\underline{52}$, 843852

Lee SH, Chang SS, Lee M, Chan RC, Lee CC (2014): Risk of osteonecrosis in patients taking bisphosphonates for prevention of osteoporosis: a systematic review and meta-analysis. Osteoporos Int 25, 1131-1139

\section{Leitlinie Osteoporose s. DVO-Leitlinie 2014}

Lelovas PP, Xanthos TT, Thoma SE, Lyritis GP, Dontas IA (2008): The laboratory rat as an animal model for osteoporosis research. Comp Med $\underline{58}, 424$ 430

Li-Weber M (2009): New therapeutic aspects of flavones: the anticancer properties of Scutellaria and its main active constituents Wogonin, Baicalein and Baicalin. Cancer Treat Rev $\underline{35}, 57-68$

Li SF, Tang JJ, Chen J, Zhang P, Wang T, Chen TY, Yan B, Huang B, Wang L, Huang MJ et al. (2015): Regulation of bone formation by baicalein via the mTORC1 pathway. Drug Des Devel Ther $\underline{9}, 5169-5183$

Lin JT, Lane JM (2004): Osteoporosis: a review. Clin Orthop Relat Res $\underline{425}$, 126134

Liu CC, Kalu DN (1990): Human parathyroid hormone-(1-34) prevents bone loss and augments bone formation in sexually mature ovariectomized rats. J Bone Miner Res $\underline{5}, 973-982$

Lovejoy JC (2003): The menopause and obesity. Prim Care $\underline{30}$, 317-325

Lüllmann-Rauch R: Taschenlehrbuch Histologie. 3. Auflage; Georg Thieme Verlag, Stuttgart 2009 
Manolagas SC (2000): Birth and death of bone cells: basic regulatory mechanisms and implications for the pathogenesis and treatment of osteoporosis. Endocr Rev 21, 115-137

Manolagas SC, Jilka RL (1995): Bone marrow, cytokines, and bone remodeling. Emerging insights into the pathophysiology of osteoporosis. $\mathrm{N}$ Engl J Med $\underline{332}$, 305-311

Marcus R (1996): Clinical review 76: The nature of osteoporosis. J Clin Endocrinol Metab $\underline{81}, 1-5$

Mascayano C, Espinosa V, Sepulveda-Boza S, Hoobler EK, Perry S (2013): In vitro study of isoflavones and isoflavans as potent inhibitors of human 12- and 15lipoxygenases. Chem Biol Drug Des 르, 317-325

Merz WA, Schenk RK (1970): Quantitative structural analysis of human cancellous bone. Acta Anat (Basel) $\underline{75}$, 54-66

Minne HW, Pfeifer M, Begerow B, Pollahne W (2002): Osteoporose. Orthopäde $\underline{31}, 681-697$

Mori G, D'Amelio P, Faccio R, Brunetti G (2013): The Interplay between the bone and the immune system. Clin Dev Immunol 2013, 720504

Mouri Y, Yoshida M, Nakano S, Yorozuya K, Fujii K, Fukutomi T, Nakaoka T, Yamada S, Hara K (2009): A case of osteonecrosis of the jaw in a breast cancer patient with bone metastases receiving long-term treatment with bisphosphonates. Breast Cancer $\underline{16}, 147-150$

Motoo Y, Sawabu N (1994): Antitumor effects of saikosaponins, baicalin and baicalein on human hepatoma cell lines. Cancer Lett $\underline{86}, 91-5$ 
Neuerburg C, Stumpf U, Schmidmaier R, Kammerlander C, Pfeilschifter J, Mutschler W, Bocker W (2015): Neue Osteoporose-Leitlinie DVO 2014 und ihre Bedeutung für den Unfallchirurgen. Unfallchirurg 118, 905-912

Neuerburg T: Wirkung von kurzzeitiger vertikaler Ganzkörpervibration mit Frequenzen unter $90 \mathrm{~Hz}$ auf das Femur ovarektomierter Ratten. Med. Diss. Göttingen 2015

Noble BS (2008): The osteocyte lineage. Arch Biochem Biophys $\underline{473}, 106-111$

Oheim R, Schinke T, Amling M, Pogoda P (2016): Can we induce osteoporosis in animals comparable to the human situation? Injury $\underline{47}$, S3-S9

Ohshima H (2010): [Secondary osteoporosis UPDATE. Bone loss due to bed rest and human space flight study]. Clin Calcium 20, 709-716

Otto S, Abu-Id MH, Fedele S, Warnke PH, Becker ST, Kolk A, Mucke T, Mast G, Kohnke R, Volkmer E et al. (2011): Osteoporosis and bisphosphonatesrelated osteonecrosis of the jaw: not just a sporadic coincidence--a multi-centre study. J Craniomaxillofac Surg $\underline{39}$, 272-277

Peters A, Friebe H: Osteoporose: Diagnostik - Prävention - Therapie. In: Stein V, Greitemann B (Hrsg.): Rehabilitation in Orthopädie und Unfallchirurgie: Methoden - Therapiestrategien - Behandlungsempfehlungen. Springer Verlag, Berlin 2005, 246-257

Reinsdorf S, Habermann B, Hochmuth K, Kurth AA (2007): Bisphosphonate in der Osteoporosetherapie. Standards und Perspektiven. Orthopäde $\underline{36}, 110-117$

Robert Koch-Institut: Daten und Fakten: Ergebnisse der Studie "Gesundheit in Deutschland aktuell 2009". Beiträge zur Gesundheitsberichterstattung des Bundes. Robert Koch- Institut, Berlin 2011 
Roodman GD (1996): Advances in bone biology: the osteoclast. Endocr Rev 17, 308-332

Sato T, Ikeda O, Yamakoshi Y, Tsubouchi M (1981): X-ray tomography for microstructural objects. Appl Opt 20, 3880-3883

Saul D, Kling JH, Kosinsky RL, Hoffmann DB, Komrakova M, Wicke M, Menger B, Sehmisch S (2016): Effect of the Lipoxygenase Inhibitor Baicalein on Muscles in Ovariectomized Rats. J Nutr Metab 2016, 14

Schünke M: Funktionelle Anatomie - Topographie und Funktion des Bewegungssystems. 2. Auflage; Georg Thieme Verlag, Stuttgart 2014

Sehmisch S, Erren M, Rack T, Tezval M, Seidlova-Wuttke D, Richter J, Wuttke W, Stuermer KM, Stuermer EK (2009): Short-term effects of parathyroid hormone on rat lumbar vertebrae. Spine $\underline{34}, 2014-2021$

Shimano MM, Volpon JB (2007): Mechanical behavior of rats' femoral proximal thirds after a period of tail suspension and exercises. Acta Ortopédica Brasileira $\underline{15}, 254-257$

Siegrist M, Lammel C, Gradinger R: Osteoporose. In: Halle M, SchmidtTrucksäss A, Hambrecht R, Berg A (Hrsg.): Sporttherapie in der Medizin: Evidenzbasierte Prävention und Therapie. Schattauer Verlag, Stuttgart 2008, 343352

Storm T, Thamsborg G, Steiniche T, Genant HK, Sorensen OH (1990): Effect of intermittent cyclical etidronate therapy on bone mass and fracture rate in women with postmenopausal osteoporosis. N Engl J Med $\underline{322}, 1265-1271$

Sturmer EK, Seidlova-Wuttke D, Sehmisch S, Rack T, Wille J, Frosch KH, Wuttke W, Sturmer KM (2006): Standardized bending and breaking test for the normal and osteoporotic metaphyseal tibias of the rat: effect of estradiol, testosterone, and raloxifene. J Bone Miner Res $\underline{21}$, 89-96 
Stuermer EK, Sehmisch S, Rack T, Wenda E, Seidlova-Wuttke D, Tezval M, Wuttke W, Frosch KH, Stuermer KM (2010): Estrogen and raloxifene improve metaphyseal fracture healing in the early phase of osteoporosis. A new fracturehealing model at the tibia in rat. Langenbecks Arch Surg 395, 163-172

Tella SH, Gallagher JC (2014): Prevention and treatment of postmenopausal osteoporosis. J Steroid Biochem Mol Biol 142, 155-170

Tezval M, Stuermer EK, Sehmisch S, Rack T, Stary A, Stebener M, Konietschke F, Stuermer KM (2010): Improvement of trochanteric bone quality in an osteoporosis model after short-term treatment with parathyroid hormone: a new mechanical test for trochanteric region of rat femur. Osteoporos Int 21, 251-261

Thomas DK, Storlien LH, Bellingham WP, Gillette K (1986): Ovarian hormone effects on activity, glucoregulation and thyroid hormones in the rat. Physiol Behav $\underline{36}, 567-573$

Thomsen JS, Laib A, Koller B, Prohaska S, Mosekilde L, Gowin W (2005): Stereological measures of trabecular bone structure: comparison of 3D micro computed tomography with 2D histological sections in human proximal tibial bone biopsies. J Microsc $\underline{218}, 171-179$

Ulfig N: Kurzlehrbuch Histologie. 2. Auflage; Georg Thieme Verlag, Stuttgart 2005

Wen Y, Gu J, Chakrabarti SK, Aylor K, Marshall J, Takahashi Y, Yoshimoto T, Nadler JL (2007): The role of 12/15-lipoxygenase in the expression of interleukin6 and tumor necrosis factor-alpha in macrophages. Endocrinology $\underline{148}, 1313-1322$

WHO (1994): Assessment of fracture risk and its application to screening for postmenopausal osteoporosis. Report of a WHO Study Group. World Health Organ Tech Rep Ser $\underline{843}, 1-129$

Wronski TJ, Dann LM, Scott KS, Cintron M (1989a): Long-term effects of ovariectomy and aging on the rat skeleton. Calcif Tissue Int $\underline{45}, 360-366$ 
Wronski TJ, Dann LM, Scott KS, Crooke LR (1989b): Endocrine and pharmacological suppressors of bone turnover protect against osteopenia in ovariectomized rats. Endocrinology 125, 810-816

Wüster C, Pourfard J, Lüttje D, Kneer W, Hadji P (2001): Osteodensitometrie. Gynäkologe $\underline{34}, 841-847$

Yamazaki I, Yamaguchi H (1989): Characteristics of an ovariectomized osteopenic rat model. J Bone Miner Res $\underline{4}, 13-22$

Zhang G, Qin L, Shi Y, Leung K (2005): A comparative study between axial compression and lateral fall configuration tested in a rat proximal femur model. Clin Biomech 20, 729-735 


\section{Danksagung}

Zunächst möchte ich mich bei Herrn Prof. Dr. med. Klaus Michael Stürmer und seinem Nachfolger Prof. Dr. med. Wolfgang Lehmann als Klinikleiter für die Ermöglichung dieses Projekts bedanken.

Bei meinem Doktorvater Herrn PD Dr. med. Stephan Sehmisch bedanke ich mich für die Überlassung dieses interessanten Themas und die Möglichkeit zur Durchführung einer experimentellen Arbeit sowie für die gute Zusammenarbeit und die hilfreichen Ratschläge.

Des Weiteren gilt mein besonderer Dank Frau Dr. rer. nat. Marina Komrakova für die hervorragende Betreuung und permanente Ansprechbarkeit und die zügigen Korrekturen.

Außerdem bedanke ich mich bei Frau Ramona Castro-Machguth und bei Frau Annette Witt für die fachkundige Hilfe bei der Durchführung aller Laborarbeiten und die ständige Hilfsbereitschaft, wodurch ich stets eine hervorragende Betreuung erfahren habe.

Mein Dank gilt außerdem Herrn Dr. Christian Dullin für die ausführliche Einweisung in die Mikro-Computertomographie und die Unterstützung bei der Auswertung der erhobenen Daten. Ferner danke ich Herrn Dr. Ulrich Schmelz für die Hilfe in Bezug auf die Analyse der Veraschung der Knochenproben.

Zu guter Letzt möchte ich mich bei der Dr. Arthur Pfungst-Stiftung, insbesondere bei der Geschäftsführerin Frau Gisela Dietrich-Haas, sehr herzlich für die Förderung in Form eines Stipendiums bedanken. 


\section{Lebenslauf}

Mein Name ist Marc Hendrik Zimmermann, ich wurde am 12.12.1988 als Sohn von Martin Berend Konrad Zimmermann und Roswitha Regina Zimmermann, geb. Marx, in Münster geboren. Meine Schwester Laura Zimmermann wurde am 03.10.1991 geboren.

Von 1995 bis 1999 besuchte ich die Grundschule Havixbeck und von 1999 bis 2009 das Gymnasium Paulinum in Münster. Im Juni 2009 erlangte ich am Gymnasium Paulinum die allgemeine Hochschulreife.

Im April 2010 nahm ich das Studium der Zahnmedizin an der Georg-AugustUniversität Göttingen auf, absolvierte dort im Dezember 2015 mein Staatsexamen und erhielt die Approbation als Zahnarzt.

Seit Mai 2014 bin ich Promotionsstudent in der Klinik für Unfallchirurgie, Orthopädie und Plastische Chirurgie der Universitätsmedizin Göttingen unter der Betreuung von Herrn PD Dr. Stephan Sehmisch und Frau Dr. Marina Komrakova. Von April 2016 bis April 2017 habe ich das allgemeinzahnärztliche Jahr in einer zahnärztlichen Praxis in Papenburg (Niedersachsen) absolviert. Seit Mai 2017 arbeite ich als Weiterbildungsassistent für Oralchirurgie in einer privaten Zahnklinik in Sulzfeld (Baden-Württemberg). 